\title{
WestVirginiaUniversity
}

THE RESEARCH REPOSITORY @ WVU

Graduate Theses, Dissertations, and Problem Reports

2013

\section{An Examination of Non-Exercise Activity Thermogenesis in Rural Youth}

Molly R. Matthews-Ewald

West Virginia University

Follow this and additional works at: https://researchrepository.wvu.edu/etd

\section{Recommended Citation}

Matthews-Ewald, Molly R., "An Examination of Non-Exercise Activity Thermogenesis in Rural Youth" (2013). Graduate Theses, Dissertations, and Problem Reports. 4979.

https://researchrepository.wvu.edu/etd/4979

This Dissertation is protected by copyright and/or related rights. It has been brought to you by the The Research Repository @ WVU with permission from the rights-holder(s). You are free to use this Dissertation in any way that is permitted by the copyright and related rights legislation that applies to your use. For other uses you must obtain permission from the rights-holder(s) directly, unless additional rights are indicated by a Creative Commons license in the record and/ or on the work itself. This Dissertation has been accepted for inclusion in WVU Graduate Theses, Dissertations, and Problem Reports collection by an authorized administrator of The Research Repository @ WVU.

For more information, please contact researchrepository@mail.wvu.edu. 


\title{
An Examination of Non-Exercise Activity Thermogenesis in Rural Youth
}

\author{
Molly R. Matthews-Ewald \\ Dissertation submitted to the \\ School of Medicine \\ at West Virginia University \\ in partial fulfillment of the requirements \\ for the degree of \\ Doctor of Philosophy \\ in \\ Public Health Sciences \\ George Kelley, D.A., Chair \\ Andrew Bradlyn, Ph.D. \\ Matthew Gurka, Ph.D. \\ Carole Harris, Ph.D. \\ Kevin Larkin, Ph.D. \\ Keith Zullig, Ph.D. \\ Department of Social and Behavorial Sciences/School of Public Health \\ Morgantown, West Virginia \\ 2013
}

Keywords: non-exercise activity thermogenesis; energy expenditure; physical activity; exercise; rural; youth; children; adolescents; obesity 


\section{ABSTRACT \\ An Examination of Non-Exercise Activity Thermogenesis in Rural Youth}

\section{Molly R. Matthews-Ewald}

Weight gain among United States' children, adolescents and adults has become a pandemic problem, and is of great public health concern, given the increased risk for myriad chronic health problems and associated medical expenditures. It is well established that increased energy expenditure through physical activity may reduce weight and improve health. However, the predominant focus of this research has been with moderate to vigorous levels of activity (MVPA). A growing body of evidence suggests that activity levels below this (i.e., light levels), may also be beneficial. Specific to light activity, a recent area of focus has been on non-exercise activity thermogenesis (NEAT), which includes non-volitional activities and activities of daily living, as well as fidgeting. Correlations exist between higher levels of NEAT and lower body weight across a variety of individuals. The main objective of this project was to increase the understanding of NEAT, utilizing objectively measured light physical activity as a proxy, among a group of rural children and adolescents during the school day. The light activity portion of the accelerometry data was used as a proxy or surrogate for NEAT because it provides an indication of the amount of NEAT in which these youth engage during the school day. In the first study, the relationship between age and NEAT during one physical education (PE) class was examined using linear regression. Accelerometry data from elementary and high school students were utilized. Results indicated that there is an inverse relationship between age and NEAT levels, such that the elementary aged children engaged in higher levels of NEAT during their PE class than did the high school students. Studies 2 and 3 utilized accelerometry data from the high school students only, across a 1-week time period, during the beginning of their semester. Study 2 examined the relative stability of NEAT both during PE class, and during the non-PE class school day. Utilizing two mixed models, performed for males and females, and including gender as a fixed effect, study 2 examined both between-person variation estimates and within-person estimates. Results from this study revealed that the between-person variation during PE class was higher among males than females, yet similar during non-PE classes. Regarding males only, more between-person variation was present during PE class than non-PE classes. Similar results occurred for the females, where more between-person variation was present during PE class than non-PE classes. Finally, within-person effects during PE class were more variable than during the non-PE class school day. Lastly, study 3 examined activity compensation. Specifically, this study sought to determine whether adolescents differentially engage in NEAT activities during the non-PE class school day, as a result of their MVPA and NEAT activity during PE class. Two generalized linear mixed models were performed. The first model was a logistic model of the odds of an individual engaging in $\geq 10 \%$ of NEAT during non-PE classes versus $<10 \%$ NEAT during non-PE classes. The second model was a traditional linear mixed model to examine whether activity compensation occurred among individuals who engaged in any NEAT. Results from both models found that there was a positive relationship between percent of time spent in NEAT during PE class and the amount of time spent in NEAT during non-PE classes. This result indicates that, among this sample, activity compensation does not occur. In fact, it appears that individuals who engage in higher levels of NEAT, do so across a variety of environments, and 
the amount of imposed physical activity does not appear to have an effect on this. One of the major strengths of these studies is that objectively measured physical activity via accelerometers was utilized. In addition, these studies were among the first to examine NEAT in a relatively large sample of rural children and adolescents. Although the utilization of light physical activity as a proxy for NEAT may have underestimated NEAT, as triaxial accelerometers and posture position measurements capture $>80 \%$ of NEAT activities, these studies provided a necessary first step for the characterization of NEAT in rural youth. Future work is needed to examine NEAT in rural youth outside of the school day, as well as whether sport or activity type during PE has an influence on NEAT. 


\section{DEDICATION}

I would like to dedicate my dissertation to my husband, Chris. You helped me through times when I did not think I would finish and have been my greatest supporter, providing laughs along the way. I am honored to have you by my side. 


\section{ACKNOWLEDGEMENTS}

I would like to thank my mentor and chair of my dissertation committee, Dr. George Kelley, for guiding me through this process. I am grateful for your willingness to have me as your mentee and the support and patience you provided.

I am also thankful to Dr. Carole Harris, who first mentored me and provided me with support. Many thanks are also due to Dr. Matthew Gurka for the incredible mentorship and patience with data analysis. My sincerest appreciation to Dr. Keith Zullig who first believed that I could complete a doctoral program and guided me through my master's thesis. I am very grateful for your encouragement to apply to this program. It has led to wonderful life changes, and I am ever thankful. I would also like to thank the other members of my committee, Dr. Andrew Bradlyn and Dr. Kevin Larkin, for their assistance and guidance on this project.

The support of my classmates, Dr. Sarah Geiger, Dr. Rose Pignataro, and Laura Kurth has been truly invaluable. You all are a very special group of women, and I am so grateful to be able to call you my friends.

I wish to thank the staff (past and present) at the Health Research Center (HRC): Dr. Lucas Moore, Susan Crayne, Jessica Coffman, Louise Moore, Meghan Reeves, and Dr. Thomas Bias. You all have been so supportive and willing to listen when I needed to talk. It has been wonderful to work with all of you. I would particularly like to thank Dr. Stephanie Frost at the HRC. You have not only been a greater educational support, but also an emotional support as I have worked through this dissertation and your encouragement has allowed me to continue progressing during times I wanted to stop.

I would also like to acknowledge the faculty and staff in the School of Public Health, particularly my professors who imparted their knowledge through many hours inside and outside of the classroom. My thanks also to Dr. Gerald Hobbs for providing additional SAS support.

Finally, I would like to thank my family. I feel so blessed to have each of you in my life. Dad and mom, you have instilled the importance of an education and have provided encouragement along the way. Carrie Poston, you have been so supportive and understanding. Nichole Scaglione, thank you so much for all of your listening and advice. You really helped me push through to the end. Dr. Connie Rebich, Nana and Pop, you have cheered me on all the way through. Laurie Ewald, your support and pep talks have been so important through this process. 


\section{TABLE OF CONTENTS}

Chapter 1 ........

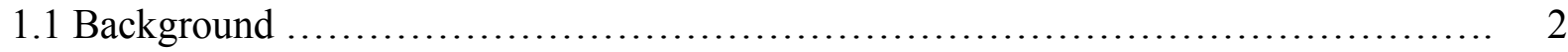

1.1.1 Overweight and Obesity in Youth............................................ 3

1.1.2 Energy Balance ................................................................ 4

1.1.3 Physical Activity and Obesity ................................................. 6

1.1.3.1 Moderate to Vigorous Physical Activity ................................. 7

1.1.3.2 Light Intensity Physical Activity ....................................... 8

1.1.4 Non-Exercise Activity Thermogenesis.......................................... 9

1.1.4.1 NEAT among Adults ............................................ 11

1.1.4.2 NEAT in Children and Adolescents ..................................... 12

1.1.5 Objective Methods to Measure Activity in Children and Adolescents............... 14

1.1.5.1 Heart Rate Monitors........................................................... 14

1.1.5.2 Doubly-Labeled Water............................................... 15

1.1.5.3 Accelerometer........................................................... 16

1.1.6 Stability of Physical Activity ................................................... 19

1.1.6.1 Stability of Moderate to Vigorous Physical Activity....................... 19

1.1.6.2 Stability of NEAT ................................................. 20

1.1.7 Activity Compensation ................................................... 20

1.1.7.1 Activity Compensation among Adults ................................... 21

1.1.7.2 Activity Compensation among Children and Adolescents ................. 23

1.2 The Purpose of the Current Research ........................................... 24

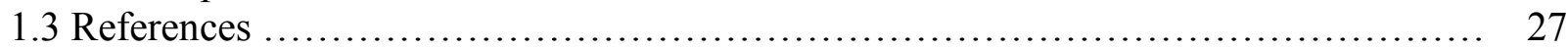

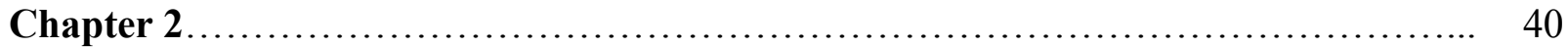

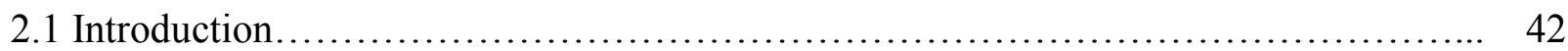

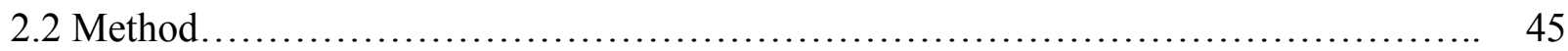

2.2.1 Data Collection ................................................................... 45

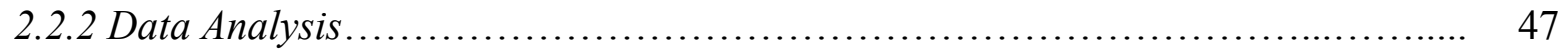

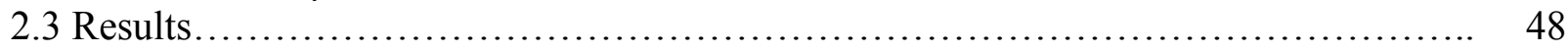

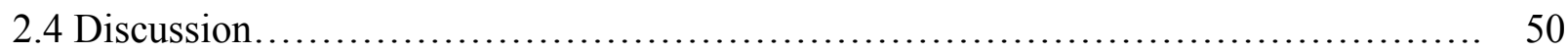

2.4.1 Strengths \& Limitations....................................................... 52

2.4.2 Conclusion ................................................................. 53

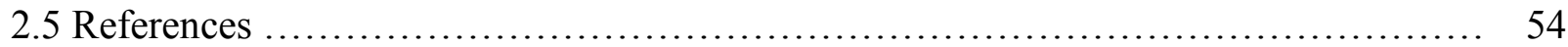

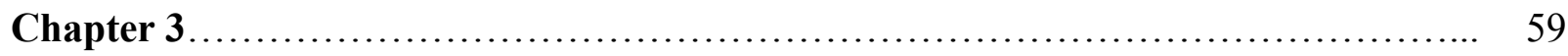

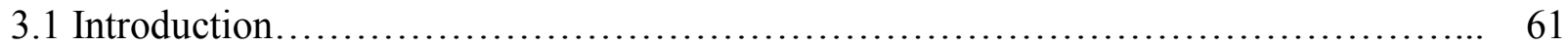

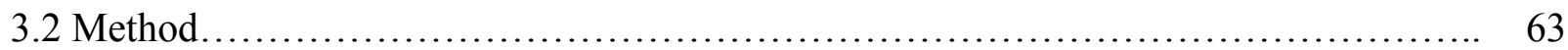

3.2.1 Data Collection .................................................................. 63

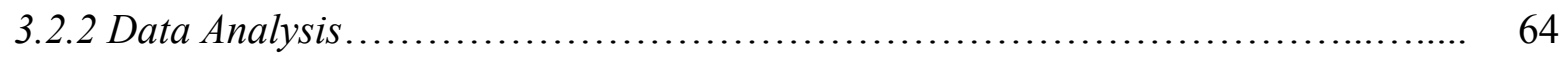




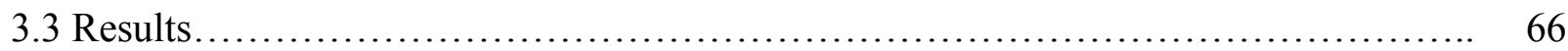

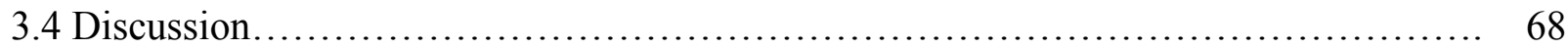

3.4.1 Strengths \& Limitations................................................. 70

3.4 .2 Conclusion........................................................... 72

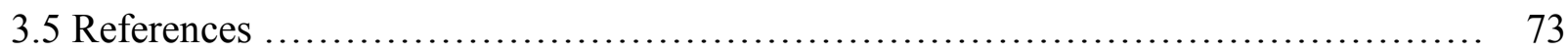

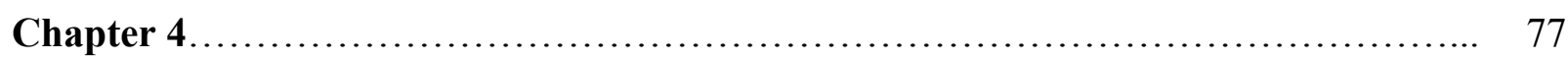

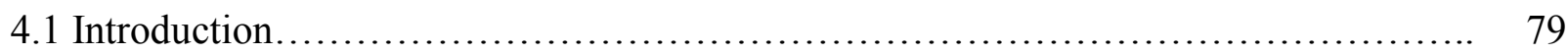

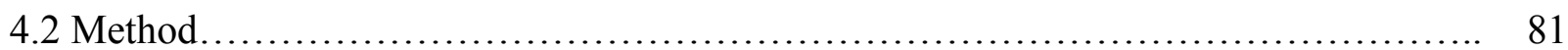

4.2.1 Data Collection........................................................ 81

4.2.2 Data Analysis....................................................... 81

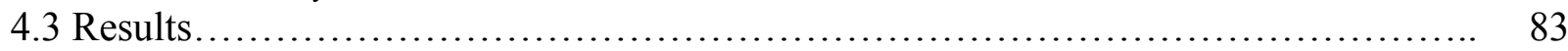

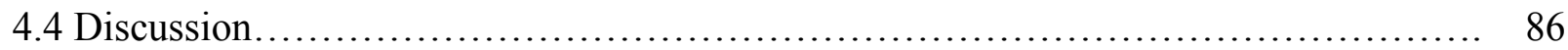

4.4.1 Strengths \& Limitations................................................. 88

4.4.2 Conclusion ............................................................. 90

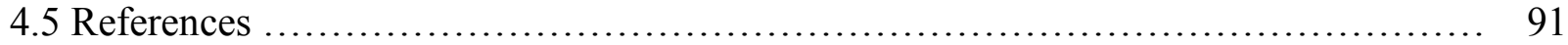

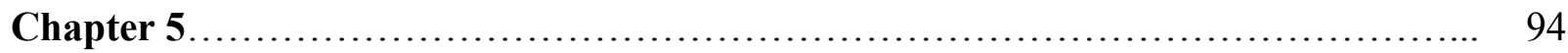

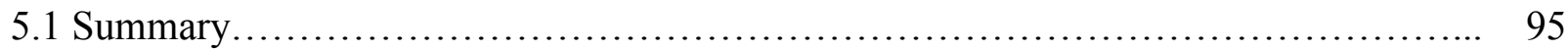

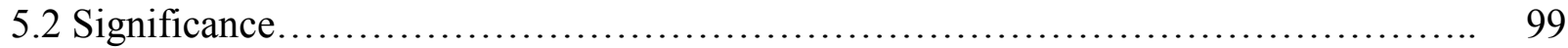

5.3 Strengths \& Limitations................................................... 100

5.4 Future Research............................................................ 101

5.5 Conclusions......................................................... 102

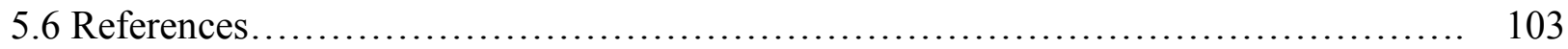


Chapter 1 


\section{Chapter 1}

\subsection{Background}

\subsubsection{Overweight and Obesity in Youth}

The accelerated rate of weight gain among the United States' (US) population has led to a pandemic problem of overweight and obese children, adolescents, and adults. Obesity-related medical costs were estimated at approximately $\$ 147$ billion in 2008 among adults (about 10\% of all medical spending) (Finkelstein, Trogdon, Cohen, \& Dietz, 2009). Increased obesity-related healthcare costs are also prevalent in childhood, estimated at approximately \$167 million in 2002 (Wang \& Dietz, 2002). Obese children spend more time in hospitals, take more medications, have longer hospitalizations, and have more frequent clinic visits than children of normal weight (Hering, Pritsker, Gonchar, \& Pilar, 2009). The financial burden may follow overweight and obese children into adulthood as an estimated $10 \%$ of young type 2 diabetic people will experience renal failure by the time they reach adulthood, likely requiring dialysis treatment throughout their life (Dean \& Flett, 2002). Unfortunately, measurements from the National Health and Nutrition Examination Survey (NHANES) indicate that about 17\% of children in the U.S. are classified as obese $\left(\geq 95^{\text {th }}\right.$ percentile $)$ and $33.6 \%$ as overweight or obese $\left(\geq 85^{\text {th }}\right.$ percentile) (Ogden, Carroll, Curtin, McDowell, Tabak, \& Flegal, 2006).

Irrespective of financial costs, overweight and obesity among children increase the risk for health problems such as poor glucose tolerance, type 2 diabetes, hyperinsulinaemia, sleep apnea, hypertension, social isolation, and depression (Lobestein, Baur, Uauy, for the IASO International Obesity TaskForce, 2004). Among adults, excess weight also contributes to an increase in physical ailments such as diabetes (Anderson, Kendall, \& Jenkins, 2003), heart disease (Eckel, \& Krauss, for the AHA Nutrition Committee, 1998), gall bladder disease, 
osteoarthritis, endocrine disorders (Lobestein et al., 2004), dyslipidemia (National Institute of Health, 1998) and selected cancers (Pischon, Nöthlings, \& Boeing, 2008). This is particularly concerning as overweight and obese children and adolescents will likely maintain this lifestyle into adulthood (Serdula, Ivery, Coates, Freedman, Williamson, \& Byers, 1993; The, Suchindran, North, Popkin, \& Gordon-Larsen, 2010), thereby leading to an increased risk of overweight and obesity, obesity-related chronic disease, and greater healthcare costs in adulthood. With more than one-third of the nation's children overweight or obese (Ogden et al., 2006), this is cause for concern.

The rates of overweight and obesity in children and adolescents have been shown to be highest in rural compared with urban (Liu, Bennett, Harun, \& Probst, 2008) and suburban (Nelson, Gordon-Larsen, Song, \& Popkin, 2006) settings. In addition, low socioeconomic groups, including many in rural areas, are disproportionately more likely to have higher rates of childhood obesity (Ogden, Carroll, Curtin, McDowell, Tabak, \& Flegal, 2006). Researchers have suggested that the relatively few physical activity opportunities within the rural setting may be a contributing factor to the increased risk of overweight or obesity in rural children (Powell, Slater, Chaloupka, \& Harper, 2006). Because the West Virginia is one of the most rural states in the U.S. (Lewis \& Burd-Sharps, 2010), it is likely then that the lack of physical activity opportunities may also apply to West Virginia.

\subsubsection{Energy Balance}

A chronic imbalance between energy consumption and energy expenditure has been identified as a factor contributing to the obesity pandemic (Brown, Williams, Ford, Ball, \& Dobson, 2005; Hill, Wyatt, Reed, \& Peters, 2003; Jéquier \& Tappy, 1999; Levine, 2007; Tataranni \& Ravussin, 2004; Webber, 2003). Genetic factors are thought to be only minimally 
responsible for obesity because the population has remained relatively stable while rates of obesity have dramatically increased (Lobestein et al., 2004). Though researchers note slight intra-individual variation in resting metabolic rates (estimated at about 4 to 6\%) (Henry, Hayter, \& Rees, 1989; Ravussin \& Bogardus, 1989), it is widely believed that the vast decline in overall physical activity leaves individuals with an overall caloric excess, thereby leading to the development of obesity and subsequent obesity-related health problems (Levine, McCrady, Boyne, Smith, Cargill, \& Forrester, 2011; Webber, 2003). These factors make it likely, then, that the relationship between physical inactivity and obesity is causal (Joosen, Gielen, Vlietinck, $\&$ Westerterp, 2005). Of note, active adults are better able to regulate their energy intake over the course of a day compared with sedentary adults, possibly leading to the ability to maintain energy balance long-term (Van Walleghen, Orr, Gentile, Davy, \& Davy, 2007). Although not explicitly examined among youth, it is possible that active youth may also be able to regulate their energy intake better than sedentary youth.

Conflicting evidence exists as to whether energy consumption has increased, decreased, or remained stable over time. Some research suggests that caloric intake has remained stable (Alexy, Sichert-Hellert, \& Kersting, 2002) or even decreased (Cavadini, Siega-Riz, \& Popkin, 2000; Prentice \& Jebb, 1995) and the number of calories consumed from fat has decreased as well (Willett \& Leibel, 2002), while the number of overweight and obese persons has increased. These researchers extrapolate these findings to hypothesize that a vast reduction in energy expenditure has led to an excess of calories, thereby leading to obesity (Katzmarzyk, Craig, \& Bouchard, 2001; Levine, Eberhardt, \& Jensen, 1999; Levine, Lanningham-Foster, McCrady, Krizan, Olaon, Kane et al., 2005; Speakman \& Selman, 2003). In contrast, other researchers have found that caloric consumption has increased in recent years (Nielsen, Siega-Riz, \& Popkin, 
2002). Researchers who have found an overall increase in caloric consumption over time speculate that the increase is due to the increases in portion sizes (Matthiessen, Fagt, BiltoftJensen, Beck, \& Ovesen, 2002; Young \& Nestle, 2003) and higher rates of consuming meals outside of the household (Bowman \& Vinyard, 2004). Other studies have implicated the consumption of sugar-sweetened beverages (SSBs) for the increase in caloric consumption and obesity among youth and adults as well (Ebbeling, Feldman, Osganian, Chomitz, Ellenbogen, \& Ludwig, 2006; Ludwig, Peterson, Gortmaker, 2001; Malik, Popkin, Després, Willett, \& hu, 2010; Malik, Schulze, \& Hu, 2006). Although a reduction in caloric consumption may also be able to reduce the number of overweight and obese youth and adults in the U.S., caloric expenditure through physical activity has the additional benefit of increasing cardiovascular health. Further, individuals who regularly exercise (both MVPA and light exercisers) experience a substantially lowers odds of overall mortality compared to sedentary individuals (Richardson, Kriska, Lantz, \& Hayward, 2004). This study also found that those individuals with cardiovascular disease (CVD) experienced an even greater benefit from being active compared with sedentary individuals in the CVD group (Richardson et al., 2004). These relationships between mortality risk and exercise remained, even after controlling for obesity, age, sex, race, smoking, cancer, health status, income, and CVD risk (Richardson et al., 2004).

Regardless of whether the chronic imbalance in energy consumption and expenditure is due to an increase in caloric consumption, decrease in energy expenditure, or a combination of the two, it is clear that increases in physical activity (PA) could affect the obesity epidemic. For example, Wang, Gortmaker, Sobol, and Kuntz (2006) estimated that the energy excess attributable to the increased weight gain among children and adolescents between 1988-1994 and 1999-2002 was about 110-165 extra calories each day. These researchers also estimated that the 
energy imbalance for children who became obese adolescents could be as much as $600-1,100$ kilocalories each day over a 10-year period (Wang et al., 2006). Larson-Meyer, Redman, Heilbronn, Martin, Ravussin, and the Pennington CALERIE Team (2010) found that overweight participants who were randomized to a calorically restrictive and aerobic exercise group experienced significant decreases in blood pressure, low-density lipoprotein cholesterol, and a significant increase in insulin sensitivity compared with overweight participants randomized to the calorically restrictive only group. Thus, it appears that increases in physical activity would potentially ameliorate the pandemic problem of overweight and obese youth and adults in the U.S. via closing the 'energy gap' and improve health above improvements from weight reduction alone.

\subsubsection{Physical Activity and Obesity}

Because genetics are thought to only play a minimal role in the current obesity epidemic, it is thought that environmental factors are likely to be the principal contributors (Lobestein et al., 2004). Two environmental factors which are thought to affect the weight status of individuals are caloric consumption and physical activity. As previously noted, research is conflicting as to whether caloric intake has increased (Bowman \& Vinyard, 2004; Matthiessen et al., 2002; Young \& Nestle, 2003), remained stable, or decreased (Alexy et al., 2002; Cavadini et al., 2000), while the number of individuals with excess weight has increased. Regardless of caloric consumption, it is also clear that energy expenditure has vastly decreased. To further support this, researchers note that obese children do not differ from their lean counterparts with regard to their resting metabolic rate (energy to maintain core body functions) nor their thermic effect of food (energy required for processing food); however, they do engage in physical activity less often (Lanningham-Foster \& Levine, 2010). These researchers also found that normal weight 
children stand for longer time periods throughout the day compared with overweight children (Lanningham-Foster \& Levine, 2010), leading to increased caloric expenditure.

Researchers note that PA is an important component for maintaining or losing weight among children, adolescents (Saris, Blair, van Baak, Eaton, Davies, Di Pietro, et al., 2003), and adults (Catenacci \& Wyatt, 2007; Hill \& Wyatt, 2005). In addition, PA has been shown to be protective against the risk for numerous chronic diseases, including, but not limited to, diabetes mellitus (Anderson, Kendall, \& Jenkins, 2003), heart disease (Eckel, \& Krauss, for the AHA Nutrition Committee, 1998), hypertension (Rahmouni, Correia, Haynes, \& Mark, 2005), osteoporosis (Zhao, Liu, Liu, Hamilton, Recker, \& Deng, 2007), anxiety, depression (Gariepy, Nitka, \& Schmitz, 2010), and selected cancers (Pischon, Nöthlings, \& Boeing, 2008) among adults. As added support, studies indicate that low levels of PA are associated with an increase in all-cause mortality (Blair, Kohl, Paffenbarger, Clark, Cooper, \& Gibbons, 1989) and obesity is associated with decreased life expectancy in the U.S. (Olshansky, Passaro, Hershow, Layden Carnes, Brody, et al., 2005).

Previous research has reported that obese adults tend to sit approximately 2.5 hours/days more than their lean counterparts (Levine, McCrady, Lanningham-Foster, Kane, Foster, et al., 2005). Similarly, a study involving accelerometry measures on 62 adults, ages 25 to 69 years, found that overweight/obese participants spent 21 fewer minutes/day engaged in at least moderate activity when compared with lean participants (Davis, Hodges, \& Gillham, 2006). Although research is clear that leading a sedentary lifestyle is likely to result in excess weight gain (Mitchell, Mattocks, Ness, Leary, Pate, Dowda et al., 2009) as well as an increased risk for the development of chronic diseases (Anderson et al., 2003; Eckel et al., 1998; Lobestein et al., 
2004; Pischon et al., 2008), there are currently no recommended clinical guidelines for how much sitting is 'too much' (Owen, Bauman, \& Brown, 2009).

\subsubsection{Moderate to Vigorous Physical Activity}

Youth in general are not receiving the recommended amount of PA each day, nor are they receiving the recommended amount of moderate to vigorous physical activity (MVPA) during physical education (PE) class (Simons-Morton, Taylor, Snider, Huang, \& Fulton, 1994). For example, current recommendations suggest that at least $50 \%$ of PE class time should be spent in MVPA (U.S. Department of Health and Human Services, 2010). Research indicates that rarely are these recommendations being met (Levin, McKenzie, Hussey, Kelder, \& Lytle, 2001; McKenzie, Marshall, Sallis, \& Conway, 2000).

Current recommendations for PA focus on MVPA levels. A total of 60 minutes spent in MVPA is currently recommended as the minimum amount of activity youth should be receiving each day to maintain a healthy lifestyle (Biddle, Sallis, \& Cavill, 1998; Strong, Malina, Blimkie, Daniels, Dishman, Gutin, et al., 2005). However, an increasing body of literature suggests that activity levels above sedentary but less than MVPA, i.e., non-exercise activity thermogenesis (NEAT), may also confer health benefits (Powell, Paluch, \& Blair, 2011). While much of the research to date has emphasized the benefits of MVPA for decreasing bodyweight among youth (Mark \& Janssen, 2009), little is known about NEAT. However, it has been recently established that lifestyle PA (i.e., at NEAT levels) is also beneficial for adults, including those who also achieve the recommended amount of MVPA (Owen, Healy, Matthews, \& Dunstan, 2010; Patel, Bernstein, Deka, Feigelson, Campbell, Gapstur, et al., 2010). 


\subsubsection{Light Intensity Physical Activity}

A systematic review and meta-analysis of cohort studies examining the benefits of lifestyle PA (NEAT) on all-cause mortality among adults found that compared with no activity, about 2.5 hours per week of low-to-moderate lifestyle PA was associated with a 19\% (95\% CI, $15 \%$ to $24 \%)$ reduction in mortality risk while 7 hours per week was associated with a $24 \%(95 \%$ CI, $19 \%$ to $29 \%$ ) reduction (Woodcock et al., 2010). Because lifestyle physical activity as a child tracks into adulthood (The et al., 2010), encouraging lifestyle PA in youth may reduce mortality risk as adults. This notion is advocated by Sallis and McKenzie (1991) who note that PA programs should be aimed at children and adolescents to prevent physical inactivity within the adult population.

\subsubsection{Non-Exercise Activity Thermogenesis (NEAT)}

As previously mentioned, NEAT refers to the amount of energy expended through daily activities, including those associated with an individual's occupation but independent of deliberate physical activity (PA). Specifically, NEAT is “...the thermogenesis that accompanies physical activities other than volitional exercise, such as the activities of daily living, fidgeting, spontaneous muscle contraction, and maintaining posture when not recumbent" (Levine, Eberhardt, \& Jensen 1999; p. 924). In a later article, Levine and colleagues (2003) go on to say that among humans NEAT involves such activities as “...walking, talking, yard work, and fidgeting" (p. 169). NEAT is estimated to account for most of the variance in total energy expenditure (TEE) that occurs independent from body weight (Levine, 2010). The figure below (figure 1) depicts the energy expenditure, above resting levels that occurs during various NEAT activities. 


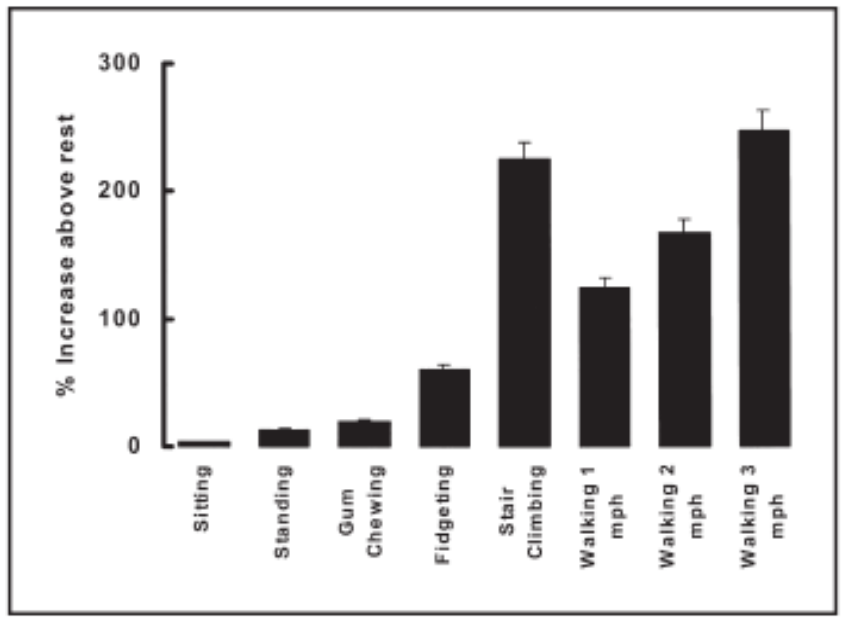

Figure 1. Energy expenditure associated with NEAT-type activities (Levine, 2004).

Measuring NEAT is difficult due to the various activities that may be encompassed (Levine, 2004). To quantify NEAT, four components must be known: 1) basal metabolic rate, 2) the thermic effect of food, 3) activity thermogenesis (specifically, exercise-related thermogenesis), and total energy expenditure (Levine, 2004). Subtracting the energy expenditure associated with an individual's basal metabolic rate, thermic effect of food, and exercise-related thermogenesis from their total energy expenditure will result in the amount of energy expenditure resulting from NEAT. In addition, NEAT can be categorized as posture NEAT (i.e., standing, sitting, lying) and movement NEAT (ambulation) (Levine, Lanningham-Foster, McCrady, Krizan, Olson, Kane, Jensen, \& Clark, 2005). In order to capture these necessary components, research has taken place, at least in part, in the laboratory setting (Levine, Melanson, Westerterp, \& Hill, 2001; McCrady \& Levine, 2010) and thus far, little research has examined NEAT in free-living individuals. Figure 2 below graphically illustrates the components of energy expenditure in sedentary adults (Levine, 2004). 


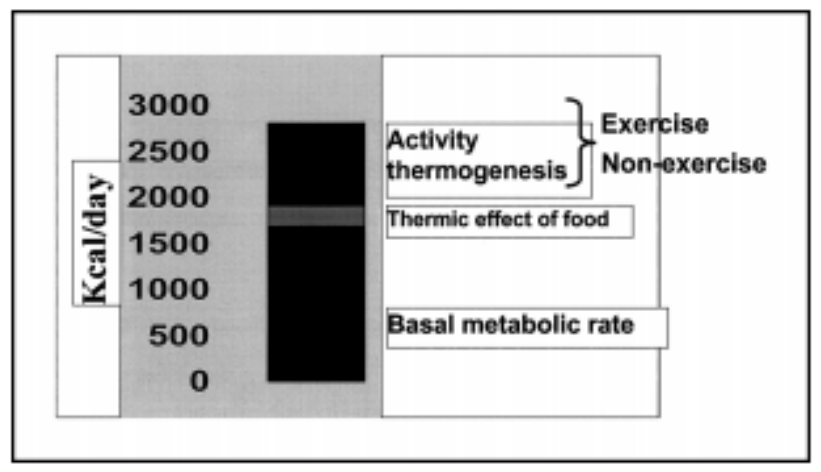

Figure 2. Energy expenditure in sedentary adults (Levine, 2004).

NEAT includes light levels of physical activity (Levine, Melanson, Westerterp, \& Hill, 2001; Mitchell, Mattocks, Ness, Leary, Pate, Dowda, Blair, \& Riddoch, 2009; Marshall \& Welk, 2008), as well as energy expenditure associated with both posture and ambulation (Levine et al., 2005). As such, measurements of light physical activity may provide estimates of NEAT. Although studies examining the accuracy of capturing NEAT via accelerometry measures have been rather limited, perhaps due to difficulties in quantification (Levine, 2004), researchers have found that in free-living individuals triaxial accelerometers and body position captures $>80 \%$ of NEAT activities (Bouten, Westerterp, Verduin, \& Janssen, 1994; Levine, 2004).

A low level of NEAT is thought to be integral to the development of obesity (Levine et al., 1999) and subsequent cardiovascular disease and stroke (Hamilton, Hamilton, \& Zderic, 2007; Manson, Greenland, LaCroix, Stefanick, Mouton, Oberman, et al., 2002; Paffenbarger, Blair, \& Lee, 2001; Vuori, 2001). Finally, the incorporation of NEAT principles allows for a gradual accumulation of energy expenditure throughout the day without requiring additional time to perform these activities because NEAT is performed in conjunction with daily activities (Beers, Roemmich, Epstein, \& Horvath, 2008). Thus, increased NEAT activity appears to be salubrious. 


\subsubsection{NEAT among Adults}

NEAT among human populations has been studied predominately in adults. Studies have examined NEAT with respect to occupation as well as body mass index (BMI). Research indicates that people in occupations which require more sedentary time, for example, clerical workers, engage in much less NEAT than individuals who are field workers (Levine et al., 2011). As occupations have moved from higher activity, to more sedentary, activity obtained while working has vastly declined (Brownson, Boehmer, \& Luke, 2005).

A study examining lean and obese sedentary adults found that lean sedentary people stand and move for 152 minutes more each day than obese sedentary adults, suggesting that low amounts of NEAT is associated, at least in part, with obesity (Levine et al., 2005). The researchers go on to note that if the obese sedentary adults in their study stood and moved in a similar fashion to the lean sedentary adults in the study, the obese sedentary adults may expend as much as 350 additional kilocalories per day (Levine et al., 2005).

In congruence with these findings, Kotz, Teske, and Billington (2008) state that NEAT has a protective effect against weight gain. In support of this, Conzett-Baumann, Jaggi, Hüsler, Hüsler, and Beer (2009) examined the number of steps walked (via pedometer) daily for 1 week by 10 young normal weight doctors (ages 28 to 34 years). They found that although all of the participants were of normal weight at the time of the study, there was an inverse relationship between BMI and number of steps taken. Conzett-Baumann and colleagues (2009) suggest that the reduced amount of NEAT seen among overweight/obese persons is not a consequence of weight status, but rather an antecedent, although there does not appear to be any long-term prospective studies explicitly examining this. 


\subsubsection{NEAT among Children and Adolescents}

Although NEAT has been examined in adults and young children to some degree, fewer studies have been conducted in adolescents. NEAT is important to examine in youth for several reasons, including: (1) the increase in obesity rates, particularly among children (Lobestein, Baur, \& Uauy for the IASO International Obesity TaskForce, 2004); (2) the theorized inverse relationship of NEAT to the development of obesity (Levine et al., 1999); and (3) NEAT's benefits for reducing morbidity and mortality from cardiovascular disease and stroke (e.g., Hamilton et al., 2007), even in instances where weight loss is not achieved. A limitation of the studies examining NEAT among youth is that they have included relatively small sample sizes. In contrast, the three studies described in chapters 2,3 , and 4 utilize two existing datasets using accelerometer data in large samples of $2^{\text {nd }}, 5^{\text {th }}, 9^{\text {th }}$, and $10^{\text {th }}$ graders. Most research has focused on higher levels of PA, i.e., $\geq 3$ metabolic equivalents (METS), with those who engage in activity levels below 3 METS categorized as “sedentary” (Pate, O’Neill, \& Lobelo, 2008), yet lower activity levels appear to confer health benefits as well.

Research in youth has shown that by incorporating the principles of NEAT into one's day, youth will expend more energy than when they are sedentary. For example, McManus (2007) stated that increased NEAT leads to positive gains in total daily energy expenditure (TDEE) and may lead to the prevention of excess fat in children. In addition, Benden and colleagues (2011) examined the caloric expenditure of youth sitting at traditional desks versus standing during a traditional class. On average, youth who were standing expended significantly more calories per minute ( 0.18 kilocalories; $17 \% ; \mathrm{p}=0.02)$ than youth who were sitting. Although youth were not achieving the recommended amount of MVPA, they were expending additional energy through NEAT. Furthermore, expending calories through lower levels of PA may be 
more achievable than MVPA during PE class due to such factors as high demands on PE teachers (Koustelios \& Tsigilis, 2005; Fraser-Thomas \& Beudoin, 2002; Morgan \& Hansen, 2007) and limited PE equipment (Fraser-Thomas \& Beudoin, 2002; McCaughtry, Barnard, Martin, Shen, \& Kulinna, 2006; Morgan \& Hansen, 2007).

It is reported that children spend only $10 \%$ to $20 \%$ of PE class time in MVPA (UCLA Center to Eliminate Health Disparities \& Samuels \& Associates, 2007). The PE class setting is one component of a youth's school day where increases in non-sedentary PA may be obtained. Additionally, PE is recognized as a means for youth to learn lifestyle PA behaviors that carry into adulthood (Pate, O'Neill, \& Mclver, 2011). McKenzie and colleagues (1999) demonstrated that PE teachers make a difference in the amount of physical activity youth engage themselves. Specifically, PE teachers who were engaged in higher levels of NEAT themselves also had more students who engaged in higher levels of NEAT. Thus, it is important to examine NEAT within the PE class setting because it may be a means through which youth can increase their caloric expenditure beyond that which can be achieved in the traditional classroom setting. Further, Levine and colleagues (2006) note that because NEAT is greatly influenced by occupation within the adult population, more NEAT research within the school environment for children should take place. Given the research with adults, it is possible that among children, NEAT may be greatly influenced by the school environment. Perhaps more encouraging still is the statement by Ravussin (2005) concluding that work by Levine and colleagues has clearly demonstrated that “...small but sustained changes in the activities of daily living can profoundly affect energy balance" (p. 531). As a result of examining NEAT in a rural sample of children and adolescents who are at an increased risk for overweight and obesity compared with youth residing in non- 
rural areas (Lutfiyya, Lipsky, Wisdom-Behounek, \& Inpanbutr-Martinkus, 2007), we may begin to understand other beneficial types of activity that take place in the PE class setting.

\subsubsection{Objective Methods to Measure Activity in Children and Adolescents}

\subsubsection{Heart Rate Monitors}

Heart rate monitors are reported to be an appropriate means to estimate energy expenditure in free-living (non-laboratory) conditions because many activities are low to moderate intensity (Ainsworth, Haskell, Whitt, Irwin, Swartz, Strath, et al., 2000). However, heart rate monitors may not detect low to moderate intensity physical activity with high efficacy, leading to possible imprecise measures of habitual daily energy expenditure in free-living conditions (Pettee et al., 2007). Additionally, heart rate monitors are highly influenced by individuals' emotions, posture, and environment (Haskell, Yee, Evans, \& Irby, 1993; Hebesteit \& Bar-Or, 1998; Montoye \& Taylor, 1984). Heart rate monitors used alone to assess low energy expenditure levels tend to have significant inaccuracies (Livingstone, Prentice, Coward, Ceesay, Strain, McKenna, et al., 1990; Luke et al., 1997). Because of these inaccuracies at low physical activity levels, researchers have been pairing heart rate monitors with motion sensors to increase the recording accuracy of individuals' total energy expenditure (Luke et al., 1997). Several studies have concluded that heart rate monitors are fairly accurate in measuring energy expenditure during high-intensity physical activity (Luke, Maki, Barkey, Cooper, \& McGee, 1997), but may be less accurate when measuring lower physical activity levels.

\subsubsection{Doubly Labeled Water}

Often considered the gold standard for measuring energy expenditure (Arvidsson, Slinde, \& Hulthén, 2009), the only true direct measure of energy expenditure is doubly labeled water (DLW) (Pettee et al., 2007). Briefly, DLW involves ingesting water that is labeled with a 
specific concentration of stable isotopes of both hydrogen and oxygen that are naturally occurring. When the body expends energy it produces both carbon dioxide and water. Energy expenditure can be calculated from the differences in isotope elimination rates. DLW is usually used to determine patterns of habitual energy expenditure (usually for 4 to 21 days) (Exercise and Physical Activity Resource Center, n.d.). While DLW can measure total energy expenditure, it does not allow for the calculation of the various levels of physical activity-i.e., sedentary, light, moderate, vigorous, is expensive, and can only be performed in a laboratory setting (Manthou, Gill, Wright, \& Malkova, 2010). Therefore, DLW is not feasible for use in measuring various levels of energy expenditure in free-living conditions.

Given that there is no feasible direct measure of energy expenditure for use in free-living conditions, and that objective measures are superior to estimating energy expenditure compared with subjective measures such as activity diaries (Reilly, 2006), many researchers utilize accelerometers and estimate energy expenditure using regression equations which have been validated in the laboratory setting.

\subsubsection{Accelerometers}

Accelerometers are currently seen as superior to other means of collecting data on physical activity because accelerometers can provide measures on “...intensity and frequency of human movement" (p. 7773, Yang \& Hsu, 2010). There are numerous types of accelerometers and each has varying degrees of reliability and validity, dependent upon the instrument and population under study. Overall, accelerometers are widely accepted as a practical means by which to measure physical activity objectively in both laboratory and free-living conditions (Mathie, Coster, Lovell, \& Celler, 2004). In addition, there are uniaxial, biaxial and triaxial accelerometers which measure activity on one, two and three planes (superior-inferior, antero- 
posterior, and medio-lateral), respectively (see Figure 3.). Although the difference is small, triaxial accelerometers have slightly better correlations with daily life activity related energy expenditure than uniaxial and biaxial accelerometers (Hendelman, Miller, Baggett, Debold, \& Freedson, 2000; Welk, Blair, Wood, Jones, \& Thompson, 2000).

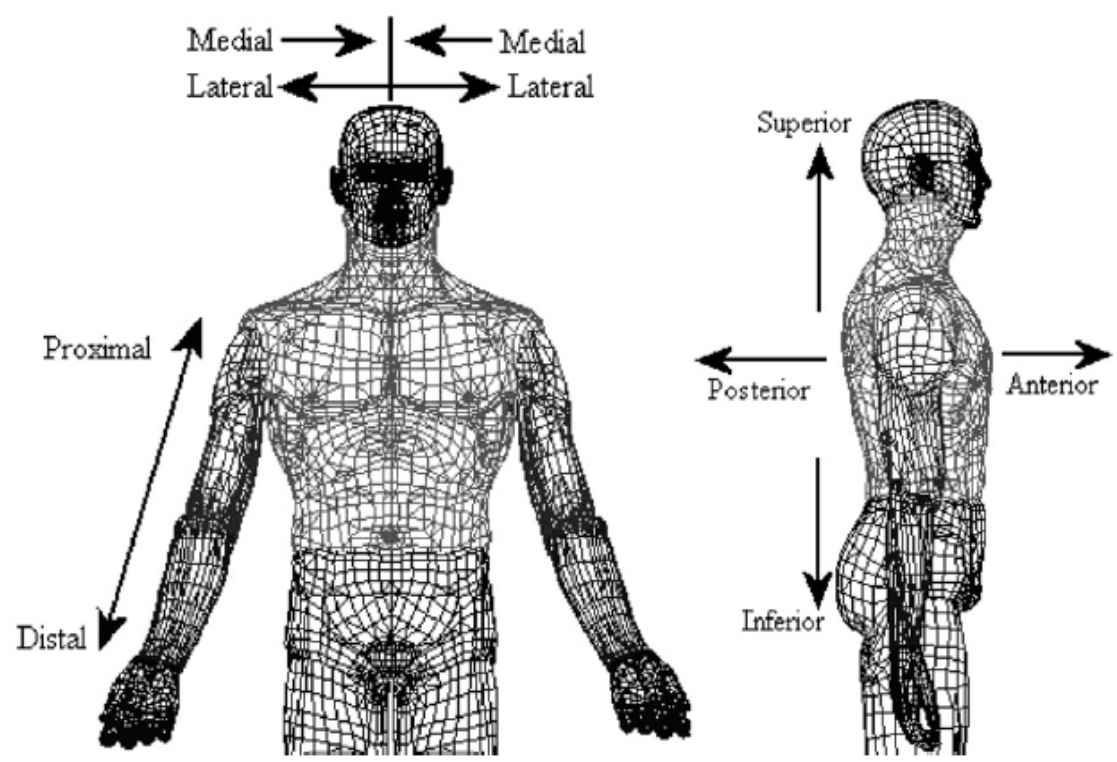

Figure 3. Planes of Movement (Hamil \& Knurzen, 2003)

The ActiGraph ${ }^{\mathrm{TM}}$ GT1M is a biaxial accelerometer that assesses superior-inferior and antero-posterior axes (Sasaki, John, \& Freedson, 2011). Prior to 2008, an earlier uniaxial model (7164) was limited to assessment in the vertical plane (Sasaki et al., 2011). Several studies that have examined the comparability between the 7164 and GT1M model with respect to the superior-inferior axis (the only common axis) have found no statistically significant differences between the two (Corder, Brage, Ramachandran, Snehalatha, Wareham, \& Ekelund, 2007; John, Tyo, \& Bassett, 2010; Kozey, Staudenmayer, Troiano, \& Freedson, 2010). Therefore, comparisons of results from various studies using the two accelerometers may be made. 
Sassaki, John, and Freedson (2011) sought to determine whether the GT1M (uniaxial) and GT3X (triaxial) accelerometers by ActiGraph ${ }^{\mathrm{TM}}$ resulted in comparable findings on the two same planes (i.e., vertical and antero-posterior). A total of 50 adults were included in the study and wore both the GT1M and GT3X accelerometers on their non-dominant hip during various intensities of physical activity. Of the 50 participants, data for 18 were removed due to a malfunction of one or both of the accelerometers. Results from the 32 remaining participants indicated that there were no statistically significant differences between the two accelerometers on the superior-inferior plane. However, the antero-posterior activity counts for the GT3X (triaxial) accelerometer were significantly lower than those from the GT1M (uniaxial) accelerometer (Sassaki et al., 2011). There was no conclusion regarding whether lower counts or higher counts were better.

A currently unpublished study by the manufacturers of ActiGraph ${ }^{\mathrm{TM}}$ examined the comparability between their biaxial $\left(\mathrm{GT}^{\mathrm{T}} \mathrm{M}^{\mathrm{TM}}\right)$ and triaxial $\left(\mathrm{GT} 3 \mathrm{X}^{\mathrm{TM}}\right)$ accelerometers (John \& Sasaki, n.d.). The researchers had 22 adult participants wear both the biaxial and triaxial accelerometers on their non-dominant hip under four different treadmill speed conditions. Using two-way ANOVAs to examine possible inter-device differences, results revealed that there were no statistically significant differences between the two accelerometers with respect to the superior-inferior axis activity counts. However, for the antero-posterior axis and composite vector, the GT3X $\mathrm{X}^{\mathrm{TM}}$ activity counts were lower. The researchers concluded that among adults, only the superior-inferior axis of the biaxial and triaxial accelerometers were comparable. These results are in contrast to studies indicating that ActiGraph ${ }^{\mathrm{TM}}$ accelerometers can be compared between one another on the antero-posterior plane (John \& Sasaki, n.d; Sassaki et al., 2011). The former notwithstanding, the ActiGraph ${ }^{\text {TM }}$ GT3X model, an instrument that provides 
measurements for three orthogonal planes (superior-inferior, antero-posterior, and medio-lateral) as well as a composite vector magnitude of the three axes, may be the preferred instrument (Sasaki, John, \& Freedson, 2011). When examined for validity against direct observation in numerous pediatric populations, the ActiGraph ${ }^{\mathrm{TM}}$ GT3X model has been shown to be highly valid (Puyau, Adolph, Firoz, \& Butte, 2002; Trost, Ward, Moorehead, Watson, Riner, \& Burke, 1998) and reliable (Wood, Kuntsi, \& Asherson, 2008). Specifically, Welk, Schaben, and Morrow (2004) found that when compared with other available accelerometers, the ActiGraph ${ }^{\mathrm{TM}}$ GT3X had the lowest error variance.

\subsubsection{Stability of Physical Activity}

The term stability can also be thought of as consistency or constancy. In other words, examining stability in PA is determining the variability of PA within an individual (intraindividual variation) from day to day as well as between individuals (inter-individual variation).

\subsubsection{Stability of Moderate to Vigorous Physical Activity}

The relative stability of different physical activity levels across different age groups has been assessed via accelerometry and self-report (Andersen, Klepp, Aas, \& Jakobsen, 1994; Janz, Witt, \& Mahoney, 1995). Studies have demonstrated that intra-individual (within person variance) MVPA remains relatively stable when examined for approximately 1 week via accelerometers (e.g., Janz et al., 1995). However, research examining the stability of MVPA across multiple years among children and adolescents suggests a vast difference in the amount of MVPA (Nader, Bradley, Houts, McRitchie, \& O’Brien, 2008; Sallis, 1993; Troiano et al., 2008). In fact, in a review of nine studies, Sallis (1993) found that PA declines consistently with age during the school age years; males' PA decreases about $2.7 \%$ each year while females' PA decreases about 7.4\% each year. Most of these studies have been conducted using self-report 
questionnaires rather than objective activity measures such as accelerometers (e.g., Telama, Yang, Viikari, Välimäki, Wanne, \& Raitakari, 2005). Nevertheless, findings from these studies suggest that although PA decreases across years, in the short-term (such as a 1 week time period), MVPA levels remain relatively consistent within individuals.

\subsubsection{Stability of NEAT}

Although the within and between person stability of MVPA has been examined among youth, the intra-individual variation (within person stability) of NEAT has yet to be explicitly examined. However, the inter-individual variation has been found to be highly variable (Levine, 2004). In addition, total energy expenditure studies have looked at both the inter- and intraindividual variance, which may provide additional support for the relative stability of NEAT. A study of inter-individual variation found that total daily energy expenditure can vary by as much as $2000 \mathrm{kcal}$ per day between individuals (Levine, Vander Weg, Hill, \&Klesges, 2006). A second study utilizing the DWL method to assess total daily energy expenditure concluded that male soldiers were estimated to expend three times more energy than incapacitated elderly persons (Black, Coward, Cole, \& Prentice, 1996). Research suggests that total energy expenditure is highly variable between individuals; thus, energy expended through NEAT principles may be variable within individuals as well. Because of the potential health benefits associated with NEAT activity levels, it is particularly important to examine the stability of NEAT activity so that we may begin to understand the nature of this activity within a group of rural youth, and can potentially identify health implications.

\subsubsection{Activity Compensation}

Activity compensation is the term used for compensatory reductions in energy expenditure as a result of imposed (forced) PA and vice versa (Rowalds, 2009). Eisenmann and 
Wickel (2009) noted that additional research is needed to examine activity compensation and whether it differs across various demographic variables such as age and gender. Activity compensation is often responsible for the perceived ineffectiveness of weight-loss exercise programs, even in such instances when compliance to the exercise regimen is close to perfect (King, Hopkins, Caudwell, Stubbs, \& Blundell, 2008). Although activity compensation has been examined indirectly in observational and intervention studies, few studies have examined activity compensation directly.

\subsubsection{Activity Compensation among Adults}

Activity compensation has been examined among adults with both objective and indirect measures and, although studies find conflicting results (e.g., Meijer, Janssen, Westerterp, Verhoeven, Saris, \& Hoor, 1991), most studies find that adults do engage in activity compensation (Goran \& Poehlman, 1992; Kempen, Saris, \& Westerterp, 1995; Stubbs, Hughes, Johnstone, Whybrow, Horgan, King, et al., 2003; Westerterp, Meijer, Janessen, Saris, \& Hoor, 1992). For example, a group of older adults $(\mathrm{N}=11)$ who were in excellent general health participated in endurance training three times each week (Goran \& Poehlman, 1992). Throughout this training period, participants' maximal oxygen consumption $\left(\mathrm{VO}_{2 \max }\right)$ and total energy expenditure under free-living conditions was assessed (Goran \& Poehlman, 1992). The participants' resting metabolic rate significantly increased, indicating that the endurance training program conferred health benefits (Goran \& Poehlman, 1992). When examining the last 10 days of the training program against pre-training levels, it was found that energy expenditure during participants' time outside of the training program was significantly reduced $(571 \pm 386 \mathrm{vs.} 340 \pm$ $452 \mathrm{kcal} /$ day) (Goran \& Poehlman, 1992). Importantly, no association was observed between changes in pre- to post-training energy expenditure and baseline fitness, fatness, leanness levels, 
or age (Goran \& Poehlman, 1992). The authors concluded that participants were engaging in compensatory reductions in energy expenditure outside of their endurance training program.

Stubbs and colleagues (2004) found similar results among a group of eight lean men, aged 18-40 years old. These researchers were interested in examining the possibility of activity compensation of an imposed exercise training program in combination with a low-fat diet over a period of 7 days. Stubbs et al. (2004) found an overall decrease in energy expenditure of 0.32 $\mathrm{MJ} /$ day, attributed to the progressive decrease in nonexercise energy expenditure throughout the study period. Though in this particular study an exercise program was combined with a low-fat diet, the finding of activity compensation supports previous energy expenditure decreases among adults (Goran \& Poehlman, 1992; Kempen, Saris, \& Westerterp, 1995; Westerterp, Meijer, Janessen, Saris, \& Hoor, 1992).

Another study that included 32 adult participants found that activity compensation did not occur (Meijer et al., 1991). The participants included non-obese adults who were enrolled in a 5month half-marathon training program (Meijer et al., 1991). Those who were already active for at least 1 hour per week or participated in running or jogging were excluded from the study (Meijer et al., 1991). Findings from this study indicated that total physical activity (as measured by an accelerometer) increased by $63 \%$ and $62 \%$ for females and males, respectively, after 20 weeks of training (Meijer et al., 1991). Outside of their training (the non-exercise portion of the day), participants did not change their level of physical activity (Meijer et al., 1991). In fact, while not statistically significant, there was a $15 \%$ increase in the males' physical activity outside the exercise intervention (Meijer et al., 1991). Goran, Calles-Escandon, Poehlman, O’Connell, and Danforth (1994) also found no indication of compensation among a group of 20 adults males. Interestingly, studies which find that activity compensation occurs as a result of 
increased imposed exercise (such as an exercise program) indicate that this compensation is more pronounced among females than males (Westerterp et al., 1992).

\subsubsection{Activity Compensation among Children and Adolescents}

Though most research indicates that adults engage in activity compensation, few studies have examined whether activity compensation occurs among children and adolescents. Those studies which have examined activity compensation among youth have found mixed results. Goodman, Mackett, and Paskins (2011) indicate that results for activity compensation are mixed and day-to-day, detailed PA data would allow researchers to address the confounding nature of children's individual characteristics. These researchers also examined activity compensation in 345 British children between 8 and 13 years of age. Both within and between comparisons of the children resulted in no statistically significant activity compensation (Goodman et al., 2011).

Other studies using questionnaires indicate that activity compensation may occur among children (e.g., Donelley, Jacobsen, Whately, O’Hill, Swift, Cherrington, et al., 1996).

Additionally, most of the studies indicating that activity compensation occurs among children do not have the main goal of examining the presence of activity compensation (e.g., Donnelley et al., 1996). Rather, these are predominately intervention studies with the goal of increasing overall physical activity. When no such increases in total physical activity are found, the researchers examine activity across intensities and find that while higher levels of physical activity (i.e., MVPA) increase, lighter physical activity levels (i.e., NEAT) have decreased, resulting in the overall activity level remaining stable from pre- to post-intervention. For example, two different intervention studies aimed at increasing physical activity among overweight/obese children found that while vigorous physical activity increased among participants, total daily physical activity remained constant (Brage, Wedderkopp, Ekelund, 
Franks, Wareham, Andersen, et al., 2004; Kang, Gutin, Barbeau, Owen, Lemmon, Allison, et al., 2002), suggesting that NEAT activities may have decreased.

Dale, Corbin, and Dale (2000) conducted one of the few studies to explicitly examine activity compensation among a group of children. Specifically, Dale et al. (2000) were interested in whether a group of $3^{\text {rd }}$ and $4^{\text {th }}$ grade $(\mathrm{N}=78)$ children engaged in activity compensation as a result of the amount of physical activity they received during the school day. Across 14 weeks, the researchers randomly assigned the children based on gender and grade to wear a uniaxial accelerometer across 4 consecutive days. On 2 of these days, children's school activities were restricted such that the children did not participate in morning recess, lunchtime recess, or their PE class. On the other 2 days, the children participated in their regularly scheduled physical activity opportunities. Dale and colleagues (2000) hypothesized that during the restricted days, the children would compensate for the physical activity restriction during the school day by participating in high levels of physical activity after school. The number of total counts for the restricted physical activity days was compared with those on the non-restricted days. The findings indicated that contrary to the hypothesis, children did not compensate for the restricted physical activity days by increasing their amount of activity after school (Dale et al., 2000).

\subsection{The Purpose of the Current Research}

This research fills a current gap in the literature because NEAT was examined in a comparatively large sample of rural, school-aged children and adolescents within and outside the PE class setting, during the school day. Rural youth are an important population to study because they are at increased risk of overweight/obesity and have been shown to have lower levels of PA compared with their urban and suburban counterparts (Liu et al., 2008; Lutfiyya et al., 2007;

Nelson et al., 2006). Physical education (PE) is an important setting for youth, particularly rural 
youth who may have less access within their environment to engage in PA (Powell, Slater, Chaloupka, \& Harper, 2006). The overall findings from this project may provide further justification for $\mathrm{PE}$ as a regular class offering and the justification for potential classroom modifications to allow for additional caloric expenditure.

Scientific research that examines the prevalence and predictors of NEAT among rural children and adolescents in the PE class setting and non-PE class school day is lacking. Additionally, activity compensation research has been limited with respect to direct measurements (such as the utilization of accelerometers) and few studies have examined this among a group of rural youth. To support the use of direct measurements of PA, a study examining the prevalence of compliance with PA guidelines found that among a sample of 400 youth, measuring PA levels via accelerometers provides more accurate prevalence rates than the commonly used self-report measures (Pate, Freedson, Sallis, Taylor, Sirard, Trost, et al., 2002). This work provides support for the use of accelerometers when assessing PA. Although triaxial accelerometers may only capture $>80 \%$ of NEAT activities (Bouden et al., 1994; Levine, 2004), the explicit examination of light physical activity will provide a preliminary characterization of NEAT among rural children and adolescents.

The results of this dissertation are expected to have a positive impact, because they can be utilized to inform future programming with respect to physical activity in children and adolescents generally, and overweight or obese children and adolescents, specifically. This project also supports a recent scientific statement from the American Heart Association recommending that schools are central to securing enough PA for youth to foster healthy lives (Pate, Davis, Robinson, Stone, McKenzie, \& Young, 2006). To date, the prevalence of NEAT, the relationship between selected predictors such as gender and grade on NEAT, as well as 
whether activity compensation occurs among rural youth, is not well established. The purpose of this project is to fill these gaps.

The objectives of the three studies were to determine the prevalence and predictors of NEAT among rural children and adolescents within and outside of the PE class setting, during the school day. The central hypotheses are that 1 ) the prevalence of NEAT will vary by grade, gender, and class setting; and, 2) that NEAT will be a relatively stable construct within the PE class setting as well as within the traditional class setting.

The study described in chapter 2 utilizes accelerometry data from a group of $2^{\text {nd }}$ and $5^{\text {th }}$ graders as well as $9^{\text {th }}$ and $10^{\text {th }}$ graders to examine whether NEAT decreases with age as MVPA does. The studies described in chapters 3 and 4 use a sample of accelerometry data from $9^{\text {th }}$ and $10^{\text {th }}$ graders across 1 week to examine the consistency of NEAT and whether adolescents engage in activity compensation based on the amount of MVPA they engage in during their PE class. The literature reviewed in this introduction provides support for the need to further examine NEAT among a relatively large group of children and adolescents and demonstrates that most research on NEAT has focused primarily on an adult population. The results of the three studies described in this paper will provide the basis for future work in this area, as well as future physical activity programming in children and adolescents. 


\subsection{References}

Aarnio, M., Winter, T., Peltonen, J. E., Kujala, U. M., \& Kaprio, J. (2002). Stability of leisuretime physical activity during adolescence: A longitudinal study among 16, 17 and 18 year-old Finnish youth. Scandinavian Journal of Medicine \& Science in Sports, 12(3), 179-185.

Alexy, U., Sichert-Hellert, W., \& Kersting, M. (2002). Fifteen-year time trends in energy and macronutrient intake in German children and adolescents: Results of the DONALD study. British Journal of Nutrition, 87, 595-604.

Anderson, J. W., Kendall, C. W. C., \& Jenkins, D. J. A. (2003). Importance of weight management in type 2 diabetes: Review with meta-analysis of clinical studies. Journal of the American College of Nutrition, 22(5), 331-339.

Anderson, N., Klepp, K., Aas, H., \& Jakobsen, R. (1994). Stability in physical activity levels in young adolescents: A 2 year follow-up of the Norwegian Longitudinal Health Behaviour Study. European Journal of Public Health, 4(3), 175-180.

Arvidsson, D., Slinde, F., \& Hulthén, L. (2009). Free-living energy expenditure in children using multi-sensor activity monitors. Clinical Nutrition, 28(3), 305-312.

Beers, E. A., Roemmich, J. N., Epstein, L. H., \& Horvath, P. J. (2008). Increasing passive energy expenditure during clerical work. European Journal of Applied Physiology, 103, 353-360.

Benden, M. E., Blake, J. J., Wendel, M. L., \& Huber, J. C. (2011).The impact of stand-biased desks in classrooms on calorie expenditure in children. American Journal of Public Health, 101(8), 1433-1436.

Biddle, S., Sallis, J. F., \& Cavill, N. A. (1998).Young and active? Young people and health enhancing physical activity-evidence and implications: A report of the Health Education Authority Symposium, Young and Active? London, UK: Health Education Authority.

Black, A. E., Coward, W. A., Cole, T. J., \& Prentice, A. M. (1996). Human energy expenditure in different affluent societies: An analysis of 574 doubly-labeled water measurements. European Journal of Clinical Nutrition, 50, 72-92.

Blair, S. N., Kohl, H. W., Paffenbarger, R. S., Clark, D. G., \& Gibbons, L. W. (1989). Physical fitness and all-cause mortality. Journal of the American Medical Association, 262, 2395-2401.

Bouten, C. V., Westerterp, K. R., Verduin, M., \& Janssen, J. D. (1994). Assessment of energy expenditure for physical activity using a triaxial accelerometer. Medicine and Science in Sports and Exercise, 26(12), 1516-1523. 
Bowman, S. A., \& Vinyard, B. T. (2004). Fast food consumption of U.S. adults: Impact on energy and nutrient intakes and overweight status. Journal of the American College of Nutrition, 23(2), 163-168.

Brage, S., Wedderkopp, N., Ekelund, U., Franks, P. W., Wareham, N. J., Anderson, L. B., \& Froberg, K. (2004). Features of the metabolic syndrome are associated with objectively measured physical activity and fitness in Danish children. Diabetes Care, 27(9), 2141-2148.

Brown, W. J., Williams, L., Ford, J. H., Ball, K., \& Dobson, A. J. (2005).Identifying the energy gap: Magnitude and determinants of 5-year weight gain in midage women. Obesity Research, 13, 1431-1441.

Brownson, R. C., Boekmer, T. K., \& Luke, D. A. (2005). Declining rates of physical activity in the United States: What are the contributors? Annual Review of Public Health, 26, 421-443.

Campbell, M. J. (2000). Cluster randomized trials in general (family) practice research. Statistical Methods in Medical Research, 9, 81-94.

Caspersen, C. J., Pereira, M. A., \& Curran, K. M. (2000).Changes in physical activity patterns in the United States, by sex and cross-sectional age. Medicine \& Science in Sports \& Exercise, 32(9), 1601-1609.

Catellier, D. J., Hannan, P. J., Murray, D. M., Addy, C. L., Conway, T. L., Yang, S., \& Rice, J. C. (2005).Imputation of missing data when measuring physical activity by accelerometry. Medicine \& Science in Sports \& Exercise, 37, S555-S562.

Catenacci, V. A., \& Wyatt, H. R. (2007).The role of physical activity in producing and maintaining weight loss. Endocrinology \& Metabolism, 3(7), 518-529.

Cavadani, C., Siega-Riz, A. M., \& Popkin, B. M. (2000).US adolescent food intake trends from 1965 to 1996. Western Journal of Medicine, 173, 378-383.

Corder, K., Brage, S., Ramachandran, A., Snehalatha, C., Wareham, N., \&Ekelund, U. (2007).Comparison of two ActiGraph models for assessing free-living physical activity in Indian adolescents. Journal of Sports Sciences, 25(14), 1607-1611.

Dale, D., Corbin, C. B., \& Dale, K. S. (2000). Restricting opportunities to be active during school time: Do children compensate by increasing physical activity levels after school? Research Quarterly for Exercise and Sport, 71(3), 240-248.

Davis, J. N., Hodges, V. A., \& Gillham, M. B. (2006).Physical activity compliance: Differences between overweight/obese and normal-weight adults. Obesity, 14(12), 2259-2265.

Dean, H., \& Flett, B. (2002). Natural history of type 2 diabetes diagnosed in childhood: Long term follow-up in young adult years. Diabetes, 51, A24-A25 [Abstract]. 
Donnelley, J. E., Jacobsen, D. J., Whatley, J. E., O’Hill, J. O., Swift, L. L., Cherrington, A., Polk, B., Tran, Z. V., \& Reed, G. (1996). Nutrition and physical activity program to attenuate obesity and promote physical and metabolic fitness in elementary school children. Obesity Research, 4, 229-242.

Donnelly, J. E., \& Lambourne, K. (2011).Classroom-based physical activity, cognition and academic achievement. Preventive Medicine, 52, S36-S42.

Ebbeling, C. B., Feldman, H. A., Osganian, S. K., Chomitz, V. R., Ellenbogen, S. J., \& Ludwig, D. S. (2006). Effects of decreasing sugar-sweetened beverage consumption on body weight in adolescents: A randomized, controlled pilot study. Pediatrics, 117(3), 673-680.

Eckel, R. H., Krauss, R. M., for the AHA Nutrition Committee. (1998). American Health Association call to action: Obesity as a major risk factor for coronary heart disease. Circulation, 97, 2099-2100.

Eisenmann, J. C., \& Wickel, E. E. (2009).The biological basis of physical activity in children: Revisited. Pediatric Exercise Science, 21, 257-272.

Exercise and Physical Activity Resource Center. (n.d.). Doubly-labeled water. Retrieved from http://www.ucsdeparc.org/index.php?option=com_content\&view=article\&id=100\&Itemid=82

Evenson, K. R., Cattellier, D., Gill, K., Ondrak, K., \& McMurray, R. G. (2008).Calibration of two objective measures of physical activity for children. Journal of Sports Science, 26, 15571565 .

Finkelstein, E. A., Trogdon, J. G., Cohen, J. W., \& Dietz, W. (2009). Annual medical spending attributable to obesity: Payer- and service-specific estimates. Health Affairs, 28(5), w822-w831.

Ford, E. S., Kohl, H. W., Mokdad, A. H., \& Ajani, U. A. (2005).Sedentary behavior, physical activity, and the metabolic syndrome among U.S. adults. Obesity Research, 13, 608-614.

Fraser-Thomas, J. L., \& Beaudoin, C. (2002). Implementing a physical education curriculum: Two teachers' experiences. Canadian Journal of Education, 27(2/3), 249-268.

Gariepy, G., Nitka, D., \& Schmitz, N. (2010). The association between obesity and anxiety disorders in the population: A systematic review and meta-analysis. International Journal of Obesity, 34(3), 407-419.

Goodman, A., Mackett, R. L., \& Paskins, J. (2011).Activity compensation and activity synergy in British 8-13 year olds. Preventive Medicine, 53, 293-298.

Goran, M. I., Calles-Escandon, J., Poehlman, E. T., O’Connell, M., \& Danforth, E., Jr. (1994). Effects of increased energy intake and/or physical activity on energy expenditure in young healthy men. Journal of Applied Physiology, 77, 366-372. 
Goran, M. I., \& Poehlman, E. T. (1992). Endurance training does not enhance total energy expenditure in healthy elderly persons. American Journal of Physiology, 265, E950-E957.

Grundy, S. M., Blackburn, G., Higgins, M., Lauer, R., Perri, M. G., \& Ryan, D. (1999).Physical activity in the prevention and treatment of obesity and its comorbidities. Medicine \& Science in Sports \& Exercise, 11, S502-S508.

Gurka, M. J., Edwards, L. J., Muller, K. E., \& Kupper, L.L. (2006).Extending the Box-Cox transformation to the linear mixed model. Journal of the Royal Statistical Society, 169, 273-288.

Hamill, J., \& Knutzen, K. (2003). In Biomechanical Basis of Human Movement. (2nd ed.) Darcy, P. (Ed). Baltimore: Lippincott, Williams, \& Wilkins.

Hamilton, M. T., Hamilton, D. G., \& Zderic, T. W. (2007). Role of low energy expenditure and sitting in obesity, metabolic syndrome, type 2 diabetes, and cardiovascular disease. Diabetes, 56(11), 2655-2667.

Haskell, W. L., Yee, M. C., Evans, A., \& Irby, P. J. (1993). Simultaneous measurement of heart rate and body motion to quantitate physical activity. Medicine \& Science in Sports \& Exercise, $25,109-115$.

Hebesteit, H., \& Bar-Or, O. (1998).Influence of climate on heart rate in children: Comparison between intermittent and continuous exercise. European Journal of Applied Physiology and Occupational Physiology, 78, 7-12.

Henry, C. J. K., Hayer, J., \& Rees, D. G. (1989). The constancy of basal metabolic rate in freeliving subject. European Journal of Clinical Nutrition, 43, 727-731.

Hering, E., Pritsker, I., Gonchar, L., \& Pilar, G. (2009). Obesity in children is association with increased health care use. Clinical Pediatrics, 48(8), 812-818.

Hill, J. O., \& Wyatt, H. R. (2005). Role of physical activity in preventing and treating obesity. Journal of Applied Psychology, 99(2), 765-770.

Hill, J. O., Wyatt, H. R., Reed, G. W., \& Peters, J. C. (2003). Obesity and the environment: Where do we go from here? Science, 299, 853-855.

Janz, K. F., Witt, J., \& Mahoney, L. T. (1995). The stability of children's physical activity as measured by accelerometery and self-report. Medicine \& Science in Sports \& Exercise, 27(9), 1326-1332.

Jéquier, E., \&Tappy, L. (1999). Regulation of body weight in humans. Physiological Reviews, 79(2), 451-480. 
John, D., Tyo, B., \& Bassett, D. (2011).Comparison of four ActiGraph accelerometers during walking and running. Medicine and Science in Sports and Exercise, 42(2), 368-374.

Joosen, A. M. C. P., Gielen, M., Vlietinck, R., \&Westerterp, K. R. (2005).Genetic analysis of physical activity in twins. American Journal of Clinical Nutrition, 82(6), 1253-1259.

Kang, H. S., Gutin, B., Barbeau, P., Owens, S., Lemmon, C. R., Allison, J., Lutaker, M. S., \& Le, N. A. (2002). Physical training improves insulin resistance syndrome markers in obese adolescents. Medicine and Science in Sports and Exercise, 34, 1920-1927.

Katzmarzyk, P. T., Craig, C. L., \& Bouchard, C. (2001).Original article underweight, overweight and obesity: relationships with mortality in the 13-year follow-up of the Canada Fitness Survey. Journal of Clinical Epidemiology, 54(9), 916-920.

Kempen, K. P. G., Saris, W. H. M., \& Westerterp, K. R. (1995). Energy balance during an 8-wk energy-restricted diet with and without exercise in obese women. American Journal of Clinical Nutrition, 62, 722-729.

Kenward, M. G., \& Roger, J. H. (1997).Small sample inference for fixed effects from restricted maximum likelihood. Biometrics. 53(3), 983-997.

King, N. A., Hopkins, M., Caudwell, P., Stubbs, R. J., \& Blundell, J. E. (2008).Individual variability following 12 weeks of supervised exercise: Identification and characterization of compensation for exercise-induced weight loss. International Journal of Obesity, 32, 177-184.

Kotz, C. M., Teske, J. A., \& Billington, C. J. (2008). Neuroregulation of nonexercise activity thermogenesis and obesity resistance. Regulatory, Integrative and Comparative Physiology, 294(3), R699-R710.

Koustelios, A., \& Tsigilis, N. (2005). The relationship between burnout and job satisfaction among physical education teachers: A multivariate approach. European Physical Education Review, 11(2), 189-203.

Kozey, S. L., Staudenmayer, J. W., Troiano, R. P., \& Freedson, P. S. (2010). A comparison of the ActiGraph 7164 and the ActiGraph GT1M during self-paced locomotion. Medicine and Science in Sports and Exercise, 42(5), 971-976.

Lanningham-Foster, \& Levine, J. A. (2010). Energy expenditure in children: The role of NEAT. In M. Freemark (Ed.), Contemporary endocrinology: Pediatric obesity: Etiology, pathogenesis, and treatement (pp. 137-151). New York, NY: Springer.

Lanningham-Foster, L., Foster, R. C., McCrady, S. K., Manohar, C. U., Jensen, T. B., Mitre, N. G., Hill, J. O., \& Levine, J. A. (2008). Changing the school environment to increase physical activity in children. Obesity, 16, 1849-1853. 
Larson-Meyer, D. E., Redman, L., Heilbronn, L. K., Martin, C. K., Ravussin, E., \& The Pennington CALERIE Team. (2010). Caloric restriction with or without exercise: The fitness vs. fatness debate. Medicine and Science in Sports and Exercise, 42(1), 152-159.

Levin, S., McKenzie, T. L., Hussey, J. R., Kelder, S. H., \& Lytle, L. A. (2001). Variability of physical activity during physical education lessons across elementary school grades.

Measurement in Physical Education and Exercise Science, 5, 207-218.

Levine, J. A. (2010). Non-exercise activity thermogenesis. Retrieved November 1, 2010 from: http://mayoresearch.mayo.edu/levine_lab/about.cfm

Levine, J. A. (2007). Nonexercise activity thermogenesis-liberating the life-force. Journal of Internal Medicine, 262, 273-287.

Levine, J. A. (2004). Non-exercise activity thermogenesis (NEAT). Nutritional Reviews, 62(7), S82-S97.

Levine, J. A., Eberhardt, N. L., \& Jensen, M. D. (1999). Role of nonexercise activity thermogenesis in resistance to fat grain in humans. Science, 283, 212-214.

Levine, J. A., Lanningham-Foster, L. M., McCrady, S. K., Krizan, A. C., Olson, L. R., Kane, P. H., Jensen, M. D., \& Clark, M. M. (2005). Interindividual variation in posture allocation: Possible role in human obesity. Science, 307(5709).584-586.

Levine, J. A., McCrady, S. K., Boyne, S., Smith, J., Cargill, K., \& Forrester, T. (2011).Nonexercise physical activity in agricultural and urban people. Urban Studies, 48(11), 2417-2427.

Levine, J. A., McCrady, S. K., Lanningham-Foster, L. M., Kane, P. H., Foster, R. C., \& Manohar, C. U. (2008). The role of free-living daily walking in human weight gain and obesity. Diabetes, 57, 548-554.

Levine, J., Melanson, E. L., Westerterp, K. R., \& Hill, J. O. (2001). Measurement of the components of nonexercise activity thermogenesis. American Journal of Physiology: Endocrinology and Metabolism, 281, E670-E675.

Levine, J. A., Vander Weg, M. W., Hill, J. O., \& Klesges, R. C. (2006). Non-exercise activity thermogenesis: The crouching tiger hidden dragon of societal weight gain. Arteriosclerosis, Thrombosis, and Vascular Biology, 26, 729-736.

Lewis, K., \& Burd-Sharps, S. (2010). The measure of America, 2010-2011: Mapping risks and resilience. New York, NY: New York University Press.

Li, C. L., Lin, J. D., Lee, S. J., \& Tseng, R. F. (2007).Associations between the metabolic syndrome and its components, watching television and physical activity. American Journal of Public Health, 121, 83-91. 
Liu, J., Bennett, K. J., Harun, N., \& Probst, J. C. (2008). Urban-rural differences in overweight status and physical activity among US children aged 10-17 years. The Journal of Rural Health, 24(4), 407-415.

Livingstone, M. B. E., Prentice, A. M., Coward, W. A., Ceesay, S. M., Strain, J. J., McKenna, P. G., Nevin, G. B., Barker, M. E., \& Hickey, R. J. (1990). Simultaneous measurement of freeliving energy expenditure by the doubly labeled water method and heart-rate monitoring. American Journal of Clinical Nutrition, 52, 59-65.

Lobestein, T., Baur, L., \& Uauy, R, for the IASO International Obesity TaskForce. (2004). Obesity in children and young people: A crisis in public health. Obesity Reviews, 5(Suppl. 1), 485.

Ludwig, D. S., Peterson, K. E., \& Gortmaker, S. L. (2001). Relation between consumption of sugar-sweetened drinks and childhood obesity: A prospective, observational analysis. Mancet, 357, 505-508.

Luke, A., Maki, K. C., Barkey, M., Cooper, R., \& McGee, D. (1997). Simultaneous monitoring of heart rate and motion to assess energy expenditure. Medicine \& Science in Sports \& Exercise, 29(1), 144-148.

Malik, V. S., Popkin, B. M., Bray, G. A., Després, J., Willett, W. C., \& Hu, F. B. (2010). Sugarsweetened beverages and risk of metabolic syndrome and type 2 diabetes: A meta-analysis. Diabetes Care, 33, 2477-2483.

Malik, V. S., Schulze, M. B., \& Hu, F. B. (2006). Intake of sugar-sweetened beverages and weight gain: A systematic review. American Journal of Clinical Nutrition, 84(2), 274-288.

Manson, J. E., Greenland, P., LaCroix, A. Z., Stefanick, M. L., Mouton, C. P., Oberman, A., Perri, M. G., Sheps, D. S., Pettinger, M. B., \& Siscovich, D. S. (2002). Walking compared with vigorous exercise for the prevention of cardiovascular events in women. New England Journal of Medicine, 347, 716-725.

Manthou, E., Gill, J. M. R., Wright, A., \& Malkova, D. (2010). Behavioural compensatory adjustments to exercise training in overweight women. Medicine and Science in Sports and Exercise, 42(6), 1121-1128.

Mark, A. E., \& Janssen, I. (2009). Influence of bouts of physical activity on overweight in youth. American Journal of Preventive Medicine, 36(5), 416-421.

Marshall, S. J., \& Welk, G. J. (2008). Definitions and measurement. In A. L. Smith \& S. J. H. Biddle (Eds.). Youth physical activity and sedentary behavior: Challenges and solutions. Champaign, IL: Human Kinetics. 
Mathie, M. J., Coster, A. C. F., Lovell, N. H., \& Celler, B. G. (2004). Accelerometry: Providing an integrated, practical method for long-term, ambulatory monitoring of human movement. Physiological Measurement, 25, 1-20.

Matthews, C. E., Ainsworth, B. E., Thompson, R. W., \& Bassett, Jr., D. R. (2002). Sources of variance in daily physical activity levels as measured by an accelerometer. Medicine \& Science in Sports \& Exercise, 8, 1376-1981.

Matthiessen, J., Fagt, S., Biltoft-Jensen, A., Beck, A. M., \& Ovesen, L. (2002). Size makes a difference. Public Health Nutrition, 6(1), 65-72.

McCaughtry, N., Barnard, S., Martin, J., Shen, B., \& Kulinna, P. H. (2006). Teachers' perspectives on the challenges of teaching physical education in urban schools: The student emotional filter. Research Quarterly for Exercise and Sport, 77(4), 486-497.

McCrady, S. K., \& Levine, J. A. (2010). Sedentariness at work; how much do we really sit? Obesity, 17(11), 2103-2105.

McKenzie, T. L., LeMaster, K. J., Sallis, J. F., \& Marshall, S. J. (1999). Classroom teachers' leisure physical activity and their conduct of physical education. Journal of Teaching in Physical Education, 19, 126-132.

McKenzie, T. L., Marshall, S. J., Sallis, J. F., \& Conway, T. L. (2000).Student activity levels, lesson context, and teacher behavior during middle school physical education. Research Quarterly for Exercise and Sport, 71, 249-259.

McManus, A. M. (2007). Physical activity-a neat solution to an impending crisis. Journal of Sports Science and Medicine, 6, 368-373.

Meijer, G. A. L., Janssen, G. M. E., Westerterp, K. R., Verhoeven, F., Saris, W. H. M., \& Hoor, F. T. (1991). The effect of a 5-month endurance-training programme on physical activity:

Evidence for a sex-difference in the metabolic response to exercise. European Journal of Applied Physiology and Occupational Physiology, 62, 11-17.

Mitchell, J. A., Mattocks, C., Ness, A. R., Leary, S. D., Pate, R. R., Dowda, M., Blair, S. N., \& Riddoch, C. (2009). Sedentary behaviour and obesity in a large cohort of children. Obesity, 17(8), 1596-1602.

Molenberghs, G., \&Verbeke, G. (2005).Discrete longitudinal data. New York: Springer-Verlag.

Montoye, H. J., \& Taylor, H. L. (1984).Measurement of physical activity in population studies. Human Biology, 56, 195-216.

Morgan, P., \& Hansen, V. (2007). Recommendations to improve primary school physical education: Classroom teachers' perspective. Journal of Educational Research, 101(2), 99-111. 
Nader, P. R., Bradley, R. H., Houts, R. M., McRitchie, S. L., \& O’Brien, M. (2008). Moderateto-vigorous physical activity from ages 9 to 15 years. Journal of the American Medical Association, 300(3), 295-305.

National Institute of Health. (1998). National Heart, Lung, and Blood Institute: Clinical guidelines to the identification, evaluation, and treatment of overweight and obesity in adults: The obesity report. Obesity Research, 6 (Suppl 2), 51S-209S.

Nelson, M. C., Gordon-Larsen, P., Song, Y., \& Popkin, B. M. (2006).Built and social environments: Associations with adolescent overweight and activity. American Journal of Preventive Medicine, 31(2), 109-117.

Nielsen, S. J., Siega-Riz, A. M., Popkin, B. M. (2002). Trends in energy intake in U.S. between 1977 and 1996: Similar shifts seen across age groups. Obesity Research, 10, 370-378.

Ogden, C. L., Carroll, M. D., Curtin, L. R., McDowell, M. A., Tabak, C. J., \&Flegal, K. M. (2006). Prevalence of overweight and obesity in the United States, 1999-2004.Journal of the American Medical Association, 295, 1549-1555.

Olshansky, S. J., Passaro, D. J., Hershow, R. C., Layden, J., Carnes, B. A., Brody, J., Hayflick, L., Butler, R. N., Allison, D. B., \& Ludwig, D. S. (2005). A potential decline in life expectancy in the United States in the $21^{\text {st }}$ century. New England Journal of Medicine, 352, 1138-1145.

Owen, N., Bauman, A., \& Brown, W. (2009). Too much sitting: A novel and important predictor of chronic disease risk? British Journal of Sports Medicine, 43(2), 81-83.

Own, N., Healy, G. N., Matthews, C. E., \& Dunstan, D. W. (2010). Too much sitting: The population health science of sedentary behavior. Exercise and Sport Science Reviews, 38(3), 105-113.

Paffenbarger, R. S. Jr., Blair, S. N., \& Lee, I. M. (2001). A history of physical activity, cardiovascular health and longevity: the scientific contributions of Jeremy N Morris, DSc, DPH, FRCP. International Journal of Epidemiology, 30, 1184 -1192.

Pate, R. R., Davis, M. G., Robinson, T. N., Stone, E. J., McKenzie, T. L., \& Young, J. C. (2006). A leadership role for schools: A scientific statement from the American Heart Association council on nutrition, physical activity, and metabolism (physical activity committee) in collaboration with the councils on cardiovascular disease in the young and cardiovascular nursing. Circulation, 114, 1214-1224.

Pate, R. R., Freedson, P. S., Sallis, J. F., Taylor, W. C., Sirard, J., Trost, S. G., \& Dowda, M. (2002). Compliance with physical activity guidelines: Prevalence in a population of children and youth. Annals of Epidemiology, 12, 303-308. 
Pate, R. R., O’Neill, J. R., \& Mclver, K. L. (2011). Physical activity and health: Does physical education matter? Quest, 63, 19-35.

Patel, A. V., Bernstein, L., Deka, A., Feigelson, H. S., Campbell, P. T., Gapstur, S. M., Colditz, G. A., \&Thun, M. J. (2010). Leisure time spent sitting in relation to total mortality in a prospective cohort of U.S. adults. American Journal of Epidemiology, 172(4), 419-429.

Pescatello, L. S., \& VanHeest, J. L. (2000). Physical activity mediates a healthier body weight in the presence of obesity. British Journal of Sports Medicine, 34, 86-93.

Pendergast, K., Wolf, A., Sherrill, B., Zhou, X., Aronne, L. J., Caterson, I., Finer, N., Hauner, H., Hill, J., Van Gaal, L., Coste, F., \&Despres, J. (2010). Impact of waist circumference difference on health-care cost among overweight and obese subjects: The PROCEED cohort. Value in Health, 13(4), 402-410.

Pettee, K. P., Tudor-Locke, C., \&Ainsworth, B. E. (2007).The measurement of energy expenditure and physical activity. In: Wolinsky, I., \& Driskell, J., (eds.) Nutritional assessment of athletes, Boca Raton, FL: CRC Press: 225-258.

Pischon, T., Nöthlings, U., \& Boeing, H. (2008).Symposium on 'diet and cancer': Obesity and cancer. Proceedings of the Nutrition Society, 67, 128-145.

Powell, K. E., Paluch, A. E., \& Blair, S. N. (2011).Physical activity for health: What kind? How much? How intense? On top of what? Annual Review of Public Health, 32, 349-365.

Powell, L. M., Slater, S., Chaloupka, F. J., \& Harper, D. (2006).Availability of physical activityrelated facilities and neighborhood demographic and socioeconomic characteristics: A national study. American Journal of Public Health, 96(9), 1676-1680.

Prentice, A. M., \& Jebb, S. A. (1995).Obesity in Britain: Gluttony or sloth? British Medical Journal, 311(7002), 437-439.

Puyau, M. R., Adoph, A. L., Firoz, A. V., \& Butte, N. F. (2002).Validation and calibration of activity monitors in children. Obesity Research, 10, 150-157.

Puyau, M. R., Adolph, A. L., Vohra, F. A., Zakeri, I., \& Butte, N. F. (2004).Prediction of activity energy expenditure using accelerometers in children. Medicine \& Science in Sports \& Exercise, 9, 1625-1631.

Puyau, M. R., Adolph, A. L., Vohra, F. A., \& Butte, N.F. (2002).Validation and calibration of physical activity monitors in children. Obesity Research, 10, 150-157.

Rahamouni, K., Correia, M. L. G., Haynes, W. G., \& Mark, A. L. (2005).Obesity-associated hypertension: New insights into mechanisms. Hypertension, 45, 9-14. 
Ravussin, E. (2005). A NEAT way to control weight? Science, 307, 530-531.

Ravussin, E., \& Bogardus, C. (1989).Relationship of genetics, age, and fitness to daily energy expenditure and fuel utilization. American Journal of Clinical Nutrition, 49, 968-975.

Richardson, C. R., Kriska, A. M., Lantz, P. M., \& Hayward, R. A. (2004). Physical activity and mortality across cardiovascular disease risk groups. Medicine and Science in Sports and Exercise, 36(11), 1923-1929.

Rowlands, A. V. (2009). Methodological approaches for investigating the biological basis for physical activity in children. Pediatric Exercise Science, 21, 273-278.

Rowlands, A. V. (2007). Accelerometer assessment of physical activity in children: An update. Pediatric Exercise Science, 19, 252-266.

Sallis, J. F. (1993). Epidemiology of physical activity and fitness in children and adolescents. Critical Reviews in Food Science and Nutrition, 33(4-5), 403-408.

Sallis, J. F., \& McKenzie, T. L. (1001).Physical education's role in public health. Research Quarterly in Exercise and Sports, 62(2), 403-408.

Saris, W. H. M., Blair, S. N., van Bakk, M. A., Eaton, S. B., Davies, P. S. W., Di Pietro, L., Fogelholm, M., Rissanen, A., Schoeller, D., Swinburn, B., Tremblay, A., Wesrerterp, K. R., \& Wyatt, H. (2003). How much physical activity is enough to prevent unhealthy weight gain? Outcome of the IASO $1^{\text {st }}$ Stock Conference and consensus statement. Obesity Reviews, 4, 101114.

Sasaki, J. E., John, D., \& Freedson, P. S. (2011).Validation and comparison of ActiGraph activity monitors. Journal of Science and Medicine in Sport, 14, 411-416.

Serdula, M. K., Ivery, D., Coates, R. J., Freedman, D. S., Williamson, D. F., \& Byers, T. (1993). Do obese children become obese adults? A review of the literature. The Journal of Preventive Medicine, 22(2), 167-177.

Simons-Morton, B. G., Taylor, W. C., Snider, S. A., Huang, I. W., \& Fulton, J. E. (1994).

Observed levels of elementary and middle school children's physical activity during physical education classes. Journal of Preventive Medicine, 23, 437-441.

Speakman, J. R., \& Selman, C. (2003).Physical activity and resting metabolic rate. Proceedings of the Nutrition Society, 62, 621-634.

Stevens, J., Taber, D. R., Murray, D. M., \& Ward, D. S. (2007).Advances and controversies in the design of obesity prevention trials. Obesity, 15, 2163-2170. 
Stubbs, R. J., Hughes, D. A., Johnstone, A. M., Whybrow, S., Horgan, G. W., King, N., \& Blundell, J. (2004). Rate and extent of compensatory changes in energy intake and expenditure in response to altered exercise and diet composition in humans. American Journal of Physiology-Regulatory, Integrative and Comparative Physiology, 286, R350-R358.

Tataranni, P. A., \& Ravussin, E. (2004).Energy metabolism and obesity. In T. A. Wadden \& A. J. Stunkard (Eds.), Handbook of obesity treatment (pp. 42-72). New York, NY: Guildford Press.

Telama, R., Yang, X., Viikari, J., Välimäki, I., Wanne, O., \& Raitakari, O. (2005).Physical activity from childhood to adulthood: A 21-year tracking study. American Journal of Preventive Medicine, 28(3), 267-273.

The, N. S., Suchindran, C., North, K. E., Popkin, B. M., \& Gordon-Larsen, P. (2010).Association of adolescent obesity with risk of severe obesity in adulthood. The Journal of the American Medical Association, 304(18), 2042-2047.

Tudor-Locke, C., Lee, S. M., Morgan, C. F., Beighle, A., \& Pangrazi, R. P. (2006).Children's pedometer-determined physical activity during the segmented school day. Medicine \& Science in Sports \& Exercise, 38(10), 1732-1738.

Troiano, R. P., Berrigan, D., Dodd, K. W., Mâsse, L. C., Tilert, T., \& McDowell, M. (2008).Physical activity in the United States measured by accelerometer. Medicine \& Science in Sports \& Exercise, 40(1), 181-188.

Trost, S. G., Loprinzi, P. D., Moore, R., \& Pfeiffer, K. A. (2011). Comparison of accelerometer cut points for predicting activity intensity in youth. Medicine \& Science in Sports \& Exercise, 43(7), 1360-1368.

Trost, S. G., Ward, D. S., Moorehead, S. M., Watson, P. D., Riner, W., \& Burke, J. R. (1998). Validity of the CSA activity monitor in children. Medicine \& Science in Sports \& Exercise, 30, 629-633.

UCLA Center to Eliminate Health Disparities, \& Samuels \& Associates. (2007). Failing fitness: physical activity and physical education in schools: Policy brief. Retrieved September 17, 2011 from: www.calendow.org/uploadedFiles/failing_fitness.pdf

U.S. Department of Health and Human Services. (2010). Strategies to improve the quality of physical education. Retrieved November 6, 2011 from http://www.cdc.gov/HealthyYouth

U.S. Department of Health and Human Services. (1999). A report of the surgeon general: Physical activity and health. Retrieved September 12, 2011 from, http://www.cdc.gov/nccdphp/sgr/pdf/adults.pdf 
Van Walleghen, E. L., Orr, J. S., Gentile, C. L., Davy, K. P., \& Davy, B. M. (2007). Habitual physical activity differentially affects acute and short-term energy intake regulation in young and older adults. International Journal of Obesity, 31, 1277-1285.

Vuori, I. M. (2001). Health benefits of physical activity with special reference to interaction with diet. Public Health Nutrition, 4(2B), 517-528.

Wang, G., \& Dietz, W. H. (2002). Economic burden of obesity in youths aged 6 to 17 years: 1979-1999. Pediatrics, 109, e81-e86.

Wang, Y., \& Beydoun, M. A. (2007).The obesity pandemic in the United States: Gender, age, socioeconomic, racial/ethnic, and geographic characteristics: A systematic review and metaregression analysis. Epidemiologic Reviews, 29, 6-28.

Wang, Y. C., Gortmaker, S. L., Sobol, A. M., \& Kuntz, K. M. (2006).Estimating the energy gap among US children: A counterfactual approach. Pediatrics, 118.E1721-e1733.

Webber, J. (2003). Energy balance in obesity. Proceedings of the Nutrition Society, 62, 539-543.

Welk, G. J., Schaben, J. A., \& Morrow, J. R., Jr. (2003). Reliability of accelerometry-based activity monitors: A generalizability study. Medicine \& Science in Sports \& Exercise, 36, 16371645 .

Westerterp, K. R., Meijer, G. A., Janssen, E. M. E., Saris, W. H. M., \& Hoor, F. T. (1992). Longterm effect of physical activity on energy balance and body composition. British Journal of Nutrition, 68, 21-30.

Willett, W. C., \& Leibel, R. L. (2002). Dietary fat is not a major determinant of body fat. American Journal of Medicine, 113, 47-59.

Wood, A. C., Kuntsi, J., \& Asherson, P. (2008). ActiGraph data are reliable, with functional reliability increasing with aggregation. Behavioral Research Methods, 40(3), 873-878.

Woodcock, J., Franci, O. H., Orsini, N., \& Roberts, I. (2010).Non-vigorous physical activity and all-cause mortality: Systematic review and meta-analysis of cohort studies. International Journal of Epidemiology, 40, 121-138.

Yang, C., \& Hsu, Y. (2010).A review of accelerometry-based wearable motion detectors for physical activity monitoring. Sensors, 10, 7772-7788.

Yaussi, S. C. (2005). The obesity epidemic: How non-PE teachers can improve the health of their students. The Clearing House, 79(2), 105-108.

Young, L. R., \& Nestle, M. (2003). Expanding portion sizes in the US marketplace: Implications for nutrition counseling. Journal of the American Dietetic Association, 103(2), 231-234. 
Zhao, L., Liu, Y., Liu, P., Hamilton, J., Recker, R. R., \& Deng, H. (2007).Relationship of obesity with osteoporosis. Endocrine Care, 92(5), 1640-1646. 
Chapter 2 


\title{
Chapter 2
}

\begin{abstract}
:
Few studies have examined non-exercise activity thermogenesis (NEAT) or light physical activity among a group of rural youth, particularly during physical education (PE) class. The purpose of this study was to determine whether the percent of PE class time spent in NEAT is related to school level (elementary versus high school) in a group of rural youth as measured objectively by accelerometers. Data from two larger studies were utilized. A linear regression was performed to examine the effect of school level on the percent of PE class time spent in NEAT. Covariates included were gender, PE teacher, and the duration of the PE class. Analyses revealed that school level was a significant predictor of the percent of PE class time spent in NEAT. Specifically, elementary school students spent more of their PE class time in NEAT than did the high school students $(p<.001)$. Consistent with previous research, males also spent significantly more time in NEAT during their PE class than females $(p=.046)$. Because students engage in relatively low levels of physical activity during PE class, and given the high demands placed on PE teachers, encouragement of NEAT activity during PE class may confer added health benefits.
\end{abstract}




\subsection{Introduction}

Overweight and obesity has reached epidemic proportions not just within the United States (Katzmaryk, 2010; Mokdad, Bowman, Ford, Vinicor, Marks, \& Koplan, 2001), but increasingly throughout the world (Roth, Qiange, Marbán, Redelt, \& Lowell, 2004). Of particular concern, an analysis by Olshansky, Passaro, Hershow, Layden, Carnes, Brody, et al. (2005) predicted that children in the current generation are likely to have a shorter lifespan, compared with their parents, due to the obesity epidemic and health consequences associated with such. This is in the opposite direction for the lifespan trend over the last century (Daniels, 2009). Because of the myriad physical and mental health consequences of obesity (Anderson, Kendall, \& Jenkins, 2003; Eckel \& Krauss, for the AHA Nutrition Committee, 1998; Lobestein, Baur, Uay, for the IASO International Obesity TaskForce, 2004; National Institute of Health, 1998; Pischon, Nöthlings, \& Boeing, 2008), it is no surprise that funding for obesity-related research has vastly increased in recent years (Spiegel \& Nabel, 2006). This increase in research has suggested that obesity among children and adolescents is associated with depression, social isolation, hypertension, poor glucose tolerance, hyperinsulinaemia, sleep apnea, hypertension, and type 2 diabetes (Lobestein et al., 2004). Two environmental factors thought to contribute to the development of excess weight are increased caloric consumption and decreased physical activity (or a combination of the two).

Research has drawn conflicting conclusions whether caloric intake has increased, decreased, or remained stable over the past decade or so. For example, some research suggests that caloric consumption has remained relatively stable (Alexy et al., 2002; Cavadini, Siega-Riz, \& Popkin 2000) or even decreased (Cavadini et al., 2000; Prentice \& Jebb, 1995) despite the increase in the number of overweight and obese persons. These researchers extrapolate these 
findings to hypothesize that a vast reduction in energy expenditure has led to an excess of calories, thereby leading to the development of obesity (Katzmarzyk, Craig, \& Bouchard, 2001; Levine, Eberhardt, \& Jensen, 1999; Levine, Lanningham-Foster, McCrady, Krizan, Olaon, Kane et al., 2005; Speakman \& Selman, 2003). In contrast, other research has found that caloric consumption has increased (Matthiessen, Fagt, Biltoft-Jensen, Beck, \& Ovesen, 2002; Nielsen, Siega-Riz, \& Popkin, 2002; Young \& Nestle, 2003). Researchers who have found an overall increase in caloric consumption over time speculate that the increase is due to the increases in portion sizes (Matthiessen, Fagt, Biltoft-Jensen, Beck, \& Ovesen, 2002; Young \& Nestle, 2003) and higher rates of consuming meals outside of the household (Bowman \& Vinyard, 2004). Regardless, it is likely that lack of physical activity and an increase in sedentary time is, at least in part, to blame. Additionally unsettling is the decreasing trend in physical activity as individuals age, with the most pronounced decrease in physical activity occurring between childhood and adolescence (Troiano, Berrigan, Dodd, Mâsse, Tilert, \& McDowell, 2007). Children residing in rural areas have been shown to be at an increased risk for the development of obesity when compared to suburban (Nelson, Gordon-Larsen, Song, \& Popkin, 2006) and urban (Liu, Bennett, Harun, \& Probst, 2008) children (Lutifyya, Lipsky, WisdomBehounek, \& Inpanbutr-Martinkus, 2007). The relatively few physical activity opportunities in rural communities have been suggested as a possible reason for rural children being at an increased risk for overweight or obesity (Powell, Slater, Chaloupka, \& Harper, 2006). In addition, Story, Nanney, and Schwartz (2009) suggested that the school environment may be an ideal avenue for childhood obesity prevention efforts. Given the former, the physical education (PE) class setting may be particularly important for rural children by assisting these children in obtaining the needed amount of physical activity to maintain a healthy lifestyle. 
Much of the focus to date has been on higher levels of physical activity (i.e., moderate to vigorous). Perhaps the focus on moderate to vigorous physical activity (MVPA) is due, at least in part, to the recommendations from the U.S. Department of Health and Human Services (2010) which suggest that at least $50 \%$ of PE class time be spent in MVPA. Despite the efforts to increase MVPA among children, especially given the known health benefits, research indicates that rarely are these MVPA recommendations being met (Levin, McKenzie, Hussey, Kelder, \& Lytle, 2001; McKenzie, Marshall, Sallis, \& Conway, 2000).

Studies that have examined MVPA unequivocally indicate that increases in MVPA confer health benefits. However, emerging evidence suggests that activity levels above sedentary but below MVPA also have health benefits. For example, among adults, low levels of physical activity are correlated with decreases in all-cause mortality (Blair, Kohl, Paffenbarger, Clark, Cooper, \& Gibbons, 1989). Relatively recently, James Levine coined the term "non-exercise activity thermogenesis" (NEAT) which refers to any “...energy expenditure of occupation, leisure, sitting, standing, walking, talking, toe-tapping, guitar playing, dancing and shopping" (p. 681, Levine, 2002). Essentially, NEAT includes all non-volitional energy expenditure. Light levels of physical activity are included in measuring NEAT (Levine, Melanson, Westerterp, \& Hill, 2001; Mitchell, Mattocks, Ness, Leary, Pate, Dowda, Blair, \& Riddoch, 2009; Marshall \& Welk, 2008), as well as energy expenditure associated with both posture maintenance and ambulation (Levine et al., 2005). Incorporating NEAT activities into one's day allows for the gradual accumulation of energy expenditure (Beers, Roemmich, Epstein, \& Horvath, 2008). Among adults, NEAT has even been found to be protective against weight gain (Kotz, Teske, \& Billington, 2008). 
Little research to date has examined the prevalence of NEAT among rural children and adolescents. Additionally, much research examining the relationship between age and physical activity decline, to date, has focused on MVPA and sedentary time while not accounting for NEAT, i.e., light, activity (Corder et al., 2010). The purpose of this study was to determine the association between the percentage of time spent in NEAT among elementary and high school students during PE class. Based on previous research which indicates a negative relationship between MVPA and age beginning as early as elementary school (Corder, van Sluijs, Ekelund, Jones, \& Griffin, 2010; Nader, Bradley, Houts, McRitchie, \& O'Brien, 2008) and continuing through adulthood (King, Castro, Wilcox, Eyler, Sallis, \& Brownson, 2000; Leslie, Owen, Salmon, Bauman, Sallis, \& Lo, 1999; Salmon, Owen, Bauman, Schmitz, \& Booth, 2000), it was hypothesized that high school students would engage in higher levels of NEAT than elementary school students. This rationale for this is based on the premise that as children age, they may still engage in physical activity but not at the same intensity level as younger children.

\subsection{Methods}

\subsubsection{Data Collection}

Collected as part of a larger study to examine the implementation of the Healthy Lifestyles Act (HLA) (discussed in detail in Harris, Bradlyn, O'Hara Tompkins, Kelley, for the Healthy Lifestyles Act Evaluation Team, 2009), the secondary data for the current investigation were derived from a total of $2022^{\text {nd }}(n=100)$ and $5^{\text {th }}(n=102)$ grade students and $2379^{\text {th }}(n=98)$ and $10^{\text {th }}(n=67)$ grade students who wore a triaxial accelerometer on their right hip. The biaxial accelerometers were placed on the $2^{\text {nd }}$ and $5^{\text {th }}$ graders' right hip by their PE teachers, whereas the $9^{\text {th }}$ and $10^{\text {th }}$ graders were instructed to place their triaxial accelerometers on their right hip on their own. Collected in spring, 2010, data for $2^{\text {nd }}$ and $5^{\text {th }}$ graders were obtained from children in 
10 West Virginia public elementary schools who wore a biaxial accelerometer on their right hip during PE class. The 10 public elementary schools were chosen based on the degree of implementation of West Virginia's obesity legislation (HLA; Harris et al., 2009). Elementary schools in West Virginia were ranked according to the degree to which each had implemented the HLA legislation. Schools were then randomly selected from high-, moderate-, and lowimplementers of the HLA Act. For participant selection, each PE teacher was asked to select the first four students in alphabetic order from their roster on the first day of the week. For the following PE class, the PE teacher was instructed to select the next four students on the roster. This pattern continued for 1 week. In addition to accelerometer data, student gender, grade level, PE teacher, and school were collected.

The $9^{\text {th }}$ and $10^{\text {th }}$ grade data set included data on 130 adolescents from seven West Virginia public high schools who wore the ActiGraph ${ }^{\mathrm{TM}}$ GTX3E triaxial accelerometer on their right hip for 1 week in the spring of 2011. An additional 97 students from seven West Virginia public high schools participated in fall, 2011 and were also included in this analysis. Students were instructed to wear the accelerometers for 1 week at the beginning of PE class and for 1 week at the end of PE class. In addition to accelerometer data, student gender, grade level, teacher, PE class time, and body mass index (BMI) percentile data were collected. The high schools were selected as they comprised all of the high schools within the 6-county intervention area of Communities Putting Prevention to Work (CPPW; see Bunnell et al., 2012 for specifics on the CPPW grant). For the present study, only the data from the first day of the adolescents' PE class from the first week that each adolescent wore the accelerometer were included. Though the elementary students wore biaxial accelerometers, and the high school students wore triaxial accelerometers, the activity component of these data were utilized for the current study and have 
been shown to be comparable (Sassaki, John, \& Freedson, 2011). The comparability of biaxial and triaxial activity data has been examined elsewhere (see Sassaki et al., 2011). This study received institutional review board approval from the referent university.

\subsubsection{Data Analysis}

Preliminary analyses were performed to obtain the sample characteristics. These included frequencies, means, and standards deviations (where appropriate), as well as independent t-tests to examine potential differences between elementary and high school level regarding PE class length as well as any gender differences.

To determine the potential association between age group and NEAT, a linear regression model was performed. The outcome was the percent of participants' PE class time spent in NEAT. The predictor was age group, where $1=$ elementary school and 2=high school, while controlling for gender ( $1=$ male, $2=$ female), duration of PE class (minutes), and PE teacher.

The elementary school students wore the accelerometer for 1 day of PE class, whereas the high school students wore the accelerometer for 1 week during PE class, for a total of five possible measures of NEAT. To utilize comparable data, the first day of PE class when the high school students wore the accelerometer was used to compare with the 1 day of accelerometer data from the elementary school students.

To convert data from the accelerometers into usable data, the statistical program MeterPlus $^{\mathrm{TM}}$ (Santech Inc., 2010) was used. Accelerometry data were specified at 5-second epochs and deduced using 15 -second time intervals. The cut points established by Evenson and colleagues (2008) were used to estimate time spent in sedentary ( $\leq 100$ counts/minute), NEAT (light; 101-2295 counts/minute), moderate (2296-4011 counts/minute), and vigorous ( $\geq 4012$ counts/minute) activity. The Evenson et al. (2008) cut points were used as these are 
recommended as most appropriate for children and adolescents (Trost, Loprinzi, Moore, \& Pfeiffer, 2011). Children and adolescents are more likely to engage in short bouts of energy expenditure compared with adults, and longer intervals such as those 1 minute long may substantially underestimate physical activity (Bailey, Olson, Pepper, Porszasz, Barstow, \& Cooper, 1995). For this reason, a 15-second time interval was utilized. As such, the cut points used were as follows: sedentary ( $\leq 25$ counts/15 seconds), NEAT (light; 26-573 counts/15 seconds), moderate (574-1002 counts/15 seconds), and vigorous ( $\geq 1003$ counts/15 seconds) activity. All analyses were performed in Statistical Analysis System (SAS) 9.3 (Cary, N.C.). Preliminary diagnostics were conducted to determine the presence of collinearity and outliers. Results were considered statistically significant at an alpha level of $p<0.05$.

\subsection{Results}

Descriptive characteristics are shown in Table 1. After removing participants who did not have accelerometer data for the first day of PE class in which the accelerometer was worn (high school $n=54$ ), a total of 357 participants were included in the study. Slightly more than half of the participants $(\mathrm{n}=192 ; 53.8 \%)$ attended elementary school. The sample included approximately equal numbers of males and females $(p=.381)$. On average, high school students spent more time in PE than elementary school students $(p<.001)$ Each participant in the sample was taught by 1 of $31 \mathrm{PE}$ teachers. 
Table 1. Sample Characteristics, by School Level

\begin{tabular}{cccc}
\hline & $\begin{array}{c}\text { Elementary } \\
(N=192) \\
\text { Mean }(S D)\end{array}$ & $\begin{array}{c}\text { High School } \\
(N=165) \\
\text { Mean }(S D)\end{array}$ & $\begin{array}{c}\text { Total Analytic } \\
\text { Sample }(N=357) \\
\text { Mean }(S D)\end{array}$ \\
\hline Gender & & & \\
\hline Male n(\%) & $89(46.6 \%)$ & $89(53.9 \%)$ & $179(50.1 \%)$ \\
Female n(\%) & $102(53.4 \%)$ & $76(46.1 \%)$ & $178(49.9 \%)$ \\
\hline Activity Level & & & \\
\hline Sedentary (\% of PE Class) & $36.7 \%(17.9 \%)$ & $70.0 \%(23.9 \%)$ & $52.7 \%(26.9 \%)$ \\
NEAT (\% of PE Class) & $56.8 \%(16.7 \%)$ & $26.7 \%(22.9 \%)$ & $43.2 \%(24.4 \%)$ \\
Moderate (\% of PE Class) & $5.4 \%(4.7 \%)$ & $1.2 \%(2.4 \%)$ & $3.4 \%(4.3 \%)$ \\
Vigorous (\% of PE Class) & $1.1 \%(2.4 \%)$ & $0.1 \%(0.3 \%)$ & $0.6 \%(1.9 \%)$ \\
PE Class Length (minutes) & $33.13(5.32)$ & $82.12(20.81)$ & $55.81(28.54)$ \\
\hline
\end{tabular}

Notes: NEAT=Non-exercise activity thermogenesis; $\mathrm{SD}=$ Standard Deviation

In order to determine whether school level (elementary versus high school) was associated with the percentage of time spent in NEAT during PE class, a linear regression was performed. The four-predictor model was able to account for $37.9 \%$ of the variance in the percentage of time spent in NEAT during PE class, $F(4,345)=52.65, p<.001$ (Table 2). Results from the linear regression revealed that controlling for gender, PE teacher, and duration of PE class, school level (elementary versus high school) was a statistically significant predictor for the percentage of time spent in NEAT during PE class $(p<.001)$. Specifically, participants in elementary school spent significantly more time in NEAT than did the high schools participants. Length of PE class nor gender were statistically significant predictors of the percentage of time a participant spent in NEAT during his/her PE class. Please see table 2 for included model variables. 
Table 2. Final Mixed Model Linear Regression Model Predicting the Percent of PE Time Spent in NEAT.

\begin{tabular}{lcccc}
\hline \multicolumn{5}{c}{ Percent of PE Time Spent in NEAT } \\
\hline & $\boldsymbol{B}$ & $\boldsymbol{S E}(\boldsymbol{B})$ & $\boldsymbol{t}$ & $\boldsymbol{P}$ \\
\hline School Level (Elementary as referent) & -0.37 & 0.07 & -5.49 & $<.001$ \\
Gender (Male as referent) & -0.03 & 0.02 & -1.77 & .077 \\
Duration of PE Class & 0.002 & 0.001 & 1.50 & .144 \\
\hline
\end{tabular}

Notes: NEAT=Non-exercise activity thermogenesis; Model adjusted for PE teacher.

\subsection{Discussion}

The purpose of this study was to determine whether lower levels of physical activity follow a similar trajectory as MVPA (i.e., whether NEAT decreases, increases, or remains stable across age groups). Contrary to the original hypothesis, the results of this study suggest an association between lower levels of light (NEAT) physical activity among high school versus elementary school students during PE class. Not only are the high school students achieving very low levels of MVPA, they are also achieving low levels of NEAT during their PE class. A striking $70 \%$ of their PE class time was spent in sedentary activity. Given the former, it may be also important to focus on NEAT activity since it may be more achievable than MVPA activity. Previous research has found that younger children tend to engage in higher levels of MVPA than older children (Nader et al., 2008). While the predominate focus of physical activity research has been on MVPA, recent research has begun to identify the health benefits that arise from lower levels of physical activity as well (Kotz et al., 2008). Research on the light/NEAT levels of physical activity indicates that some activity, irrespective of the intensity, is better than none. The current study contributes to the body of literature in that it demonstrates, in this sample, an association between lower levels of light (NEAT) physical activity among high school versus elementary school students during PE class. This finding has important implications for schools, and more specifically, for PE teachers. It is possible, given the high demands on PE teachers and 
limited equipment (Fraser-Thomas \& Beudoin, 2002; Morgan \& Hansen, 2007), that caloric expenditure through lower levels of physical activity (i.e., at NEAT levels) may be more achievable than MVPA within the PE class setting. Unfortunately, it appears that the majority of time during high school students PE class is spent in sedentary endeavors. As such, additional support for PE teachers, including training, may be necessary to encourage physical activity at all levels above sedentary during PE class. For example, walking while waiting for a turn to utilize equipment would enable youth to engage in NEAT activity levels rather than remaining sedentary, and thus, leading to the achievement of health benefits from the activity.

From previous research, children appear to engage in higher levels of physical activity outside of the school day, especially on the weekends (Sener, Copperman, Pendyala, \& Bhat, 2008) and during organized physical activity programs (Ross, Dotson, Gilbert, \& Katz, 1985) such as team sports. Thus, future research should examine NEAT activity levels outside of the school day to determine whether this is also the case for NEAT. Research also indicates that curricular physical activity time does not inhibit academic performance even when some time is moved away from academic classes to PE (Shephard, 1997), and may even improve academic achievement (Coe, Pivarnik, Womack, Reeves, \& Malina, 2006; Dwyer, Sallis, Blizzard, Lazarus, \& Dean, 2001; Field, Diego, \& Sanders, 2001).

\subsubsection{Strengths \& Limitations}

Certain limitations exist with this study. First, this project utilized previously collected data. Consequently, we were limited by the available data. For example, while BMI percentile data were available for the high schools students, such data were not available for elementary school children. Therefore, we were unable to determine the potential association between BMI and NEAT in our sample of elementary school students. Similarly, due to the use of 
accelerometry data, specifically utilizing light physical activity levels as a proxy for NEAT, NEAT may be underestimated because some NEAT activities such as brisk walking may register as light to moderate activity levels (Sallis, Frank, Saelens, \& Kraft, 2004). However, because NEAT includes light activity levels (Levine, Melanson, Westerterp, \& Hill, 2001; Mitchell, Mattocks, Ness, Leary, Pate, Dowda, Blair, \& Riddoch, 2009; Marshall \& Welk, 2008), and triaxial accelerometers measure $>80 \%$ of NEAT activities (Bouden et al., 1994; Levine, 2004), utilizing the light activity portion of the accelerometry data may provide some insights into the NEAT levels among these children and adolescents.

Second, the data from adolescents were restricted to 6 counties within West Virginia. Thus, we may not be able to generalize to children and adolescents from other areas of West Virginia or to adults, children, and adolescents outside of West Virginia. Third, these data were cross-sectional. Therefore, only conclusions about the association between variables can be made. In addition, although the activity portion of the biaxial and triaxial accelerometers has been examined and found to comparable (Sassaki et al., 2011), it is possible that there may still be differences in activity component collection, because the elementary students wore biaxial accelerometers whereas the high school students wore triaxial accelerometers. Finally, it has been suggested that 4 or more days of accelerometery data are optimal for providing reliable measures of PA in children (Janz, Witt, \& Mahoney, 1995). Because only 1 day of accelerometry data during PE was available, the results are not based on the optimal number of observations. However, these results will provide the basis for future work in this area. 


\subsubsection{Conclusion}

The results of this study suggest an association between lower levels of light (NEAT) physical activity among high school versus elementary school students during PE class.

However, a need exists for further research in this area, including a sample of PE classes as well as accounting for different types of PE lessons, before any final conclusions can be drawn. 


\subsection{References}

Alexy, U., Sichert-Hellert, W., \& Kersting, M. (2002). Fifteen-year time trends in energy and macronutrient intake in German children and adolescents: Results of the DONALD study. British Journal of Nutrition, 87, 595-604.

Anderson, J. W., Kendall, C. W. C., \& Jenkins, D. J. A. (2003). Importance of weight management in type 2 diabetes: Review with meta-analysis of clinical studies. Journal of the American College of Nutrition, 22(5), 331-339.

Bailey, R. C., Olson, J., Pepper, S. L., Porszasz, J., Barstow, T. J., \& Cooper, D. M. (1995). The level and tempo of children's physical activities: An observational study. Medicine and Science in Sports and Exercise, 27(7), 1033-1041.

Beers, E. A., Roemmich, J. N., Epstein, L. H., \& Horvath, P. J. (2008). Increasing passive energy expenditure during clerical work. European Journal of Applied Physiology, 103, 353-360.

Blair, S. N., Kohl, H. W., Paffenbarger, R. S., Clark, D. G., \& Gibbons, L. W. (1989). Physical fitness and all-cause mortality. Journal of the American Medical Association, 262, 2395-2401.

Bouten, C. V., Westerterp, K. R., Verduin, M., \& Janssen, J. D. (1994). Assessment of energy expenditure for physical activity using a triaxial accelerometer. Medicine and Science in Sports and Exercise, 26(12), 1516-1523.

Bunnell, R., O’Neil, D. Soler, R., Payne, R., Giles, W. H., Collins, J., Bauer, U., Communities Putting Prevention to Work Program Group. (2012). Fifty communities putting prevention to work: Accelerating chronic disease prevention through policy, systems, and environmental change. Journal of Community Health, online first.

Cavadani, C., Siega-Riz, A. M., \& Popkin, B. M. (2000).US adolescent food intake trends from 1965 to 1996. Western Journal of Medicine, 173, 378-383.

Coe, D. P., Pivarnik, J. M., Womack, C. J., Reeves, M. J., \& Malina, R. M. (2006). Effect of physical education and activity levels of academic achievement in children. Medicine and Science in Sports and Exercise, 38(8), 1515-1519.

Corder, K., van Sluijs, E. M. F., Ekelund, U., Jones, A. P., \& Griffin, S. J. (2010).Changes in children's physical activity over 12 months: Longitudinal results from the SPEEDY study. Pediatrics, 126, e926-e935.

Daniels, S. R. (2009). Complications of obesity in children and adolescents. International Journal of Obesity, 33, S60-S65.

Dwyer, T., Sallis, J. F., Blizzard, L., Lazarus, R., \& Dean, K. (2001).Relationship of academic performance to physical activity and fitness in children. Pediatric Exercise Science, 13, 225-237. 
Eckel, R. H., Krauss, R. M., for the AHA Nutrition Committee. (1998). American Health Association call to action: Obesity as a major risk factor for coronary heart disease. Circulation, 97, 2099-2100.

Evenson, K. R., Cattellier, D., Gill, K., Ondrak, K., \& McMurray, R. G. (2008).Calibration of two objective measures of physical activity for children. Journal of Sports Science, 26, 15571565.

Field, T., Diego, M., \& Sanders, C. E. (2001). Exercise is positively related to adolescents' relationships and academics. Adolescence, 36, 105-110.Harris CV, Bradlyn AS, O'Hara Tompkins N, Kelley GA, for the Healthy Lifestyles Act Evaluation Team [Internet]. West Virginia Healthy Lifestyles Act: Year One Evaluation Report. c2009 [cited 2012 Jan 3]. Available from: http://www.hsc.wvu.edu/som/hrc/ecocwv/2816.asp.

Fraser-Thomas, J. L., \& Beaudoin, C. (2002). Implementing a physical education curriculum: Two teachers' experiences. Canadian Journal of Education, 27(2/3), 249-268.

Janz, K. F., Witt, J., \& Mahoney, L. T. (1995). The stability of children's physical activity as measured by accelerometery and self-report. Medicine \& Science in Sports \& Exercise, 27(9), 1326-1332.

Katzmaryk, P. T. (2010). Obesity: An emerging epidemic - temporal trends in North America. In: Moffat, T., \& Prowse, T., (eds.) Human diet and nutrition in biocultural perspective: Past meets present (studies of the biosocial society), Berghahn Books, Inc.: 223-240.

King, A. C., Castro, C., Wilcox, S., Eyler, A. A., Sallis, J. F., \& Brownson, R. C. (2000). Personal and environmental factors associated with physical inactivity among different racialethnic groups of U.S. middle-aged and older-aged women. Health Psychology, 19(4), 354-364.

Kotz, C. M., Teske, J. A., \& Billington, C. J. (2008). Neuroregulation of nonexercise activity thermogenesis and obesity resistance. Regulatory, Integrative and Comparative Physiology, 294(3), R699-R710.

Leslie, E., Owen, N., Salmon, J., Bauman, A., Sallis, J. F., \& Lo, S. K. (1999). Insufficiently active Australian college students: Perceived personal, social, and environmental influences. Preventive Medicine, 28, 20-27.

Levin, S., McKenzie, T. L., Hussey, J. R., Kelder, S. H., \& Lytle, L. A. (2001). Variability of physical activity during physical education lessons across elementary school grades. Measurement in Physical Education and Exercise Science, 5, 207-218.

Levine, J. A. (2002). Non-exercise activity thermogenesis (NEAT). Best Practice \& Research Clinical Endocrinology and Metabolism, 16(4), 679-702. 
Levine, J. A., Lanningham-Foster, L. M., McCrady, S. K., Krizan, A. C., Olson, L. R., Kane, P. H., Jensen, M. D., \& Clark, M. M. (2005). Interindividual variation in posture allocation: Possible role in human obesity. Science, 307, 584-586.

Levine, J., Melanson, E. L., Westerterp, K. R., \& Hill, J. O. (2001). Measurement of the components of nonexercise activity thermogenesis. American Journal of Physiology: Endocrinology and Metabolism, 281, E670-E675.

Liu, J., Bennett, K. J., Harun, N., \& Probst, J. C. (2008). Urban-rural differences in overweight status and physical activity among US children aged 10-17 years. The Journal of Rural Health, 24(4), 407-415.

Lobestein, T., Baur, L., \& Uauy, R, for the IASO International Obesity TaskForce. (2004). Obesity in children and young people: A crisis in public health. Obesity Reviews, 5(Suppl. 1), 485.

Marshall, S. J., \& Welk, G. J. (2008). Definitions and measurement. In A. L. Smith \& S. J. H. Biddle (Eds.). Youth physical activity and sedentary behavior: Challenges and solutions. Champaign, IL: Human Kinetics.

Matthiessen, J., Fagt, S., Biltoft-Jensen, A., Beck, A. M., \& Ovesen, L. (2002). Size makes a difference. Public Health Nutrition, 6(1), 65-72.

McKenzie, T. L., Marshall, S. J., Sallis, J. F., \& Conway, T. L. (2000).Student activity levels, lesson context, and teacher behavior during middle school physical education. Research Quarterly for Exercise and Sport, 71, 249-259.

Mitchell, J. A., Mattocks, C., Ness, A. R., Leary, S. D., Pate, R. R., Dowda, M., Blair, S. N., \& Riddoch, C. (2009). Sedentary behaviour and obesity in a large cohort of children. Obesity, 17(8), 1596-1602.

Mokdad, A. H., Bowman, B. A., Ford, E. S., Vinicor, F., Marks, J. S., \& Koplan, J. P. (2001). The continuing epidemics of obesity and diabetes in the United States. Journal of the American Medical Association, 286, 1195-1200.

Morgan, P., \& Hansen, V. (2007). Recommendations to improve primary school physical education: Classroom teachers' perspective. Journal of Educational Research, 101(2), 99-111.

Nader, P. R., Bradley, R. H., Houts, R. M., McRitchie, S. L., \& O’Brien, M. (2008). Moderateto-vigorous physical activity from ages 9 to 15 years. Journal of the American Medical Association, 300(3), 29s-30s.

National Institute of Health. (1998). National Heart, Lung, and Blood Institute: Clinical guidelines to the identification, evaluation, and treatment of overweight and obesity in adults: The obesity report. Obesity Research, 6(Suppl 2), 51S-209S. 
Nelson, M. C., Gordon-Larsen, P., Song, Y., \& Popkin, B. M. (2006).Built and social environments: Associations with adolescent overweight and activity. American Journal of Preventive Medicine, 31(2), 109-117.

Nielsen, S. J., Siega-Riz, A. M., Popkin, B. M. (2002). Trends in energy intake in U.S. between 1977 and 1996: Similar shifts seen across age groups. Obesity Research, 10, 370-378.

Olshansky, S. J., Passaro, D. J., Hershow, R. C., Layden, J., Carnes, B. A., Brody, J., Hayflick, L., Butler, R. N., Allison, D. B., \& Ludwig, D. S. (2005). A potential decline in life expectancy in the United States in the $21^{\text {st }}$ century. The New England Journal of Medicine, 352(11), 11381145 .

Pischon, T., Nöthlings, U., \& Boeing, H. (2008).Symposium on 'diet and cancer': Obesity and cancer. Proceedings of the Nutrition Society, 67, 128-145.

Powell, L. M., Slater, S., Chaloupka, F. J., \& Harper, D. (2006).Availability of physical activityrelated facilities and neighborhood demographic and socioeconomic characteristics: A national study. American Journal of Public Health, 96(9), 1676-1680.

Ross, J. G., Dotson, C. O., Gilbert, G. G., \&Katz, S. J. (1985). After physical education: Physical activity outside of school physicaleducation programs.Journal of Physical Education, Recreation and Dance, 56, 35-39.

Roth, J., Qiang, X., Marbán, S. L., Redelt, H., \& Lowell, B. C. (2004). The obesity pandemic: Where have we been and where are we going? Obesity Research, 12, 88S-101S.

Sallis, J. F., Frank, L. D., Saelens, B. E., \& Kraft, M. K. (2004). Active transportation and physical activity: Opportunities for collaboration on transportation and public health research. Transportation Research Part A: Policy and Practice, 38(4), 249-268.

Salmon, J., Owen, N., Bauman, A., Schmitz, M. K. H., \& Booth, M. (2000).Leisure-time, occupational, and household physical activity among professional, skilled, and less-skilled workers and homemakers. Preventive Medicine, 30, 191-199.

Santech Inc. (2010). http://www.meterplussoftware.com. Meterplus 4.2.

Sasaki, J. E., John, D., \& Freedson, P. S. (2011).Validation and comparison of ActiGraph activity monitors. Journal of Science and Medicine in Sport, 14, 411-416.

Sener, I. N., Copperman, R. B., Pendyala, R. M., \&Bhat, C. R. (2008). An analysis of children's leisure activity engagement: Examining the day of week, location, physical activity level, and fixity dimensions. Transportation, 35, 673-696.

Shephard, R. J. (1997). Curricular physical activity and academic performance. Pediatric Exercise Science, 9, 113-125. 
Spiegel, A. M., \&Nabel, E. G. (2006). NIH research on obesity and type 2 diabetes: Providing the scientific evidence base for actions to improve health. Nature Medicine 12, 67-69.

Story, M., Nanney, M. S., \& Schwartz, M. B. (2009). Schools and obesity prevention: Creating school environments and policies to promote healthy eating and physical activity. Milbank Quarterly, 87(1), 71-100.

Troiano, R. P., Berrigan, D., Dodd, K. W., Mâsse, L. C., Tilert, T., \& McDowell, M.

(2008).Physical activity in the United States measured by accelerometer. Medicine \& Science in Sports \& Exercise, 40(1), 181-188.

U.S. Department of Health and Human Services.(2010). Strategies to improve the quality of physical education. Retrieved November 6, 2011 from http://www.cdc.gov/HealthyYouth

Young, L. R., \& Nestle, M. (2003). Expanding portion sizes in the US marketplace: Implications for nutrition counseling. Journal of the American Dietetic Association, 103(2), 231-234. 
Chapter 3 


\section{Chapter 3}

Abstract: Decreased physical activity is thought to play a role in the increase in weight gain among adolescents. The predominate focus has been on moderate to vigorous physical activity (MVPA), although recent research also suggests that lighter levels of physical activity, including non-volitional physical activity, called non-exercise activity thermogenesis (NEAT), may also impact weight status. Previous research has examined the relative variability of physical activity among adolescents, though the predominance of this work has been regarding MVPA. Studies examining the variability of NEAT have focused on the inter-individual variation rather than the intra-individual variation. The purpose of this study was to examine both the inter- and intraindividual variability of NEAT across 1 week in a group of rural adolescents. Two unconditional mixed models were performed; one for NEAT during PE class and one for NEAT during the non-PE class school day, separated by gender. Results indicated that the inter-individual covariance parameter estimates were similar for males and females during the non-PE class school day; however, during PE class, the covariance parameter estimates were dissimilar. Additionally, the intra-individual variation of NEAT among males was 1.38 times that of the intra-individual variation of NEAT among females within PE class. However, during the non-PE classes, the intra-individual variation of NEAT among males was 0.86 times that of the intraindividual variation of NEAT among females. The inter-individual variation among males during PE class was 18.33 times that of males during non-PE classes, whereas the inter-individual variation among females during PE class was 11.43 times that of females during non-PE classes. Last, with respect to between-subject effects, during PE class, NEAT was more variable $\left(\sigma^{2}=0.037\right)$ than during the non-PE class school day $\left(\sigma^{2}=0.004\right)$. Specifically, the inter-individual variation during PE class was 9.25 times that of the inter-individual variation during non-PE classes. Results revealed that (1) NEAT among males is consistently more variable than NEAT among females and (2) NEAT is more variable during PE class than during non-PE classes. Though this is a necessary first step, future research should examine variability of NEAT among adolescents outside of the school day as well to better understand its nature. 


\subsection{Introduction}

Evidence points to the likelihood that a decrease in caloric expenditure, through decreases in physical activity, is to blame for the increase in weight status (Lobestein, Baur, Uauy, for the IASO International Obesity TaskForce, 2004). Excess weight among both adults and children has become a pandemic within the United States (Katzmaryk, 2010; Mokdad, Bowman, Ford, Vinicor, Marks, \& Koplan, 2001), as well as across the world (Roth, Qiange, Marbán, Redelt, \& Lowell, 2004). Unfortunately, youth residing in rural areas are disproportionately susceptible to the development of overweight and obesity (Lutfiyya, Lipsky, Wisdom-Behounek, \& Inpanbutr-Martinkus, 2007). Due to the accelerated rate with which adolescents and children are becoming overweight and obese, obesity research in this area has also increased (Daniels, 2006). For the past century, life expectancy has increased; however, Olshansky and colleagues (2005) predict that the current generation of children will have a shorter life span than their parents, due largely to the increase in obesity and its related health problems.

In order to combat the obesity epidemic, efforts have been focused on increasing moderate to vigorous physical activity (MVPA) through interventions (e.g., Howe, Freedson, Alhassan, Feldman, \& Osganian, 2012) and physical activity recommendations, particularly during PE class (U.S. Department of Health and Human Services, 2010). Rarely are these recommendations being met, however (Levin, McKenzie, Hussey, Kelder, \& Lytle, 2001; McKenzie, Marshall, Sallis, \& Conway, 2000).

MVPA has been established as a means by which to reduce excess weight, thereby reducing the risk for adverse weight-related health problems. Emerging evidence suggests that physical activity levels below MVPA but above sedentary (e.g., non-exercise activity 
thermogenesis) may also be beneficial to overall health (Powell, Paluch, \& Blair, 2011). Nonexercise activity thermogenesis (NEAT) can be defined as activities that expend energy which are not associated with purposeful exercise (Levine, 2007). Examples of NEAT include fidgeting, maintaining posture, engaging in housework, and other daily life activities (Levine, 2007). NEAT is hypothesized to account for the most variance in energy expenditure by individuals independent of body weight (Levine, 2010), and low levels of NEAT are speculated to be a factor in the development of obesity (Levine et al., 1999). NEAT activity levels throughout the course of the day allows for the accumulation of low levels of energy expenditure without requiring a specific block of time to expend energy (Beers, Roemmich, Epstein, \& Horvath, 2008), as is needed with MVPA activities. As a consequence, it may be important to further examine the role that NEAT plays in individuals' daily lives, particularly among youth residing in rural areas. NEAT among youth residing in rural areas should be a focus because they are at an increased risk for the development of overweight and obesity compared with urban (Liu, Bennett, Harun, \& Probst, 2008) and suburban (Nelson, Gordon-Larsen, Song, \& Popkin, 2006) youth.

Physical activity has been readily examined in human populations, in general. However, King, Hopkins, Caudwell, Stubbs, and Blundell (2008) note that studies often will report physical activity of a group in aggregate and not examine the intra-individual variability. Also lacking is research examining the inter-individual variability of physical activity; though, more research has taken place in the area. For the purposes of this study, inter-individual variability refers to the constancy or stability of physical activity between individuals and intra-individual variability refers to the variability of physical activity within the individual himself or herself from day to day. 
To the authors' knowledge, no research to date has examined the variability of NEAT among a group of rural adolescents. The purpose of this study was to specifically address this research deficit by examining the variability of NEAT in adolescents in a rural community of West Virginia over a 1 week period. Based on research examining the stability of MVPA among children and adolescents (Janz et al., 1995), it was hypothesized that levels of NEAT would remain a relatively stable construct within individuals across days. Further, based on research examining the stability of physical activity between individuals, total energy expenditure is highly variable (e.g., Black, Coward, Cole, \& Prentice, 1996; Levine, Vander Weg, Hill, \&Klesges, 2006), leading to the hypothesis that the levels of NEAT would be relatively variable across individuals.

\subsection{Method}

\subsubsection{Data Collection}

A total of $2689^{\text {th }}$ and $10^{\text {th }}$ grade students were enrolled in an accelerometer study. For this secondary analysis, data were collected during the spring 2010-2011 school year and the fall 2011-2012 school year. Students were instructed to wear the ActiGraph ${ }^{\mathrm{TM}}$ GTX3E triaxial accelerometer on their right hip for 1 week at the beginning of their PE term and for 1 week at the end of their PE term. For the purposes of this study, PE term refers to the school term/semester in which a student was enrolled in PE class. In addition to accelerometer data, student gender, grade level, teacher, PE class time, and BMI percentile data were collected. All of the high schools within the 6-county intervention area of Communities Putting Prevention to Work (CPPW; see Bunnell et al., 2012 for specifics on the CPPW grant) were selected for inclusion in the study. Although data were collected for 1 week at the beginning of the term and 
1 week at the end of the term, for the purposes of this study, only data from the beginning of the term were utilized due to the yield of a greater sample size.

\subsubsection{Data Analysis}

To detect the presence of any collinearity and outliers, preliminary diagnostics were performed. Using light intensity physical activity as a proxy for NEAT because NEAT includes light activity levels (Levine, Melanson, Westerterp, \& Hill, 2001; Mitchell, Mattocks, Ness, Leary, Pate, Dowda, Blair, \& Riddoch, 2009; Marshall \& Welk, 2008) and energy expenditure associated with both posture and ambulation (Levine et al., 2005), the stability of NEAT in adolescents was examined. Two mixed models were performed utilizing PROC MIXED in Statistical Analysis System (SAS) 9.3 (Cary, N.C.), where one model examined the variability of NEAT within (intra-individual variability) and between (inter-individual variability) individuals during PE class, whereas the other model examined the variability of NEAT within and between individuals outside of PE class, during the school day. Because males generally engage in higher levels of physical activity compared with females (e.g., Ridgers, Fairclough, \& Stratton, 2010), the intra-individual variation was examined separately by gender $(0=$ male, $1=$ female $)$ using the GROUP function.

The main analyses were performed for males and females, both during PE class and outside of PE class, within the school day. These two models (PE and non-PE NEAT) only included gender as a fixed effect, with participant as a random effect to allow for between-person variation estimates and within-person estimates.

The intra-individual variation of NEAT was examined over a period of 1 week during the school day (both in PE class and traditional/non-PE classes), as this is reflective of variations in NEAT from day-to-day within participants (Matthews, Ainsworth, Thompson, \& Bassett, Jr., 
2002). This variation is the residual variance estimated from the mixed model, or the variance not accounted for by the random effects included in the model. A low level of intra-individual variation of NEAT reflects relative stability of NEAT across 1 week of accelerometry measurement during the school day. We also examined the inter-individual variation of NEAT (i.e., the variance of the subject random effect) to determine the variability of NEAT across adolescents, separately for males and females. Intraclass correlations (ICC) were also calculated for both models by dividing each respective within-person covariance parameter estimate by the sum of the within-person covariance parameter estimate (intercept) and the between-person covariance parameter estimate (residual). ICCs can range from 0.0 (poor agreement) to 1.0 (perfect agreement), where lower numbers correspond to a greater degree of within-person (or intra-individual) variability.

To convert the data from the accelerometers into analyzable data, the statistical program MeterPlus $^{\mathrm{TM}}$ (Santech Inc., 2010) was used. Accelerometry data were specified at 5 -second epochs and then deduced using 15-second time intervals. The cut points established by Evenson and colleagues (2008) were used to estimate time spent in sedentary ( $\leq 100$ counts/minute), NEAT (light; 101-2295 counts/minute), moderate (2296-4011 counts/minute), and vigorous ( $\geq$ 4012 counts/minute) activity. The Evenson et al. (2008) cut points were used as these are recommended as most appropriate for children and adolescents (Trost, Loprinzi, Moore, \& Pfeiffer, 2011).

Further, a 15 -second time interval was specified because previous research indicates that children and adolescents are more likely to engage in short bouts of energy expenditure compared with adults. Because of the differential in energy expenditure bouts, longer intervals such as those used with adults (i.e., 1 minute) may substantially underestimate physical activity 
(Bailey, Olson, Pepper, Porszasz, Barstow, \& Cooper, 1995). As such, the following cut points were used: sedentary ( $\leq 25$ counts/15 seconds), NEAT (light; $26-573$ counts/15 seconds), moderate (574-1002 counts/15 seconds), and vigorous ( $\geq 1003$ counts/15 seconds) activity. All data were analyzed with the Statistical Analysis System (SAS), 9.3 (Cary, N.C.). This study received institutional review board approval from the referent university.

\subsection{Results}

\subsubsection{Descriptives}

A total of 204 participants were included for the current study. Approximately equal numbers of males and females were included and the average participant BMI percentile was at a healthy weight, based on the Centers for Disease Control and Prevention (2011). The majority of participants' PE class was spent in sedentary activity levels.

\begin{tabular}{lc}
\hline Table 1. Sample Characteristics $(\mathrm{N}=219)^{*}$ & Mean $(S D)$ \\
\hline Gender & $112(52.34 \%)$ \\
\hline Male $\mathrm{n}(\%)$ & $102(47.66 \%)$ \\
Female $\mathrm{n}(\%)$ & $74.18(26.56)$ \\
BMI Percentile & \\
\hline Activity Level & $48.28 \%(31.39 \%)$ \\
\hline Sedentary (\% of PE Class) & $24.55 \%(21.74 \%)$ \\
NEAT (\% of PE Class) & $1.28 \%(2.80 \%)$ \\
Moderate to Vigorous (\% of PE Class) & $25.89 \%(41.45 \%)$ \\
Non-wear (\% of PE Class) & $81.42(21.23)$ \\
\hline PE Class Length (minutes)
\end{tabular}

Note: NEAT=Non-exercise activity thermogenesis; $\mathrm{SD}=$ Standard Deviation; BMI=Body Mass Index; *Ns may be different due to missing data.

\subsubsection{Main Analyses}

In order to determine the relative stability of NEAT among the current group of adolescents, two separate mixed models were run using the PROC MIXED procedure in SAS (Cary, N.C.). The two outcomes were: 1) the percent of NEAT obtained within PE class, and 2) 
the percent of NEAT obtained outside of PE class, within the school day. Both models produced separate covariance estimates for males and females. Both models were also run including PE teacher; however, results remained consistent (BIC: -306.1 and -329.1, respectively). The final model is presented in table 2 below.

Results revealed that the intra-individual covariance parameter estimates were similar for males and females during the non-PE class school day, whereas during PE class, the covariance parameter estimates were dissimilar. Specifically, the intra-individual variation of NEAT among males was 1.38 times that of the intra-individual variation of NEAT among females within PE class. However, during the non-PE classes, the intra-individual variation of NEAT among males was 0.86 times that of the intra-individual variation of NEAT among females. Finally, interindividual variation among males during PE class was 18.33 times that of males during non-PE classes, whereas the inter-individual variation among females during PE class was 11.43 times that of females during non-PE classes.

Regarding between-subject effects, during PE class, NEAT was more variable $\left(\sigma^{2}=0.037\right)$ than during the non-PE class school day $\left(\sigma^{2}=0.004\right)$. Specifically, the inter-individual variation during PE class was 9.25 times that of the inter-individual variation during non-PE classes. Please see Table 2 for specifics.

\begin{tabular}{l} 
Table 2. Within and Between Subject Effects and Intraclass Correlation Coefficients \\
\cline { 3 - 4 } PE Class
\end{tabular}

Note: All $p \mathrm{~s}<.001$ 


\subsection{Discussion}

This study was the first to examine both inter- and intra-individual variability of NEAT among a group of West Virginia rural adolescents. Accelerometry data were collected and analyzed from 1 week of wear time during the school day. Inter-individual variation of NEAT was higher among participants during PE class as compared to the variability during non-PE classes. In addition, the intra-individual variation of NEAT among males was higher than females during PE class, yet similar during non-PE classes. The ICC for males during PE class was higher, at 0.231 , than for females during PE class (0.170), suggesting greater intra-individual variability, or less stability among females during PE class than among males. ICC for both males and females during non-PE classes was low ( 0.130 and 0.134 , respectively), indicating greater intra-individual variability during non-PE classes as compared to PE class. ICCs have not been readily examined with regard to intra-individual variability of physical activity measured by accelerometers. One of the few studies that did examine ICCs with regard to MVPA among adolescents girls found an ICC $=0.145$ (Stevens, Taber, Murray, \& Ward, 2007). The ICCs for NEAT physical activity for both males and females during PE class in the current sample is higher (0.231 and 0.170, respectively) than the ICC Stevens and colleagues (2007) found among their sample. However, the ICCs for males' and females' NEAT non-PE class time was lower than the ICC from the Stevens et al. (2007) study. This differential suggests that MVPA among Stevens et al.'s (2007) sample of adolescent girls is less stable than NEAT during PE class, but more stable than NEAT during non-PE classes among participants in the current study.

The higher NEAT inter-individual variability during PE class may indicate that some adolescents in the sample are "sub-performing" during their PE class time. It is possible that while some students are engaged in lower levels of physical activity, others are rather sedentary. 
Because this finding was similar in both the unadjusted (Table 2) and model adjusting for PE teacher (not presented), it appears that among this sample PE teacher has little effect on the amount of NEAT in which adolescents engage.

However, the findings of higher inter-individual variability of NEAT during PE class compared with non-PE classes may highlight the potential for an important role for PE teachers to encourage students to engage in physical activity. It is clear that NEAT is much more variable during PE class than non-PE classes. As such, factors such as PE teachers and physical activity opportunities during PE class may be key in increasing overall movement. PE teachers could encourage students to do so, through requiring walking while waiting for one's turn, for example.

Examination of intra-individual variability revealed that NEAT is highly variable among males during PE class as compared with females, indicating that, generally speaking, more discrepancies exist between males than between females. It is possible that there is a higher degree of variability among males than among females because, in general, females tend to engage in lower levels of overall physical activity compared with males (Belcher, Berrigan, Dodd, Emken, Chou, \& Spuijt-Metz, 2010; Ridgers et al., 2010).

Due to the higher variance of NEAT among males as compared to females during PE class, future research may consider examining whether this finding remains when examining adolescents who participate in single gender PE classes. In a study utilizing pedometers as a proxy for overall physical activity, researchers examined activity levels of students participating in one of three class types: 1) coeducational PE classes, 2) coeducational PE classes, but split by gender for activity, or 3) single gender PE classes (Hannon \& Ratliffe, 2005). These class types were examined for three types of activities: 1) ultimate frisbee, 2) flag football, and 3) soccer. 
This study was motivated by the startling contrast in overall physical activity levels between male and female youth. Males consistently engage in higher levels of overall physical activity both during PE class, during school, and outside of school (Sallis, Zakarian, Hovell, \& Hofstetter, 1996). Results from the Hannon and Ratliffe (2005) study revealed that regardless of whether students were in single-gender only, coeducational classes but split based on gender, or coeducational PE classes, females had fewer steps than males. Interestingly, when steps were examined by type of activity (i.e., flag football, ultimate frisbee, soccer), males in the singlegender class were less active than males in both the coeducational split classes and the coeducational PE classes (Hannon \& Ratliffe, 2005).

Perhaps most interesting is the finding that during PE class NEAT is highly variable. Levine (2010) noted that NEAT accounts for the most variance in total energy expenditure not accounting for body weight. Given this, it is possible that among adolescents, those who engage in high levels of NEAT during PE class may also have higher levels of total energy expenditure, compared to those with lower levels of NEAT during PE class. Future research should further explore this relationship. If this is the case, there are potential implications for PE teachers such as a need for additional training to increase all physical activity levels during PE class to increase overall energy expenditure, potentially incurring health benefits for these adolescents.

\subsubsection{Strengths \& Limitations}

The current study has certain limitations. First, the data from adolescents were restricted to 6 counties within West Virginia. Thus, we may not be able to generalize to children and adolescents from other areas of West Virginia or to adults, children, and adolescents outside of West Virginia. A second limitation is that this study only utilized accelerometry data during the school day. In the future, it may be important to examine the variability of NEAT among 
adolescents outside of the school day as well. Third, this study utilized previously collected data. As a consequence, the data were somewhat limited with regard to specifically examining NEAT. For example, light physical activity levels captured through accelerometers were used as a proxy for NEAT. Although NEAT includes light activity levels (Levine, Melanson, Westerterp, \& Hill, 2001; Mitchell, Mattocks, Ness, Leary, Pate, Dowda, Blair, \& Riddoch, 2009; Marshall \& Welk, 2008) as well as both posture maintenance and ambulation (Levine et al., 2005) and triaxial accelerometers and inclinometers are able to capture $>80 \%$ of NEAT activities (Bouten et al., 1994; Levine, 2004), NEAT may have been underestimated. However, specifically examining light activity from the accelerometry data may provide some insights into the NEAT levels among these adolescents.

Fourth, data for type of sport or activity during accelerometry monitoring were not available. Previous research has found that both differences in preference for activities between males and females (Fromel, Formankova, \& Sallis, 2002), as well as gender differences for physical activity, with males engaging in higher activity levels during team-sport activities during PE class than females (Kulinna, Martin, Lai, Kliber, \& Reed, 2003). In the future, activity type should be taken into account, as this could potentially have an influence on both the interand intra-individual variability of NEAT for male and female youth.

Finally, results indicate that adolescents differentially engage in NEAT throughout the school day. Because NEAT appears to have high inter-individual variability, which is supported by other research (Levine et al., 2006), it may be important for future research to determine the characteristics of individuals who engage in high levels of NEAT. This research may then assist in determining how to promote NEAT among adolescents. 
Although this study has certain limitations, it is the first to examine the variability of NEAT during the school day, both during PE class and during non-PE classes among a group of rural adolescents. This is particularly important because youth residing in rural areas are at an increased risk for overweight and obesity compared with urban and suburban residing youth (Lutfiyya et al., 2007). Further, data were available across a 1 week time period, allowing more accurate characterization of NEAT among this sample. Much of the previous research examining the variability of physical activity in general has been conducted using self-report questionnaires rather than objective activity measures such as accelerometers (e.g., Telama, Yang, Viikari, Välimäki, Wanne, \& Raitakari, 2005). Thus, an additional strength of the current study is the use of objectively measured physical activity data from a relatively large group of rural adolescents.

\subsubsection{Conclusion}

Among West Virginia adolescents sampled, NEAT was more variable during PE class than the non-PE class school day. Further, within PE class, males' NEAT tended to be more variable than females' NEAT. Although more research is needed to fully understand the intraand inter-individual variability of NEAT among adolescents, this study provided a preliminary characterization of NEAT variability during the school day. 


\subsection{References}

Beers, E. A., Roemmich, J. N., Epstein, L. H., \& Horvath, P. J. (2008). Increasing passive energy expenditure during clerical work. European Journal of Applied Physiology, 103, 353-360.

Belcher, B. R., Berrigan, D., Dodd, K. W., Emken, B. A., Chou, C., \& Spuijt-Metz, D. (2010). Physical activity in US youth: Impact of race/ethnicity, age, gender, \& weight status. Medicine and Science in Sport and Exercise, 42(12), 2211-2221.

Black, A. E., Coward, W. A., Cole, T. J., \& Prentice, A. M. (1996). Human energy expenditure in different affluent societies: An analysis of 574 doubly-labeled water measurements. European Journal of Clinical Nutrition, 50, 72-92.

Bouten, C. V., Westerterp, K. R., Verduin, M., \& Janssen, J. D. (1994). Assessment of energy expenditure for physical activity using a triaxial accelerometer. Medicine and Science in Sports and Exercise, 26(12), 1516-1523.

Bunnell, R., O’Neil, D. Soler, R., Payne, R., Giles, W. H., Collins, J., Bauer, U., Communities Putting Prevention to Work Program Group. (2012). Fifty communities putting prevention to work: Accelerating chronic disease prevention through policy, systems, and environmental change. Journal of Community Health, online first.

Centers for Disease Control and Prevention (2011). Healthy weight-it's not a diet, it's a lifestyle! Retrieved February 13, 2013, from http://www.cdc.gov/healthyweight/ assessing/bmi/childrens_bmi/about_childrens_bmi.html.

Daniels, S. R. (2006). The consequences of childhood overweight and obesity. The Future of Children, 16(1), 47-67.

Janz, K. F., Witt, J., \& Mahoney, L. T. (1995). The stability of children's physical activity as measured by accelerometery and self-report. Medicine \& Science in Sports \& Exercise, 27(9), 1326-1332.

Frömel, K., Formánková, S., \& Sallis, J. (2002). Physical activity and sport preferences of 10- to 14-year old children: A 5-year prospective study. Gymnica, 32(1), 11-16.

Hannon, J. C., \& Ratliffe, T. (2005). Physical activity levels in coeducational and single-gender high school physical education settings. Journal of Teaching in Physical Education, 24, 149-164.

Katzmaryk, P. T. (2010). Obesity: An emerging epidemic - temporal trends in North America. In: Moffat, T., \& Prowse, T., (eds.) Human diet and nutrition in biocultural perspective: Past meets present (studies of the biosocial society), Berghahn Books, Inc.: 223-240. 
King, N. A., Hopkins, M., Caudwell, P., Stubbs, R. J., \& Blundell, J. E. (2008).Individual variability following 12 weeks of supervised exercise: Identification and characterization of compensation for exercise-induced weight loss. International Journal of Obesity, 32, 177-184.

Kulinna, P., Martin, J., Lai, Q., Kliber, A., \& Reed, B. (2003). Student physical activity patterns: Grade, gender, and activity influences. Journal of Teaching in Physical Education, 22, 298-310.

Levin, S., McKenzie, T. L., Hussey, J. R., Kelder, S. H., \& Lytle, L. A. (2001). Variability of physical activity during physical education lessons across elementary school grades. Measurement in Physical Education and Exercise Science, 5, 207-218.

Levine, J. A. (2010). Non-exercise activity thermogenesis. Retrieved November 1, 2010 from: http://mayoresearch.mayo.edu/levine_lab/about.cfm

Levine, J. A. (2007). Nonexercise activity thermogenesis-liberating the life-force. Journal of Internal Medicine, 262, 273-287.

Levine, J. A., Eberhardt, N. L., \& Jensen, M. D. (1999). Role of nonexercise activity thermogenesis in resistance to fat grain in humans. Science, 283, 212-214.

Levine, J. A., Lanningham-Foster, L. M., McCrady, S. K., Krizan, A. C., Olson, L. R., Kane, P. H., Jensen, M. D., \& Clark, M. M. (2005). Interindividual variation in posture allocation: Possible role in human obesity. Science, 307, 584-586.

Levine, J., Melanson, E. L., Westerterp, K. R., \& Hill, J. O. (2001). Measurement of the components of nonexercise activity thermogenesis. American Journal of Physiology: Endocrinology and Metabolism, 281, E670-E675.

Levine, J. A., Vander Weg, M. W., Hill, J. O., \& Klesges, R. C. (2006). Non-exercise activity thermogenesis: The crouching tiger hidden dragon of societal weight gain. Arteriosclerosis, Thrombosis, and Vascular Biology, 26, 729-736.

Liu, J., Bennett, K. J., Harun, N., \& Probst, J. C. (2008). Urban-rural differences in overweight status and physical activity among US children aged 10-17 years. The Journal of Rural Health, 24(4), 407-415.

Lobestein, T., Baur, L., \& Uauy, R, for the IASO International Obesity TaskForce. (2004). Obesity in children and young people: A crisis in public health. Obesity Reviews, 5(Suppl. 1), 485.

Lutfiyya, M. N., Lipsky, M. S., Wisdom-Behounek, J., Inpanbutr-Martinkus, M. (2007). Is rural residency a risk factor for overweight and obesity for U.S. children? Obesity, 15(9), 2348-2356. 
Marshall, S. J., \& Welk, G. J. (2008). Definitions and measurement. In A. L. Smith \& S. J. H. Biddle (Eds.). Youth physical activity and sedentary behavior: Challenges and solutions. Champaign, IL: Human Kinetics.

McKenzie, T. L., Marshall, S. J., Sallis, J. F., \& Conway, T. L. (2000). Student activity levels, lesson context, and teacher behavior during middle school physical education. Research Quarterly for Exercise and Sport, 71, 249-259.

Mitchell, J. A., Mattocks, C., Ness, A. R., Leary, S. D., Pate, R. R., Dowda, M., Blair, S. N., \& Riddoch, C. (2009). Sedentary behaviour and obesity in a large cohort of children. Obesity, 17(8), 1596-1602.

Mokdad, A. H., Bowman, B. A., Ford, E. S., Vinicor, F., Marks, J. S., \& Koplan, J. P. (2001). The continuing epidemics of obesity and diabetes in the United States. Journal of the American Medical Association, 286, 1195-1200.

Nelson, M. C., Gordon-Larsen, P., Song, Y., \& Popkin, B. M. (2006).Built and social environments: Associations with adolescent overweight and activity. American Journal of Preventive Medicine, 31(2), 109-117.

Olshansky, S. J., Passaro, D. J., Hershow, R. C., Layden, J., Carnes, B. A., Brody, J., Hayflick, L., Butler, R. N., Allison, D. B., \& Ludwig, D. S. (2005). A potential decline in life expectancy in the United States in the $21^{\text {st }}$ century.The New England Journal of Medicine, 352(11), 11381145 .

Powell, K. E., Paluch, A. E., \& Blair, S. N. (2011).Physical activity for health: What kind? How much? How intense? On top of what? Annual Review of Public Health, 32, 349-365.

Ridgers, N. D., Fairclough, S. J., \& Stratton, G. (2010). Variables associated with children's physical activity levels during recess: the A_CLASS project. International Journal of Behavioral Nutrition and Physical Activity, 7, 74-81.

Roth, J., Qiang, X., Marbán, S. L., Redelt, H., \& Lowell, B. C. (2004). The obesity pandemic: Where have we been and where are we going? Obesity Research, 12, 88S-101S.

Sallis, J. F., Zakarian, J. M., Hovell, M. F., \& Hofstetter, C. R. (1996). Ethnic, socioeconomic, and sex differences in physical activity among adolescents. Journal of Clinical Epidemiology, 49(2), 125-134.

Santech Inc. (2010). http://www.meterplussoftware.com. Meterplus 4.2.

Telama, R., Yang, X., Viikari, J., Välimäki, I., Wanne, O., \& Raitakari, O. (2005). Physical activity from childhood to adulthood: A 21-year tracking study. American Journal of Preventive Medicine, 28(3), 267-273. 
U.S. Department of Health and Human Services. (2010). Strategies to improve the quality of physical education. Retrieved November 6, 2011 from http://www.cdc.gov/HealthyYouth 
Chapter 4 


\section{Chapter 4}

Abstract: Overweight and obesity are increasing among rural youth. Increases in physical activity are effective in reducing weight. However, the predominant focus of research in this domain has been on moderate to vigorous physical activity (MVPA). Perhaps as a consequence of documented sedentary lifestyles, even individuals who obtain the recommended amount of MVPA, yet remain sedentary throughout a large portion of the day are still at an increased risk for cardiovascular disease and other health problems. Recent focus has revealed that activity levels below MVPA (i.e., light activity) may also confer health benefits. Non-exercise activity thermogenesis (NEAT) is commonly used to refer to activity that is non-volitional energy expenditure such as activities of daily living or fidgeting. Because evidence suggests that individuals who engage in higher levels of NEAT tend to be leaner than those who engage in lower levels of NEAT, NEAT may have particular benefits to health. The purpose of this study was to examine whether adolescents engage in activity compensation during their non-physical education (PE) classes, as a result of the amount of imposed activity during their PE class (both MVPA and NEAT levels). Utilizing two distinct generalized linear mixed models, results revealed that adolescents do not engage in activity compensation during the school day. In fact, in both models there was a positive relationship between NEAT during PE class and NEAT outside of PE class $(p s<.0001)$. For the logistic model, gender $(p=.0063)$ was also positively related with NEAT in non-PE classes, whereas PE class length was negatively related $(p=.0156)$ to NEAT during non-PE classes. Results from the second model found the PE class length was negatively related $(p=.0398)$ as well. Future research should examine whether similar patterns exist outside of the school day. 


\subsection{Introduction}

With the increased risk for morbidity and mortality among overweight/obese persons compared with those of normal weight (Daniels, 2009), it is not surprising that there has been a focus on reducing, and ultimately, preventing obesity among children. A means by which to do so is to increase the amount of moderate to vigorous physical activity (MVPA) children are receiving (e.g., Kaufman, Hirst, Buse, Foster, Goldberg, Schneider, et al., 2011). Myriad studies indicate that increasing MVPA leads to a reduction in weight and, subsequently, may result in an amelioration of the adverse consequences associated with excess weight such as type 2 diabetes (LaMonte, Blair, \& Church, 2005). Additionally, there is a dose-response relationship between increasing levels of leisure-time MVPA and declining obesity (Seo \& Li, 2010).

Although decreased body weight through increasing MVPA via interventions can be achieved, in some cases interventions appear unsuccessful at reducing weight among youth and adults alike (e.g., Goran \& Poehlman, 1992; Stubbs, Hughes, Johnstone, Whybrow, Horgan, King, et al., 2004). Generally, when weight loss has not been achieved, at the conclusion of these interventions it has been determined that individuals were engaging in activity compensation (Goran \& Poehlman, 1992; Stubbs et al., 2004), though the presence of activity compensation among children and adolescents is mixed (Goodman, Mackett, \& Paskins, 2011). With these studies, activity compensation is defined as “...compensatory adjustments in exercise and nonexercise activity... and a reduction in physical activity in nonexercise time" (King, Hopkins, Caudwell, Stubbs, \& Blundell, 2008). This nonexercise activity component is of interest, as research has recently begun focusing on non-exercise activity thermogenesis (NEAT), which refers to energy expended through non-volitional activities such as those of daily living and fidgeting, as well as posture maintenance (Levine, Eberhardt, \& Jensen 1999). Since NEAT is 
difficult to measure, and a component of NEAT is light activity (Levine, Melanson, Westerterp, \& Hill, 2001; Mitchell, Mattocks, Ness, Leary, Pate, Dowda, Blair, \& Riddoch, 2009; Marshall \& Welk, 2008), light levels of activity provides an indicator of NEAT activity levels. In addition, research indicates that triaxial accelerometers and tilt meters (inclinometers) are able to capture $>80 \%$ of NEAT activities (Bouden et al., 1994; Levine, 2004).

For the purposes of the current study, activity compensation is defined as compensatory reductions in energy expenditure as a result of imposed PA and vice versa (Rowlands, 2009). Few studies have explicitly been interested in examining activity compensation as it is defined here. Furthermore, of the studies for which the purpose was to examine activity compensation, the focus was on total physical activity, where the light levels of physical activity were not explicitly examined (e.g., Dale, Corbin, \& Dale, 2000). Most studies examining compensation examine the compensation of energy expenditure with energy intake rather than compensating for activity during the day with non-activity later in the day. For example, King and colleagues (2008) sought to examine whether a 12-week exercise intervention was successful in reducing body weight among a group of 35 adult men and women. As a result of these few studies of compensation that largely arise as an afterthought of intervention studies, Eisenmann and Wickel (2009) called for additional research to examine the activity compensation phenomenon in general, as well as whether it differs across demographic variables (e.g., gender and age).

No research to date has examined the presence of activity compensation specifically as it relates to NEAT among a group of rural adolescents. Therefore, the purpose of this study was to determine whether adolescents engage in activity compensation throughout the school day, and whether this compensation is dependent upon the amount of NEAT and MVPA adolescents engage in during PE class. Because previous research among youth is rather inconclusive with 
regard to whether youth engage in activity compensation (Goodman, Mackett, \& Paskins, 2011), no specific hypothesis was generated.

\subsection{Method}

\subsubsection{Data Collection}

A total of $2689^{\text {th }}$ and $10^{\text {th }}$ grade students were enrolled in an accelerometer study. Data were collected during the spring 2010-2011 school year and the fall 2011-2012 school year. Students were instructed to wear the ActiGraph ${ }^{\text {TM }}$ GTX3E triaxial accelerometer on their right hip for 1 week at the beginning of the term during which they were enrolled in PE and for 1 week at the end of their PE term. In addition to accelerometer data, student gender, grade level, teacher, PE class time, and BMI data were collected. The high schools were selected as they comprised all of the high schools within the 6-county intervention area of Communities Putting Prevention to Work (CPPW; please see Bunnell, O’Neil, Soler, Payne, Giles, Collins, Bauer, Communities Putting Prevention to Work Program Group, 2012 for background of the project). Although data were collected for 1 week at the beginning of the term and 1 week at the end of the term, for the purposes of this study, only data from the beginning of the term were utilized because of the greater number of potential participants.

\subsubsection{Data Analysis}

To convert the accelerometry data from the accelerometers into usable data, the statistical program MeterPlus $^{\mathrm{TM}}$ (Santech Inc., 2010) was used. Accelerometry data were specified at 5second epochs and deduced using 15-second time intervals. The cut points established by Evenson and colleagues (2008) were used to estimate time spent in sedentary $(\leq 100$ counts/minute), NEAT (light; 101-2295 counts/minute), moderate (2296-4011 counts/minute), and vigorous ( $\geq 4012$ counts/minute) activity. The Evenson et al. (2008) cut points were used as 
these are recommended as most appropriate for children and adolescents (Trost, Loprinzi, Moore, \& Pfeiffer, 2011). Because children and adolescents are more likely to engage in short bouts of energy expenditure compared with adults and longer intervals such as those longer than 1 minute may substantially underestimate physical activity (Bailey, Olson, Pepper, Porszasz, Barstow, \& Cooper, 1995), a 15-second time interval was utilized. As such, the cut points used were as follows: sedentary ( $\leq 25$ counts/15 seconds), NEAT (light; $26-573$ counts/15 seconds), moderate (574-1002 counts/15 seconds), and vigorous ( $\geq 1003$ counts/15 seconds) activity.

Preliminary diagnostics were conducted to determine the presence of collinearity and outliers. Upon initial examination of the data, more than $25 \%$ of accelerometer wear time during non-PE classes was spent in $0 \%$ NEAT. As a result, two distinct models of activity compensation were fit using generalized linear mixed models (SAS PROC GLIMMIX and MIXED).

The first generalized linear mixed model was a logistic model of the odds of an individual engaging in $\geq 10 \%$ NEAT during non-PE class time versus $<10 \%$ NEAT during nonPE class time (PROC GLIMMIX). For this logistic mixed model, NEAT during non-PE class time was recoded so that those who engaged in NEAT for $\geq 10 \%$ of their non-PE class time were coded as " 1 " and those with $<10 \%$ of NEAT during non-PE class time were coded as "0." Odds ratios were then calculated for each of the variables of interest. For interpretation purposes, odds ratios were specified at 10-minute increments for class length, MVPA during PE class, and NEAT during PE class.

The second model was a traditional general linear mixed model of a normally distributed outcome (PROC MIXED) that examined only those who engaged in any NEAT time during nonPE class time and excluded those with $0 \%$ of non-PE class time spent in NEAT. NEAT was kept 
as a continuous variable. The objective of the second model was to examine whether compensation occurred.

For the logistic model, the cut point of $10 \%$ was selected because this percentage is located approximately between the median $(8.8 \%)$ and $75^{\text {th }}$ percentile $(13.4 \%)$ for the participants' non-PE class time spent in NEAT and for interpretability purposes. Mixed models were utilized to include random effects that accounted for the clustered, longitudinal design of the data collection. In particular, a random effect of PE teacher was included to account for correlations among students in the same PE class. Fixed effects of interested included: 1) gender, 2) total number of minutes spent in MVPA during PE class, 3) body mass index percentile (BMI percentile), 4) total number of minutes spent in NEAT during PE class, and 5) duration of PE class. Results were considered significant at the $p \leq 0.05$ level. All data were analyzed with the Statistical Analysis System (SAS), 9.3 (Cary, N.C.). This study received institutional review board approval from the referent university.

\subsection{Results}

\subsubsection{Descriptives}

After removing participants without reported BMI percentile $(n=53)$, a total of 166 participants were included for the current study. Approximately equal numbers of males and females were included in the final analyses and participants' average BMI percentile was at a healthy weight, based on the Centers for Disease Control and Prevention (2011). Please see table 1 for sample characteristics. 


\begin{tabular}{lc}
\hline Table 1. Sample Characteristics $(\mathrm{N}=219)^{*}$ & \\
\hline & Mean $(S D)$ \\
\hline Gender & $112(52.34 \%)$ \\
Male n(\%) & $102(47.66 \%)$ \\
Female $\mathrm{n}(\%)$ & $74.18(26.56)$ \\
BMI Percentile & \\
\hline Activity Level-During PE Class & $48.28 \%(31.39 \%)$ \\
\hline Sedentary (\% of PE Class) & $24.55 \%(21.74 \%)$ \\
NEAT (\% of PE Class) & $1.28 \%(2.80 \%)$ \\
Moderate to Vigorous (\% of PE Class) & $25.89 \%(41.45 \%)$ \\
Non-wear (\% of PE Class) & \\
\hline Activity Level-During Non-PE Classes & $65.96 \%(33.20 \%)$ \\
\hline Sedentary (\% of Non-PE Classes) & $8.69 \%(7.19 \%)$ \\
NEAT (\% of Non-PE Classes) & $0.20 \%(0.48 \%)$ \\
Moderate to Vigorous (\% of Non-PE Classes) & $20.35 \%(41.45 \%)$ \\
Non-wear (\% of Non-PE Classes) & $81.42(21.23)$ \\
\hline PE Class Length (minutes) & \\
\hline Non &
\end{tabular}

Note: NEAT=Non-exercise activity thermogenesis; $\mathrm{SD}=$ Standard Deviation; BMI=Body Mass Index ; Percentages may not equal $100 \%$ due to missing data $; *$ Ns may be different due to missing data

\subsubsection{Main Analyses}

Final fixed effects for both models included participant gender and BMI percentile zscore, duration of PE class (in minutes), and the number of minutes spent in MVPA and NEAT during PE class. Results revealed that after controlling for these factors, participants did not engage in activity compensation. Rather, adolescents who engaged in a greater number of minutes in NEAT during PE class also spent a greater percentage of their time during the non-PE class school day in NEAT $(p<.001)$. Please see Table 2 for specifics. 
Table 2. Model of Odds of $\geq 10 \%$ non-PE Time Spent in NEAT.

\begin{tabular}{l|ccccc}
\hline & $\boldsymbol{O R}(\mathbf{C I})$ & $\boldsymbol{B}$ & $\boldsymbol{S E} \boldsymbol{B}$ & $\boldsymbol{t}$ & $\boldsymbol{p}$ \\
\hline $\begin{array}{l}\text { Gender (Male as } \\
\text { referent) }\end{array}$ & $1.72(1.17,2.58)$ & 0.553 & 0.20 & 2.74 & $0.0063^{* *}$ \\
$\begin{array}{l}\text { PE Class Length } \\
\text { BMI Percentile z- }\end{array}$ & $0.85(0.74,0.97)$ & -0.016 & 0.007 & -2.39 & $0.0168^{*}$ \\
$\begin{array}{l}\text { score } \\
\begin{array}{l}\text { Number of Minutes } \\
\text { Spent in MVPA } \\
\text { during PE Class }\end{array}\end{array}$ & $1.54(0.87,1.24)$ & 0.036 & 0.092 & 0.39 & 0.6961 \\
$\begin{array}{l}\text { Number of Minutes } \\
\text { Spent in NEAT } \\
\text { during PE Class }\end{array}$ & $1.04(1.03,1.05)$ & 0.004 & 0.0004 & 8.94 & 0.3492 \\
\hline
\end{tabular}

Note: MVPA=Moderate to Vigorous Physical Activity; NEAT=Non-exercise activity thermogenesis; $\mathrm{CI}=$ confidence interval; Model adjusted for PE teacher. ${ }^{*} \mathrm{p}<.05 ;{ }^{*} \mathrm{p}<.01 ; * *<.001$

From table 2 it is also evident that there is a positive relationship between percent of time spent in NEAT during PE classes and odds of spending more than or equal to $10 \%$ of non-PE class time in NEAT. A significantly negative relationship exists between individuals who had $10 \%$ or more of their non-PE class time spent in NEAT and the duration of their PE class. Specifically, as the length of the participants' PE class increases, the likelihood that an individual engaged in $10 \%$ or more of their non-PE class time in NEAT decreased. Although effects are small, gender, PE class length, and PE class NEAT minutes are all significantly related to an increased odds in participants spending $>10 \%$ of non-PE time in NEAT. From the odds ratios displayed in Table 2 it is evident that males have a 1.72 greater odds of spending $\geq 10 \%$ of nonPE time in NEAT than females. In addition, for every 10 minutes spent in PE, there is 0.85 odds of spending $\geq 10 \%$ non-PE class time in NEAT. Lastly, for every 10 minutes spent in NEAT during PE class there is a 1.04 odds of spending $\geq 10 \%$ non-PE class time in NEAT. 
Table 3. Final Mixed Model of non-PE NEAT for Those with > 0\% non-PE NEAT Examining Activity Compensation.

\begin{tabular}{lcccc}
\hline & $\boldsymbol{B}$ & $\boldsymbol{S E} \boldsymbol{B}$ & $\boldsymbol{t}$ & $\boldsymbol{p}$ \\
\hline Gender (Male as referent) & 0.007 & 0.005 & 1.34 & 0.1824 \\
PE Class Length & -0.0004 & 0.0002 & -2.20 & $0.0398^{*}$ \\
BMI Percentile z-score & -0.001 & 0.002 & -0.35 & 0.7245 \\
Number of Minutes Spent in MVPA during PE & 0.001 & 0.001 & 1.09 & 0.2766 \\
Class & & & & \\
Number of Minutes Spent in NEAT during PE & 0.001 & 0.0001 & 11.85 & $<.0001^{* * *}$ \\
Class & & & & \\
\hline
\end{tabular}

Note: NEAT=Non-exercise activity thermogenesis; Model adjusted for PE teacher.; ${ }^{*} \mathrm{p}<.05 ;{ }^{* *} \mathrm{p}<.01 ;{ }^{* * *}<.001$

Table 3 presents the results from the linear mixed model of those individuals who had any NEAT during their non-PE classes. Similar patterns exist to those found from the logistic model provided in Table 2 . Specifically, there is a significantly negative relationship between PE class length and the percent of non-PE class time spent in NEAT. For every increase in the percentage of NEAT during non-PE class, there is a 0.0004 minute decrease in PE class time. There is also a significant and positive relationship between the number of minutes spent in NEAT during PE class and the percent of non-PE class time spent in NEAT. For every increase in percentage of NEAT during non-PE class, there is a 0.001 minute increase in NEAT activity during PE class. No gender differences were observed in this analysis.

\subsection{Discussion}

The purpose of the current study was to determine whether adolescents engage in activity compensation during non-PE classes due to the amount of physical activity achieved during their PE class. Results from the current study revealed that this is not the case. Specifically, adolescents in this sample who engaged in higher levels of physical activity during PE class (both MVPA and NEAT), also engaged in higher levels of NEAT during the non-PE class school day. This suggests that adolescents who engage in higher levels of NEAT during times of high 
activity will also tend to do so during more sedentary-type activities such as participation in nonPE class activities. Given previous research on NEAT, this is not surprising. The argument can be made that this is the case because NEAT is "...the thermogenesis that accompanies physical activities other than volitional exercise, such as the activities of daily living, fidgeting, spontaneous muscle contraction, and maintaining posture when not recumbent" (p. 924; Levine, Eberhardt, \& Jensen 1999). Thus, because NEAT includes non-volitional activities, adolescents who engage in increased levels of NEAT appear to do so across environments and activities, though the strength of this relationship among this sample of adolescents is relatively small.

This study contributes to the body of literature in that it demonstrates that, in the current sample, adolescents engage in NEAT activity levels relatively consistently between their PE and non-PE classes. That is to say, adolescents in this sample who engaged in greater levels of NEAT during PE class also engaged in greater levels of NEAT during their non-PE classes. This finding is important in that it demonstrates that adolescents who tend to engage in NEAT activity levels tend to do so across various school activities. Because of the hypothesized relationship between NEAT activity levels and body weight (Kotz, Teske, \& Billington, 2008), as well as the research suggesting that physical activity leads to increased concentration (e.g., Tomporowski, 2003), teachers may wish to allow such activities as fidgeting in the classroom (i.e., an "activitypermissive environment”; Lanningham-Foster, Foster, McCrady, Manohar, Jensen, Mitre, Hill, \& Levine, 2008), which has been shown to increase energy expenditure compared to traditional, more sedentary classroom environments.

In instances where it may be feasible, school systems may wish to foster NEAT in the non-PE classroom environment via classroom modification. Although sparse, researchers have begun examining the implementation of standing desks in classrooms to increase the overall 
energy expenditure of children (Benden, Blake, Wendel, \& Huber, 2011; Benden, Wendel, Jeffrey, Zhao, \& Morales, 2012; Lanningham-Foster et al., 2008). This classroom modification has even been suggested to decrease the risk of children gaining weight (Wingrat \& Exner, 2005), through NEAT principles (Benden et al., 2012; Davidson, 2007). Although this sort of classroom modification has had little research attention and warrants further consideration (Davidson, 2007), initial findings suggest that academic performance and behavior may be improved by classroom modification (Benden et al., 2012; Benden, Blake, Wendel, \& Huber, Jr., 2011). Taking an ecological model approach (McLeroy, Bibeau, Steckler, \& Glanz, 1988) through implementing classroom changes at the school system level, potential redesign of schools (Lanningham-Foster, Foster, McCrady, Manohar, Jensen, Mitre, Hill, \& Levine, 2008) will reach a greater number of children than interventions at the individual level to increase children's energy expenditure. In addition, encouraging activity throughout the day through school design may allow for children to develop behavior that discourages sedentary behavior outside the school day, as well as continuing lifestyle activities into adulthood, whereby potentially impacting the obesity epidemic.

\subsubsection{Strengths \& Limitations}

Although this study was the first to examine whether activity compensation occurs throughout the school day, this study is not without limitations. First, this study utilized data which were previously collected. As a result, we were limited by the available data. For example, data were limited to only 6 counties within West Virginia, and the results may not be generalizable to adolescents outside of the 6 counties in West Virginia. In addition, although light physical activity is a component of NEAT, and was used as a proxy for NEAT in the current study, NEAT may be underestimated, as triaxial accelerometers and inclinometers 
capture $>80 \%$ of NEAT (Bouten, Westerterp, Verduin, \& Janssen, 1994; Levine, 2004).

However, because NEAT includes light activity levels (Levine, Melanson, Westerterp, \& Hill, 2001; Mitchell, Mattocks, Ness, Leary, Pate, Dowda, Blair, \& Riddoch, 2009; Marshall \& Welk, 2008) and posture maintenance as well as movement (Levine et al., 2005), specifically examining these light levels of activity among this group of adolescents may provide some insights into the NEAT levels. Future research should examine these relationships further to gain a better understanding. For example, the addition of inclinometers may provide additional assistance with characterizing NEAT (Levine, 2004) among adolescents.

Second, the odds ratios found in Table 2 were relatively small, indicating that although there is a relationship between the amount of NEAT during non-PE class time and the amount of NEAT during PE class, gender, and PE class length, it is not strong. A third limitation of the current study is that caloric intake was not measured. It is possible that the students were compensating for their caloric expenditure via the number of calories they consumed. For example, in several studies which examined the efficacy of weight-reduction interventions among adults, it was found that despite the participants taking part in interventions to decrease the amount of energy they consumed, they were also decreasing the amount of PA in which they engage, leading to a suppressed effect of the intervention (Goran \& Poehlman, 1992; Stubbs et al., 2004). The results from interventions such as these appear to researchers that the intervention was unsuccessful in achieving weight loss when, in fact, other factors are having influence.

Other studies among children examining physical activity intervention effects found no evidence of an increase in physical activity among the intervention group (Harrell, McMurray, Bangdiwala, Frauman, Gansky, \& Bradley, 1996). 
In studies among children where the intervention group did increase physical activity levels, there were decreases in physical activity outside of the school day. In fact, the comparison group actually engaged in more physical activity outside of the school day than did the intervention group (Donnelly, Jacobsen, Whatley, Hill, Swift, Cherrington, et al., 1996). Taken together, it appears that when interventions occur, there may be some existence of activity compensation outside of the school day. Because of the current results and the results from previous studies, future research should examine whether activity compensation occurs outside of the school day as a result of the amount of physical activity engaged in during PE class.

\subsubsection{Conclusion}

Findings from this study suggest that adolescents who engage in high levels of light (NEAT) physical activity tend to do so regardless of class environment (i.e., PE or non-PE classes). Based on the results of the current study, it appears that when children are not required to engage in activity levels above their usual physical activity level (such as imposed physical activity), no activity compensation occurs. However, future research needs to examine whether activity compensation occurs outside of the school day. 


\subsection{References}

Benden, M. E., Blake, J. J., Wendel, M. L., \& Huber, Jr. CJ. C. (2011). The impact of standbiased desks in classrooms on calorie expenditure in children. American Journal of Public Health, 101, 1433-1436.

Benden, M. E., Wendel, M. L., Jeffrey, C. E., Zhoa, H., \& Morales, M. L. (2012). Withinsubjects analysis of the effects of a stand-biased classroom intervention on energy expenditure. Journal of Exercise Physiology, 15(2), 9-19.

Bouten, C. V., Westerterp, K. R., Verduin, M., \& Janssen, J. D. (1994). Assessment of energy expenditure for physical activity using a triaxial accelerometer. Medicine and Science in Sports and Exercise, 26(12), 1516-1523.

Bunnell, R., O’Neil, D. Soler, R., Payne, R., Giles, W. H., Collins, J., Bauer, U., Communities Putting Prevention to Work Program Group. (2012). Fifty communities putting prevention to work: Accelerating chronic disease prevention through policy, systems, and environmental change. Journal of Community Health, online first.

Centers for Disease Control and Prevention (2011). Healthy weight-it's not a diet, it's a lifestyle! Retrieved February 13, 2013, from http://www.cdc.gov/healthyweight/ assessing/bmi/childrens_bmi/about_childrens_bmi.html.

Dale, D., Corbin, C. B., \& Dale, K. S. (2000). Restricting opportunities to be active during school time: Do children compensate by increasing physical activity levels after school? Research Quarterly for Exercise and Sport, 71(3), 240-248.

Daniels, S. R. (2009). Complications of obesity in children and adolescents. International Journal of Obesity, 33, S60-S65.

Davidson, F. (2007). Childhood obesity prevention and physical activity in schools. Health Education, 107(4), 377-395.

Donnelly, J. E., Jacobsen, D. J., Whatley, J. E., Hill, J. O., Swift, L. L., Cherrington, A., Polk, B., Tran, Z. V., \& Reed, G. (1996). Nutrition and physical activity program to attenuate obesity and promote physical and metabolic fitness in elementary school children. Obesity Research, 4(3), 229-243.

Duncan, M. J., \& Staples, V. (2010). The impact of a school-based video game play intervention on children's physical activity during recess. Human Movement, 11(1), 95-99.

Harrell, J. S., McMurray, R. G., Bangdiwala, S. I., Frauman, A. C., Gansky, S. A., \& Bradley, C. B. (1996). Effects of a school-based intervention to reduce cardiovascular disease risk factors in elementary-school children: The Cardiovascular Health in Children (CHIC) Study. Journal of Pediatrics, 128(6), 797-805. 
Kaufman, F., Hirst, K., Buse, J., Foster, G. D., Goldberg, L., Schneider, M., Staten, M., Benditti, E. M., White, M., \& Yin, Z., for the HEALTHY Study Group. (2011). Effect of secular trends on a primary prevention trial: The HEALTHY study experience. Childhood Obesity, 7(4), 291-297.

King, N. A., Hopkins, M., Caudwell, P., Stubbs, R. J., \& Blundell, J. E. (2008). Individual variability following 12 weeks of supervised exercise: Identification and characterization of compensation for exercise-induced weight loss. International Journal of Obesity, 32, 177-184.

Kotz, C. M., Teske, J. A., \& Billington, C. J. (2008). Neuroregulation of nonexercise activity thermogenesis and obesity resistance. Regulatory, Integrative and Comparative Physiology, 294(3), R699-R710.

Eisenmann, J. C., \& Wickel, E. E. (2009). The biological basis of physical activity in children: Revisited. Pediatric Exercise Science, 21, 257-272.

Goodman, A., Mackett, R. L., \& Paskins, J. (2011). Activity compensation and activity synergy in British 8-13 year olds. Preventive Medicine, 53, 293-298.

Goran, M. I., \& Poehlman, E. T. (1992). Endurance training does not enhance total energy expenditure in healthy elderly persons. American Journal of Physiology, 265, E950-E957.

Kempen, K. P. G., Saris, W. H. M., \& Westerterp, K. R. (1995). Energy balance during an 8-wk energy-restricted diet with and without exercise in obese women. American Journal of Clinical Nutrition, 62, 722-729.

LaMonte, M. J., Blair, S. N., \& Church, T. S. (2005). Physical activity and diabetes prevention. Journal of Applied Physiology, 99(3), 1205-1213.

Lanningham-Foster, L., Foster, R. C., McCrady, S. K., Manohar, C., Jensen, T. B., Mitre, N. G., Hill, J. O., \& Levine, J. A. (2008). Changing the school environment to increase physical activity in children. Obesity, 16(8), 1849-1853.

Levine, J. A. (2004). Non-exercise activity thermogenesis (NEAT). Nutrition Reviews, 62(7), S82-S97.

Levine, J. A., Eberhardt, N. L., \& Jensen, M. D. (1999). Role of nonexercise activity thermogenesis in resistance to fat grain in humans. Science, 283, 212-214.

Levine, J., Melanson, E. L., Westerterp, K. R., \& Hill, J. O. (2001). Measurement of the components of nonexercise activity thermogenesis. American Journal of Physiology: Endocrinology and Metabolism, 281, E670-E675.

Marshall, S. J., \& Welk, G. J. (2008). Definitions and measurement. In A. L. Smith \& S. J. H. Biddle (Eds.). Youth physical activity and sedentary behavior: Challenges and solutions. Champaign, IL: Human Kinetics. 
McLeroy, K. R., Bibeau, D., Steckler, A., \& Glanz, K. (1988). An ecological perspective of health promotion programs. Health Education Quarterly, 15(4), 351-377.

Mitchell, J. A., Mattocks, C., Ness, A. R., Leary, S. D., Pate, R. R., Dowda, M., Blair, S. N., \& Riddoch, C. (2009). Sedentary behaviour and obesity in a large cohort of children. Obesity, $17(8), 1596-1602$.

Rowlands, A. V. (2009). Methodological approaches for investigating the biological basis for physical activity in children. Pediatric Exercise Science, 21, 273-278.

Santech Inc. (2010). http://www.meterplussoftware.com. Meterplus 4.2.

Seo, D., \& Li, K. (2010). Leisure-time physical activity dose-response effects on obesity among US adults: Results from the 1999-2006 National Health and Nutrition Examination Survey. Journal of Epidemiology and Community Health, 64, 426-431.

Stubbs, R. J., Hughes, D. A., Johnstone, A. M., Whybrow, S., Horgan, G. W., King, N., \& Blundell, J. (2004). Rate and extent of compensatory changes in energy intake and expenditure in response to altered exercise and diet composition in humans. American Journal of Physiology-Regulatory, Integrative and Comparative Physiology, 286, R350-R358.

Tomporowski, P. D. (2003). Cognitive and behavioral responses to acute exercise in youths: A review. Pediatric Exercise Science, 15, 348-359.

Westerterp, K. R., Meijer, G. A., Janssen, E. M. E., Saris, W. H. M., \& Hoor, F. T. (1992). Longterm effect of physical activity on energy balance and body composition. British Journal of Nutrition, 68, 21-30.

Wingrat, J. K., \& Exner, C. E. (2005). The impact of school furniture on fourth grade children's on-task and sitting behaviors in the classroom: A pilot study. Work, 25(3), 263-272. 


\section{Chapter 5}




\section{Chapter 5}

\subsection{Summary}

The principal objective of these studies was to gain a better understanding of nonexercise activity thermogenesis (NEAT) among a group of rural children and adolescents during the school day. The school day was specifically targeted as schools may unintentionally suppress physical activity among children due to the focus on cognitive outcomes (McKenzie \& Kahan, 2008). Although research has been limited, some research does indicate that NEAT confers health benefits (Hamilton, Hamilton, \& Zderic, 2007; Manson, Greenland, LaCroix, Stefanick, Mouton, Oberman, et al., 2002; Paffenbarger, Blair, \& Lee, 2011; Vuori, 2001). Research demonstrating the health benefits of NEAT has predominately focused on adults, and has not specifically targeted those residing in rural communities. Children residing in rural areas have an increased risk for the development of obesity as compared to children residing in both urban (Liu, Bennett, Harun, \& Probst, 2008) and suburban (Nelson, Gordon-Larsen, Song, \& Popkin, 2006) areas (Lutfiyya, Lipsky, Wisdom-Behounek, \& Inpanbutr-Martinkus, 2007). This increased risk has been hypothesized to be due to the limited physical activity opportunities in rural areas (Powell, Slater, Chaloupka, \& Harper, 2006). As such, focusing on the physical activity, particularly NEAT activity levels of rural children and adolescents provides evidence that may be utilized for subsequent physical activity interventions, as well as obesity prevention strategies.

The study described in chapter 2 examined the relationship between age and NEAT levels of physical activity during PE class. Utilizing accelerometry data from both elementary and high school students during 1 day of PE class, a linear regression was performed, where the outcome was the percentage of time that participants spent in NEAT activity during their PE 
class. Adjusting for gender, duration of PE class (in minutes), and PE teacher, it was found that elementary students spent a significantly larger percentage of their PE class time in NEAT than the high school students in the sample $(p<.001)$. Analyses also revealed that males spent a significantly larger percentage of their PE class time in NEAT than females $(p=.046)$.

This study contributed to the current knowledge base of NEAT in that it demonstrated, among this sample of rural youth, that lower levels of physical activity (i.e., NEAT) during PE class tend to follow the same trajectory as moderate to vigorous physical activity (MVPA) levels (Belcher, Berrigan, Dodd, Emken, Chou, \& Spuijt-Metz, 2010; Nader, Bradley, Houts, McRitchie, \& O'Brien, 2008). That is, NEAT during PE class for high school students is lower than for elementary school students. These findings have potential implications for supporting PE teachers through additional trainings to encourage physical activity at all levels above sedentary, potentially leading to additional health benefits.

Chapter 3 described a study in which the constancy or stability of NEAT was examined. Two mixed models were fit using PROC MIXED in SAS (Cary, N.C.). The two models examined both the inter- and intra-individual variability of NEAT during PE class and during the non-PE class school day. The intra-individual variation was examined separately by gender using the GROUP function, due to previous research indicating that males engage in higher levels of overall physical activity compared with females (Ridgers, Fairclough, \& Stratton, 2010). Results from this study revealed that for the PE class models, the intra-individual variation of NEAT among males was 1.38 times that of females'. During non-PE class, the intra-individual variation of NEAT among males was about 0.86 times that of females'. When results for the intra-individual variation were examined, findings indicated that NEAT is more variable during PE class $\left(\sigma^{2}=0.037\right)$ than non-PE classes $\left(\sigma^{2}=0.004\right)$. Examining the intraclass correlations 
(ICC) separately by gender, during PE class there was higher intra-individual variation among females $(0.170)$ than among males $(0.231)$. However, the ICC was similar for both males and females ( 0.130 and 0.134 , respectively) during non-PE class, but lower than both ICCs during PE class, indicating a greater amount of intra-individual variability for both males and females during non-PE classes compared with PE class. Previous research examining ICCs for MVPA were found to be 0.145 among adolescent girls (Stevens, Taber, Murray, \& Ward, 2007), which is higher than the ICCs for males and females during non-PE class, but lower than the ICCs during PE class for males and females in chapter 3. It appears that MVPA among Stevens et al.'s (2007) sample of adolescent girls is more stable than NEAT during non-PE classes, but less stable than NEAT during PE class.

Although activity type during PE class was not controlled for, this study was able to provide some valuable information. Because inter- and intra-variability of NEAT have not been readily examined, this study provided an initial characterization of NEAT during the school day among a group of rural West Virginia adolescents. Findings provide the foundation for additional work to take place. For example, because previous research suggests that a gender difference exists regarding sport-type or activity preference (Frömel, Formánková, \& Sallis, 2002), future research may wish to continue the examination of NEAT for males and females by different activity type. It is possible that females may engage in higher levels of physical activity, including NEAT levels, when participating in a sport which they prefer.

In addition, these initial results may provide some information that could have implications for activity during PE class. For example, the high inter-individual variability during PE class suggests that although PE teacher has little effect on whether individuals engage in NEAT, because of the relatively low levels of NEAT during participants' PE classes, PE 
teachers may be able to support the addition of more NEAT activity during PE class by asking students to walk while waiting for their turn to participate in an activity. Because of the positive relationship between NEAT during PE class and NEAT during non-PE classes, it is possible that increases in NEAT during PE class may result in additional NEAT activity levels during non-PE classes, whereby conferring health benefits of additional physical activity.

The final study, described in chapter 4, examined whether activity compensation occurs as a result of imposed moderate to vigorous physical activity (MVPA) and NEAT during PE class. To determine whether activity compensation occurs among a group of rural West Virginia adolescents, two separate generalized linear mixed models were performed. The logistic model examined the odds of participants engaging in $10 \%$ or more of their non-PE class time in NEAT versus participants engaging in less than $10 \%$ of their non-PE class time in NEAT. The second model, a traditional linear mixed model examined whether the amount of NEAT activity during non-PE classes was dependent upon the amount of total physical activity accrued during PE class. This second model utilized data from individuals who engaged in any NEAT time during their non-PE classes and excluded individuals for whom $0 \%$ NEAT activity during non-PE class time was recorded.

Results from the logistic model found that when controlling for gender, PE teachers, duration of PE class, and BMI percentile, participants did not engage in activity compensation. In fact, participants who engaged in a greater number of minutes of both MVPA and NEAT during PE class also spent a greater percentage of their non-PE class time in NEAT. Gender and PE class length were also significantly related. Specifically, males were at an increased likelihood to engage in NEAT during the non-PE class school day than females $(p=.0377)$, and individuals who participated in shorter PE class lengths were more likely to engage in NEAT 
during the non-PE class school day $(p=.0156)$. Further investigation regarding this result should take place, however, before any recommendations regarding class length are made.

Results from the second linear mixed model concurred with the results from the logistic model. Regarding individuals who had any NEAT activity during their non-PE class school day, the participants who engage in a greater number of NEAT minutes during their PE class also spent a significantly larger percentage of their non-PE class school day in NEAT $(p<.0001)$. Individuals who participated in shorter PE classes also spent a significantly higher percentage of their non-PE class school day in NEAT $(p=.0398)$.

Findings from both models are encouraging and add to the previous research indicating that participants who engage in higher levels of NEAT during PE also tend to do so during their non-PE classes as well. Extrapolating these findings, it would appear that adolescents' amount of NEAT activity is independent of class type (i.e., PE or non-PE class). Although this study did not examine whether activity compensation occurs outside of the school day, it did provide evidence that NEAT activity compensation does not occur as a result of physical activity incurred during PE class. Given previous intervention work suggesting that activity compensation may occur (Donnelly, Jacobsen, Whatley, Hill, Swift, Cherrington, et al., 1996), it may be important for researchers to examine the potential for decreases in NEAT outside of the school day.

\subsection{Significance}

The purpose of these three studies was to contribute to the current NEAT literature by focusing on rural youth. The long-term goal of these studies was to increase the knowledge base of the characteristics of NEAT in youth residing in rural areas. These studies were significant for several reasons. First, these were the first to examine NEAT among a group of rural children and adolescents. Because of the increased weight status of rural children and adolescents compared 
with urban (Liu, Bennett, Harun, \& Probst, 2008) and suburban (Nelson, Gordon-Larsen, Song, \& Popkin, 2006), this particular population was important to examine. Second, these studies included a comparatively large group of individuals, providing more accurate representation of NEAT among this sample of children and adolescents. Third, study 1 revealed that NEAT activity, like MVPA, seems to decline as children age. Fourth, study 2 found that NEAT is more variable within individuals during PE class than non-PE classes, and that the between-person variation was similar for males and females during non-PE classes, yet dissimilar during PE classes. Lastly, study 3 demonstrated that perhaps unlike evidence to suggest that activity compensation occurs with MVPA, activity compensation may not occur with lower activity levels such as NEAT.

\subsection{Strengths \& Limitations}

These studies' findings have both strengths and limitations. The current studies were strengthened by the fact that they utilized objectively measured physical activity data via accelerometers. Second, these studies were among the first to examine NEAT in a comparatively large sample of rural children and adolescents. Salmon (2010) notes that focusing only on MVPA activity levels may not effect sedentary behaviors which are known to have deleterious

effects on health (Owen, Bauman, \& Brown, 2009). The use of light physical activity levels as a proxy for NEAT may also add to the literature in that higher correlations exist between light physical activity and sedentary time versus moderate to vigorous physical activity and sedentary time (Salmon, 2010). This is to say, it is more likely that children who spend less time in sedentary behaviors are more likely to be engaging in light rather than moderate to vigorous physical activity levels. 
As with all studies, these studies had limitations. First, body mass index (BMI) percentile data were not available for the children included in the first study. Thus, conclusions regarding the relationship between NEAT and BMI percentile were not able to be determined among the group of elementary children. However, BMI percentile data were available for the adolescent group, allowing conclusions to be made between BMI percentile and NEAT for study 3. Second, the data utilized were previously collected. As a consequence, analyses were limited by the available data. For example, adolescent data were only available from high school students attending one of six high schools. An additional limitation due to the limited data was that light activity was utilized as a proxy for NEAT. Although light physical activity and energy expenditure associated with both posture and movement (Levine et al., 2005) are components of NEAT (Levine, Melanson, Westerterp, \& Hill, 2001; Mitchell, Mattocks, Ness, Leary, Pate, Dowda, Blair, \& Riddoch, 2009; Marshall \& Welk, 2008), using only light activity levels may have underestimated NEAT, due to the fact that $>80 \%$ of NEAT may be capture through triaxial accelerometers and tilt meters (inclinometers) (Bouten, Westerterp, Verduin, \& Janssen, 1994; Levine, 2004). Although not $100 \%$ of NEAT activities will be captured, using triaxial accelerometers to quantify NEAT is a necessary first step. Thus, generalizability of the results for each of the three studies is limited. Although limitations are present, these studies do provide a necessary first step for the characterization of NEAT in rural youth.

\subsection{Future Research}

Although this dissertation provides additional information regarding NEAT activity among a group of rural children and adolescents, additional research is certainly needed. For example, the three studies only examined NEAT within the school day. Research examining physical activity interventions suggests that activity compensation is exacerbated outside of the 
school day. As such, future work should examine whether activity compensation occurs outside of the school day as a result of the amount of physical activity achieved during the school day. In addition, it was previously noted that although activity was measured across a school week, activity type during PE class was not taken into account. In the future, researchers should examine the sport or activity in which youth are engaging during PE to determine whether sport or activity type has an influence on the amount of NEAT. 


\subsection{Conclusions}

Findings from these three studies have contributed to the understanding and

characterization of NEAT during the school day, both during and outside of PE class, among a rural sample of children and adolescents. 


\subsection{References}

Belcher, B. R., Berrigan, D., Dodd, K. W., Emken, B. A., Chou, C., \& Spuijt-Metz, D. (2010). Physical activity in US youth: Impact of race/ethnicity, age, gender, \& weight status. Medicine and Science in Sport and Exercise, 42(12), 2211-2221.

Bouten, C. V., Westerterp, K. R., Verduin, M., \& Janssen, J. D. (1994). Assessment of energy expenditure for physical activity using a triaxial accelerometer. Medicine and Science in Sports and Exercise, 26(12), 1516-1523.

Donnelly, J. E., Jacobsen, D. J., Whatley, J. E., Hill, J. O., Swift, L. L., Cherrington, A., Polk, B., Tran, Z. V., \& Reed, G. (1996). Nutrition and physical activity program to attenuate obesity and promote physical and metabolic fitness in elementary school children. Obesity Research, 4(3), 229-243.

Fromel, K., Formankova, S., \& Sallis, J. (2002). Physical activity and sport preferences of 10- to 14-year old children: A 5-year prospective study. Gymnica, 32(1), 11-16.

Hamilton, M. T., Hamilton, D. G., \& Zderic, T. W. (2007). Role of low energy expenditure and sitting in obesity, metabolic syndrome, type 2 diabetes, and cardiovascular disease. Diabetes, 56(11), 2655-2667.

Levine, J. A. (2004). Non-exercise activity thermogenesis (NEAT). Nutrition Reviews, 62(7), S82-S97.

Levine, J. A., Lanningham-Foster, L. M., McCrady, S. K., Krizan, A. C., Olson, L. R., Kane, P. H., Jensen, M. D., Clark, M. M. (2005). Interindividual variation in posture allocation: Possible role in human obesity. Science, 307, 584-586.

Levine, J., Melanson, E. L., Westerterp, K. R., \& Hill, J. O. (2001). Measurement of the components of nonexercise activity thermogenesis. American Journal of Physiology: Endocrinology and Metabolism, 281, E670-E675.

Liu, J., Bennett, K. J., Harun, N., \& Probst, J. C. (2008). Urban-rural differences in overweight status and physical activity among US children aged 10-17 years. The Journal of Rural Health, 24(4), 407-415.

Nader, P. R., Bradley, R. H., Houts, R. M., McRitchie, S. L., \& O'Brien, M. (2008). Moderateto-vigorous physical activity from ages 9 to 15 years. Journal of the American Medical Association, 300(3), 295-305.

Nelson, M. C., Gordon-Larsen, P., Song, Y., \& Popkin, B. M. (2006).Built and social environments: Associations with adolescent overweight and activity. American Journal of Preventive Medicine, 31(2), 109-117. 
Manson, J. E., Greenland, P., LaCroix, A. Z., Stefanick, M. L., Mouton, C. P., Oberman, A., Perri, M. G., Sheps, D. S., Pettinger, M. B., \& Siscovich, D. S. (2002). Walking compared with vigorous exercise for the prevention of cardiovascular events in women. New England Journal of Medicine, 347, 716-725.

Marshall, S. J., \& Welk, G. J. (2008). Definitions and measurement. In A. L. Smith \& S. J. H. Biddle (Eds.). Youth physical activity and sedentary behavior: Challenges and solutions. Champaign, IL: Human Kinetics.

McKenzie, T. L., \& Kahan, D. (2008). Physical activity, public health, and elementary schools. The Elementary School Journal, 108(3), 171-180.

Mitchell, J. A., Mattocks, C., Ness, A. R., Leary, S. D., Pate, R. R., Dowda, M., Blair, S. N., \& Riddoch, C. (2009). Sedentary behaviour and obesity in a large cohort of children. Obesity, 17(8), 1596-1602.

Owen, N., Bauman, A., \& Brown, W. (2009). Too much sitting: A novel and important predictor of chronic disease risk? British Journal of Sports Medicine, 43, 81-83.

Paffenbarger, R. S. Jr., Blair, S. N., \& Lee, I. M. (2001). A history of physical activity, cardiovascular health and longevity: the scientific contributions of Jeremy N Morris, DSc, DPH, FRCP. International Journal of Epidemiology, 30, 1184 -1192.

Powell, L. M., Slater, S., Chaloupka, F. J., \& Harper, D. (2006). Availability of physical activityrelated facilities and neighborhood demographic and socioeconomic characteristics: A national study. American Journal of Public Health, 96(9), 1676-1680.

Ridgers, N. D., Fairclough, S. J., \& Stratton, G. (2010). Variables associated with children's physical activity levels during recess: the A_CLASS project. International Journal of Behavioral Nutrition and Physical Activity, 7, 74-81.

Salmon, J. (2010). Novel strategies to promote children's physical activities and reduce sedentary behavior. Journal of Physical Activity and Health, 7(Suppl 3), S299-S306.

Vuori, I. M. (2001). Health benefits of physical activity with special reference to interaction with diet. Public Health Nutrition, 4(2B), 517-528. 